\title{
TRANSPLANT TOURISM: NEW ZEALAND RESIDENTS DECIDING ON COMMERCIAL KIDNEY TRANSPLANTATION OVERSEAS
}

BY

\section{OLIVIA FRANCES ANDERSON}

\author{
A thesis \\ submitted to the Victoria University of Wellington \\ in fulfilment of the requirements for the degree of \\ Masters of Sociology
}

Victoria University of Wellington 2019 



\begin{abstract}
The demand for organs exceeds supply in almost every country, including New Zealand. As such, scholars have argued that this has contributed to a rise in illegal kidney purchase and commercial transplantation. Taking into account the likelihood that patients in New Zealand have been involved, this research considers the factors that motivate these patients to circumvent the transplant opportunities here in favour of a commercial transplant overseas. In addition, this project examines the ethical concerns that arise for medical professionals who suspect or become aware of a patient's intention to procure an organ outside of New Zealand. Interviews were conducted with eight medical professionals working in the field of kidney donation and transplantation, two key informants (stakeholder and academic), and two patients. The patients have previously undergone a kidney transplant in New Zealand and have both to varying degrees - considered transplant tourism. Using narrative thematic analysis, the data was organised into three predominant themes; The Desire for Health, Transplant Tourism: An Uncommon Phenomenon, and The Healthcare Response. Numerous insights were generated from this analysis. While transplant tourism is considered by many patients in New Zealand, it is pursued infrequently and arguably only by those with connections to common destination countries. When such instances occur, medical professionals in New Zealand encounter a variety of ethical, legal, and professional dilemmas that affect their ability to prevent transplantrelated crimes. This research concludes that patients (regardless of whether or not they pursue transplant tourism) experience feelings of frustration and hopelessness as a result of their illness experiences along with the current healthcare infrastructures. Assisting patients in setting realistic expectations of their treatment options, as well as increasing the transparency of the deceased donor waiting list is recommended. Moreover, it is suggested that transplant professionals at all levels are offered education about organ trafficking and transplant tourism, and a policy statement on organ trafficking and transplant tourism should be developed to clarify the rights and obligations of medical professionals in relation to organ purchase and offer guidance on how they can interact with patients who travel or plan to travel abroad for a transplant.
\end{abstract}




\section{Acknowledgements}

My deepest thanks go to all of the participants, for their willingness to talk openly about their ideas and experiences, and for sharing their time. I was fortunate to have as my supervisor Associate Professor Rhonda Shaw, who continually offered invaluable support, wisdom and gentle reassurance. Your belief and kind words of encouragement enhanced my confidence a great deal and I am truly appreciative of your guidance throughout this process. Many thanks go to Kidney Health New Zealand for their assistance in participant recruitment and interest in this research. I also wish to acknowledge the help and support provided by the School of Social and Cultural Studies staff. Finally, I would like to offer my special thanks to Jarrod and my family for their ongoing encouragement throughout my study. 


\section{Table of Contents}

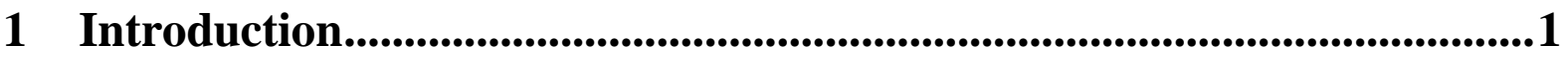

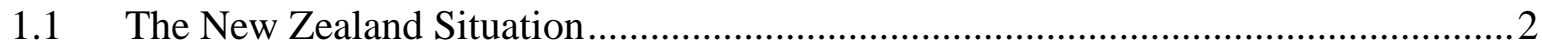

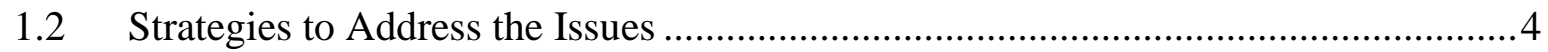

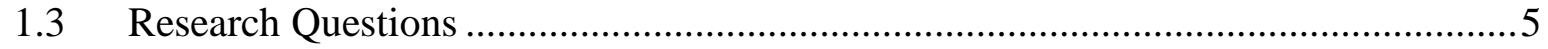

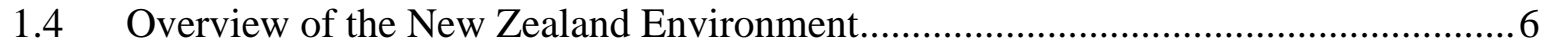

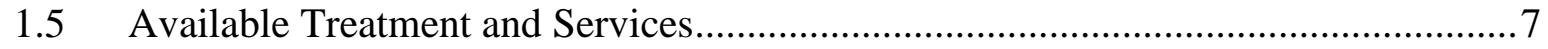

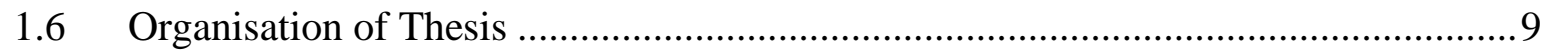

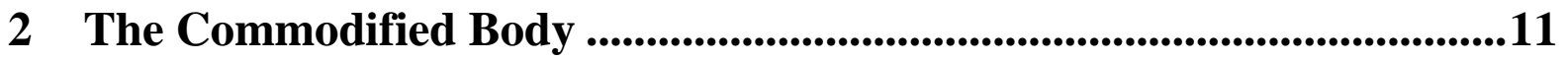

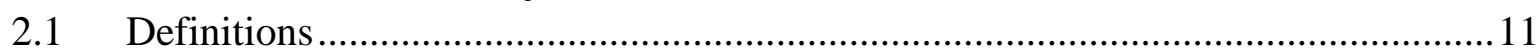

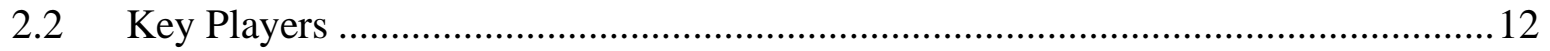

2.3 Global Condemnation of Organ Trafficking and Unethical Transplantation ...........17

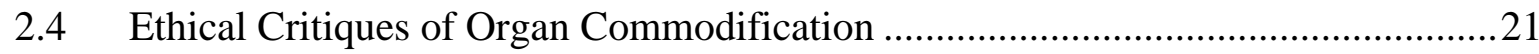

3 Theoretical Framework.........................................................................................227

3.1 The Medical Context: From Paternalism to Autonomy ..........................................2 27

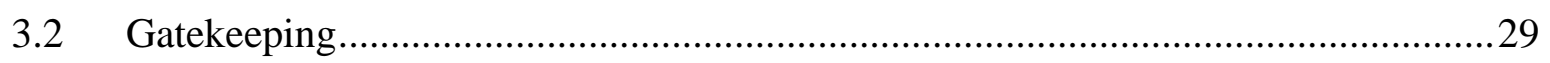

3.3 The Cultural Context: Health and Illness in the Technological Age ......................31

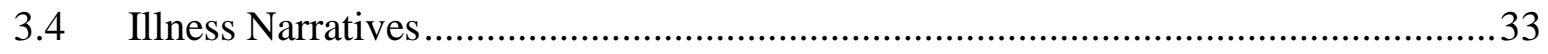

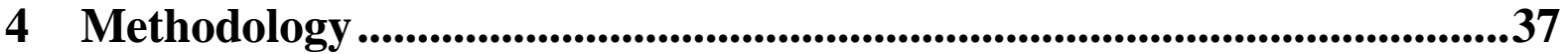

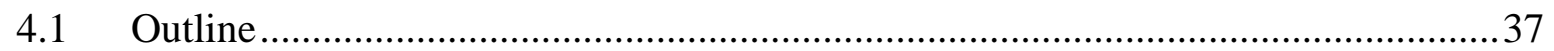

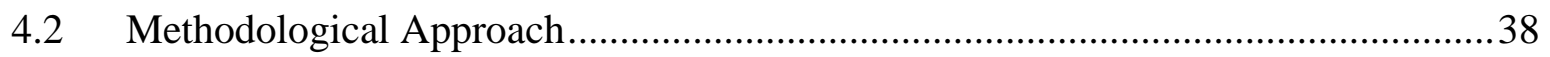

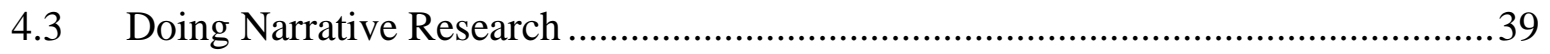

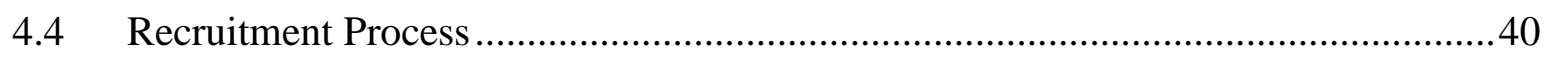

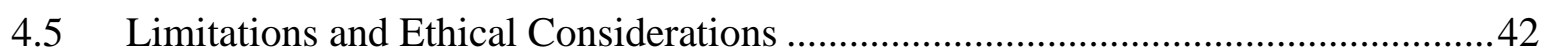

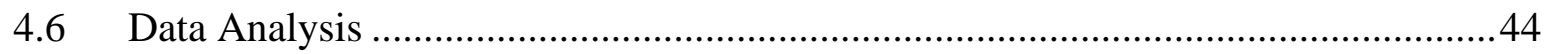

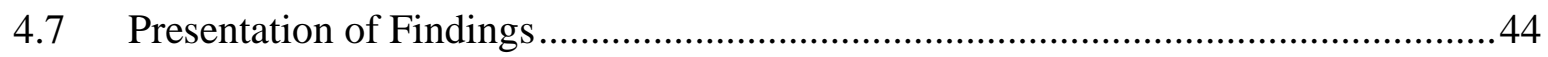

5 The Desire for Health ........................................................................................446

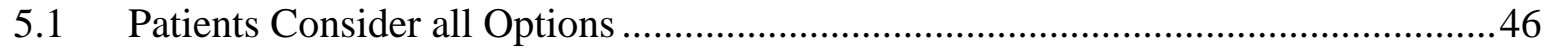

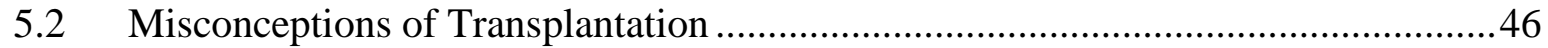

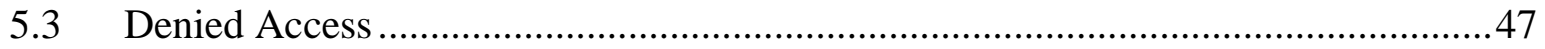

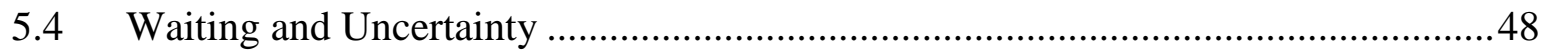

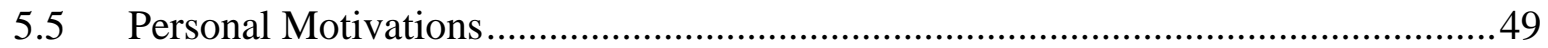

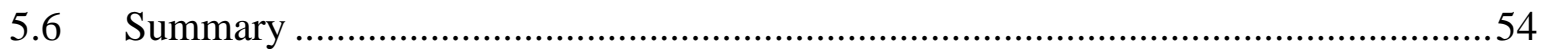


6 Transplant Tourism: An Uncommon Phenomenon...................................55

6.1 The Rate of Transplant Tourism ……………………......................................5

6.2 Reports of New Zealand Transplant Tourists ………………………………….....57

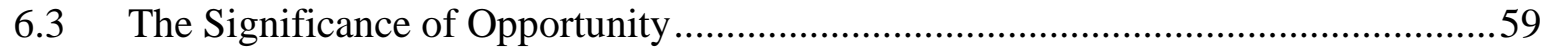

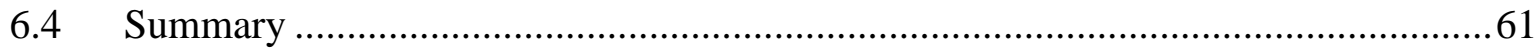

7 The Healthcare Response........................................................................62

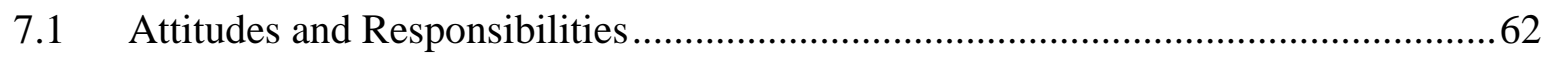

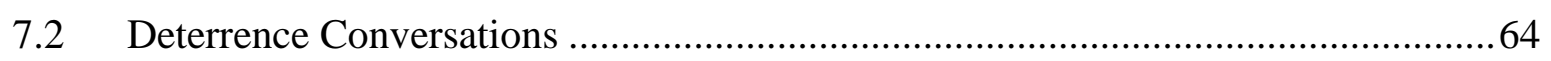

7.3 Potential Limitations of Deterrence Conversations .................................................67

7.4 Reflections on How to Prevent Transplant Tourism ...............................................6

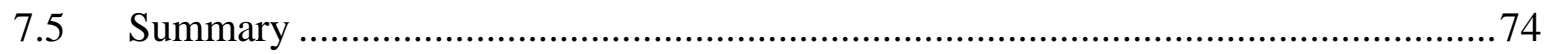

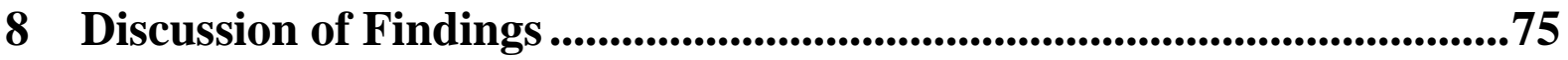

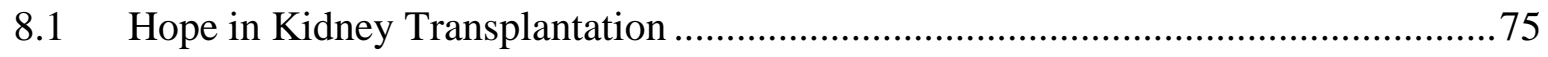

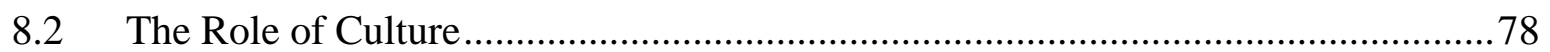

8.3 Medical Professionals' Rights and Obligations …………………………............... 82

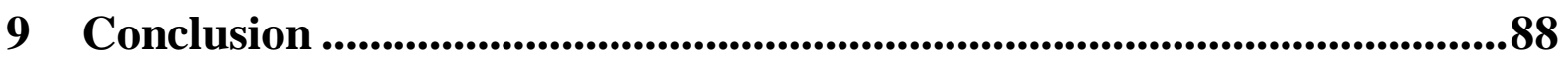

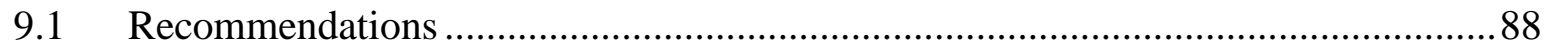

9.2 Suggestions for Further Research .................................................................

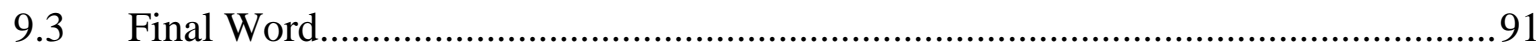

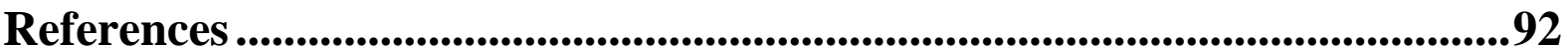

Appendix 1: Ethics Approval...................................................................................104

Appendix 2: Patient Recruitment Advertisement .............................................105

Appendix 3: Medical Professional Recruitment Email ................................106

Appendix 4: Participant Information Sheet (Patients) ...................................107

Appendix 5: Participant Information Sheet (Professionals).......................109

Appendix 6: Consent Form ............................................................................111 


\section{List of Tables}

\section{Page}

Table 1 Transplant Operations Performed Overseas on New Zealand

Dialysis Patients 2004-2017

Table 2 Demographics and Relevant Information of Transplant Tourism

58

Table 3 Number of Patients and Patient Ethnicity by Destination Country

61 


\section{List of Abbreviations Used}

ANZDATA

CKD

DDKT

DOI

ESRF

GODT

HD

HLA

HTOR

ICU

ISN

IVF

KHNZ

LDKT

MCNZ

NRTS

NZKAS

NZMA

ODNZ

PD

PMP

RRT

TSANZ

TTS

U.K.

UN

UNTOC

U.S.

WHA

WHO

WMA
Australia and New Zealand Dialysis and Transplant Registry

Chronic kidney disease

Deceased donor kidney transplant

Declaration of Istanbul

End-stage renal failure

Global Observatory on Donation and Transplantation

Haemodialysis

Human Leukocyte Antigens

Human trafficking for the purpose of organ removal

Intensive care unit

International Society of Nephrology

In-vitro fertilisation

Kidney Health New Zealand

Live donor kidney transplant

Medical Council of New Zealand

National Renal Transplant Service

New Zealand Kidney Allocation Scheme

New Zealand Medical Association

Organ Donation New Zealand

Peritoneal dialysis

Per million population

Renal replacement therapy

Transplantation Society of Australia and New Zealand

The Transplantation Society

United Kingdom

United Nations

United Nations Convention against Transnational Organized Crime

United States

World Health Association

World Health Organisation

World Medical Association 


\section{Introduction}

'Transplant tourism' refers to the global phenomenon in which people are engaging in cross-border travel for an organ transplant, typically involving transplant commercialism and/or organ trafficking (Ambagtsheer, Zaitch \& Weimar, 2013; Delmonico, 2009; Gill et al., 2008). It represents a new form of global economy in which people's body parts, most often kidneys, are transformed into a commodity. Traditionally, the prevailing moral guideline of organ procurement stipulates kidneys should be donated as an act of altruism, rather than as the object of a financial transaction. That is, altruistic organ donation should be an intentional and voluntary act which seeks to enhance the welfare of others, without external influence, expectations of reciprocation or commercialisation (Shaw, 2019). As such, the global trade in kidneys is commonly regarded as a threat to public health, and any involvement in the purchasing and selling of organs is prohibited in all countries, excluding Iran.

Across high-income countries, increasing rates of chronic kidney disease (CKD) and endstage renal failure (ESRF) have contributed to a significant gap between the supply and demand of kidneys. Many countries with transplant programmes have endeavoured to boost the rate of altruistic donation; however, progress is often slow moving or the rates of donation have plateaued (Matas \& Delmonico, 2012). Under these circumstances, access to transplantation through conventional means is restricted, causing dialysis patients to endure bouts of uncertainty, frustration and, on occasion, suspicions regarding the prioritisation and allocation of donor kidneys (Berglund \& Lundin, 2012). Despite being a criminal offence in most countries, a global increase in the number of patients opting to travel abroad to pay for, and undergo, a commercial kidney transplant has been observed. This demonstrates the urgent need for researchers to closely examine and understand the root causes that encourage participation in transplant tourism and how best to prevent patients from pursuing this path to treatment.

Transplant tourism has been the focus of a handful of studies, concentrating on patients from Sweden, Hong Kong, Macedonia/Kosovo, the Netherlands, and Canada (Berglund \& Lundin, 2012; Gill et al., 2011; Leung \& Shiu, 2007; Van Balen et al., 2016). Increasingly, New Zealand academics have been writing about organ donation and transplantation (Coombs \& Woods, 2017; Gavin, Malpas \& Bartlett, 2015; Malpas, 2018; Martin, 2013a, 2013b, 2014; Polaschek, 2003; Shaw, 2015a, 2015b; Tong et al., 2012). However, limited attention has been given to the involvement of New Zealand residents in transplant tourism. In this thesis, I am interested in examining the extent to which New Zealand residents are participating in 
transplant tourism. This research will not only address a notable gap in academic literature, but it will contribute to the body of work on transplant tourism, which is of particular importance given the level of difficulty inherent in researching this 'hidden' activity.

The trade in kidneys is a global issue that requires responses and efforts from the international medical community as well as individual states. New Zealand has made national and international commitments to deter and discourage illicit transplant practices. In this study I take the position that, in order to uphold such commitments, we first have a responsibility to understand any involvement of our own in the global kidney market. To better understand potential deficits within our own healthcare system, we also have a responsibility to listen to, and consider, the factors that encourage residents to circumvent the treatment services offered domestically in favour of treatment abroad. The insight this generates has the potential to highlight areas of improvement and encourage discussion on how best to address the concerns of patients and medical staff.

\subsection{The New Zealand Situation}

New Zealand faces similar challenges to that of other countries, confronted with growing demand for renal replacement therapy (RRT) and an insufficient supply of transplantable kidneys. According to the Australia and New Zealand Dialysis and Transplant Registry's (ANZDATA) $41^{\text {st }}$ Report (2018), the incidence and prevalence of RRT in New Zealand continues to climb. In 2017, there were 615 new RRT patients, with an overall incidence rate of 128 per million population (pmp). At the end of 2017, there were a total of 4658 prevalent patients receiving RRT (972 pmp); of which, 2768 (59\%) were dialysis dependent. Of these, 912 of were identified as Māori, 809 were New Zealand European, 737 were Pacific, 249 were Asian, 50 were categorised as 'Other', 9 did not report their ethnicity and 2 were identified as Aboriginal/Torres Strait Islander. At the beginning of 2017, there were a total of 491 active patients on the waiting list for a deceased donor kidney. During that year, 241 were taken off the list. At the end of 2017, the number of people on the list was 451 .

In New Zealand, the total number of deceased donors has continued to increase while the number of live donors has recently decreased. In 2016, there were 82 living kidney donors and 95 deceased kidney donors which, in 2017, were recorded at 69 and 121 respectively (Organ Donation New Zealand [ODNZ], 2019). Still, the current rates are inadequate, falling short of the demand rate for transplantable kidneys. In 2017, 127 kidneys were retrieved from consenting deceased donors, which equates to a deceased donation rate of $26 \mathrm{pmp}$. In total, 121 
of the retrieved kidneys were transplanted into 118 recipients. There were 69 live kidney donations, at a rate of 14 pmp. Sadly, a total of 474 patients died during 2017 - 423 were dependent on dialysis at the time, and 51 were transplant patients.

In 2017, there were a total of just 187 kidney transplants performed in New Zealand (39 pmp), equating to 6.7 kidney transplants per 100 dialysis patients that year. Of all transplant recipients, 85 were New Zealand European, 40 were Pacific, 28 were Asian, 23 were Māori, 8 were categorised as 'Other' and the remaining 3 did not report ethnicity. As previously mentioned, information on the subject of New Zealand patients travelling overseas for paid transplantation is extremely limited. In more recent years, the ANZDATA Annual Reports have included a small section regarding overseas transplantation. Their figures indicate that between 2004 and 2017, a total of 15 residents have undergone overseas kidney transplantation (presented in Table 1).

Table 1

Transplant Operations Performed Overseas on New Zealand Dialysis Patients 2004-2017

\begin{tabular}{|l|c|}
\hline Year & Number of Patients \\
\hline $\mathbf{2 0 0 4}$ & 1 \\
$\mathbf{2 0 0 5}$ & 2 \\
$\mathbf{2 0 0 6}$ & 2 \\
$\mathbf{2 0 0 7}$ & 1 \\
$\mathbf{2 0 0 8}$ & 0 \\
$\mathbf{2 0 0 9}$ & 1 \\
$\mathbf{2 0 1 0}$ & 1 \\
$\mathbf{2 0 1 1}$ & 2 \\
$\mathbf{2 0 1 2}$ & 1 \\
$\mathbf{2 0 1 3}$ & 1 \\
$\mathbf{2 0 1 4}$ & 0 \\
$\mathbf{2 0 1 5}$ & 1 \\
$\mathbf{2 0 1 6}$ & 1 \\
\hline
\end{tabular}

Note. Data sourced from the ANZDATA website http://www.anzdata.org.au

Chapter 7 of the report includes a disclaimer, it follows: "Each year a small number of Australian and New Zealand dialysis patients travel overseas to receive a kidney transplant. It is possible that these numbers are an underestimate of the true number, since some patients may not return to Australia/New Zealand and hence be reported to ANZDATA registry as lost 
to follow-up" (p. 6). It is important to note that no clarification is offered about the nature of these transplants. With the limited information provided, one cannot determine whether the transplants referred to were illegal, commercial, or involved organ trafficking.

\subsection{Strategies to Address the Issues}

There have been numerous efforts to increase living and deceased organ donation rates and access to transplantation in New Zealand. For more than a decade, Organ Donation New Zealand (ODNZ) together with Donation Link teams have made considerable progress in increasing New Zealand's rates of deceased organ donation. In 2005, Organ Donation Link teams were created across New Zealand Intensive Care Units (ICU) and consist of ICU Link Nurse(s), Operating Theatre (OT) Link Nurse(s) and an ICU Link Doctor (Watts et al., n.d.). The team members operate as local experts and liaison persons for organ and tissue donation and provide a link between donating hospitals and ODNZ donor coordinators (Ministry of Health, n.d.). In recent years, an 'expanded' Link team initiative has been underway and continues to receive government support (ODNZ, 2017). Following endorsement from the Minister of Health and National Health Boards, the National Renal Transplant Service (NRTS) was established in 2014 with the aim to provide leadership, oversight and support for the implementation of initiatives to improve access to kidney transplantation. Moreover, the NRTS are responsible for a work programme to increase live donor kidney transplantation.

In 2017, The Ministry of Health published a comprehensive national strategy to increase deceased organ donation and transplantation. Guidance was taken from reforms implemented in Australia and the United Kingdom (U.K.) that have proved successful in increasing deceased organ donation rates in their respective jurisdictions. Recognising that deceased donation cannot occur without the consent of family/whānau, this strategy broadly focuses on improving two key areas: (1) public awareness and (2) facilitating the decision to donate. A number of recommendations were generated, presented as six strategic priorities: Implement public awareness campaigns and media engagement; improve the recording of donor intent in a way that is reliable, easy to access, and cost effective; provide training for organ donation clinical conversations prioritised for those 'on the ground' in ICUS and provided for other relevant medical staff; improve clinical capacity to identify, manage, and support organ donation and increase resources (ICU beds, staff, etc.); establish a national agency to have overall responsibility for organ donation and a clinical governance framework to support best practice; measure progress to ensure New Zealand society and the health system achieve a manageable, sustainable, respectful and ethical increase in organ donation (Ministry of Health, 2017). In 
light of this report, the government introduced the Organ Donors and Related Matters Bill (2019) that intends to implement a number of the recommendations outlined in the National Strategy. Specifically, the bill is seeking to improve organ donation rates, set up a national organ donation agency, and provide financial support to eligible donors recovering from donor surgery.

Although New Zealand's rates of live organ donation are relatively high by international standards, important efforts have been made to facilitate and support live donation. The barriers to live kidney donation in New Zealand are well documented. An important finding from several New Zealand studies in this area is the financial hardship that living kidney donors can endure as a result of their donation (Martin, 2013b; Shaw \& Bell, 2015). In recognition of this barrier, since December 2017, eligible live organ donors in New Zealand have been entitled to $100 \%$ compensation for their loss of earnings for a maximum of 12 weeks while they recover post-surgery. The purpose of the Compensation for Live Organ Donors Act (2016) is to remove a potential financial deterrent to organ donation for live donors. Similar schemes have been introduced overseas and can be clearly differentiated from financial incentives.

\subsection{Research Questions}

When I embarked on this project, the original title was Transplant Tourism: New Zealand residents who undergo kidney transplantation overseas. Given changes to the nature of the data collection, due to difficulties recruiting participants who sought transplantation offshore, the title of the thesis was changed (see Methods section for further discussion). This explains the difference in the thesis title and the ethical clearance documents in the Appendices (e.g. information sheet, consent form, etc.). Still, the overall aim of this research is to identify the motivations for transplant tourism, the rates of involvement, and the responses of New Zealand medical professionals. Thus, the three research questions I seek to address are:

\section{Do New Zealand kidney failure patients consider paid transplantation abroad?}

- What factors encourage patients to consider circumventing the waiting list?

- What factors are preventing patients from pursuing transplant tourism?

- Do patients have any moral concerns during their decision-making, and if so, what are they? 
Interviewing patients who are considering (or have decided against) transplant tourism provides a unique opportunity to discuss any reservations and concerns they grappled with during their decision-making and may also highlight key differences between those who pursue commercial transplantation and those who do not.

\section{Do New Zealand residents engage in transplant tourism?}

- How often?

- What factors encourage patients to circumvent the waiting list?

- What methods are patients using to obtain organs/transplants abroad?

Currently there is limited information available about New Zealand residents pursuing paid transplantation abroad, so it is important to understand the scale of involvement. Considering the factors that encourage residents to accept the risks and pursue this option may highlight deficits within our own healthcare system and contribute to academic literature in this area.

\section{How do medical professionals handle occurrences of transplant tourism?}

- What is their stance towards transplant tourism?

- What is the role of medical professionals in deterring this practice?

- What personal, ethical and legal difficulties do medical professionals encounter?

Medical professionals in high-income countries are present while patients are deciding or arranging to travel abroad, or are involved in treating patients returning from overseas. Not only does this make them privy to information regarding transplant tourism, but medical professionals are in the best position to deter or prevent patients from pursuing the option.

\subsection{Overview of the New Zealand Environment}

In New Zealand, like many other jurisdictions, the overriding view is that organ donation should be an intentional and voluntary choice, in the absence of financial gain. As such, human trafficking for the purposes of organ removal (HTOR) is criminalised in the Crimes Act 1961, and the commercialisation of human organs is prohibited by the Human Tissue Act 2008. 


\subsubsection{Crimes Act 1961}

In New Zealand, the relationship between human trafficking and the organ trade is acknowledged in Section 98D of the Crimes Act 1961. Here it is stated that trafficking in persons for the purposes of organ removal is prohibited. Organ trafficking is not recognised in the act as a crime on its own but must be attached in some way to human trafficking. Therefore, it can be suggested that this act is geared towards those orchestrating illegal organ transplants. While an important piece of legislation, it does little to address the reality of residents who travel outside of New Zealand for paid transplantation.

\subsubsection{Human Tissue Act 2008}

The Human Tissue Act commenced in April 2008 and is New Zealand's first national legal document prohibiting payment for organs. Therefore, this act ensures that the decision to donate occurs in the absence of external financial pressure. The purpose of this act is threefold, one of which is to help ensure that the collection of human tissue "generally does not involve the requirement or acceptance, or the offering or provision, of financial or other consideration for the tissue" (s 56). Section 56 states trading in human tissue is generally prohibited and if an individual knowingly or intentionally requires or accepts, or offers or provides, financial or other consideration for human tissue they have committed an offence punishable by conviction to imprisonment for a term not exceeding 1 -year or a fine not exceeding $\$ 50,000$. However, this act is limited in that it cannot be applied beyond national borders. Given that transplant tourism is a transnational crime, this act may not be applied to an activity that occurred outside of New Zealand. Therefore, it cannot be applied to residents who travel to another country for a paid transplant, and then return to New Zealand for post-operative care.

\subsection{Available Treatment and Services}

In New Zealand, patients with kidney failure have three treatment options: Dialysis, Transplantation and Conservative Treatment (also known as palliative or supportive care). There are two types of dialysis offered in New Zealand, haemodialysis (HD) and peritoneal dialysis (PD). Although some patients will be recommended a type of dialysis, most can choose the type that best suits their lifestyle (Kidney Health New Zealand [KHNZ], n.d. -c). HD is required thrice weekly, usually for four to five hours at a time, and can be carried out at home, in hospital or at a satellite clinic (KHNZ, n.d. -c). According to ANZDATA (2018), at the end of 2017, 1913 (69\%) people were receiving HD, 436 of whom were on HD at home. Alternatively, PD is typically completed four times per day, from 20 to 40 minutes per fluid 
exchange (KHNZ, n.d. -c). Unlike HD, PD does not require a machine and therefore can be done almost anywhere. At the end of 2017, there were 855 (31\%) people were receiving PD and, of all home-based dialysis patients, the majority (66\%) were receiving PD treatment (ANZDATA, 2018). Unless a patient receives a new kidney, dialysis is a life-long treatment option.

Transplantation is the second treatment option in New Zealand. Although one can expect to live reasonably well on dialysis, kidney transplantation is considered the best treatment for the majority of patients with kidney failure. It is possible for patients in New Zealand to receive a live donor kidney transplant (LDKT) or a deceased donor kidney transplant (DDKT). For a LDKT, a kidney can be donated by genetic/emotional relatives or well-meaning strangers. Within the New Zealand medical community, these two groups are commonly referred to as directed donors and non-directed donors respectively. This is because genetic and emotional relatives 'direct' who receives their kidney while altruistic strangers who donate cannot say who their kidney is allocated to (Ministry of Health, 2019). Potential donors must be in good health, over the age of 18 years old, and must complete a series of medical tests and a psychosocial evaluation (KHNZ, n.d. -b). According to ANZDATA (2018), a total of 69 LDKTs took place in 2017, 33 from a genetically related donor, 28 from an emotionally related donor and eight from a non-directed donor (four via kidney exchange and four via the waiting list). The other option is a DDKT, where a kidney is provided by a deceased donor. In these cases, the family of the donor must consent to the donation. During 2017, 118 DDKTs were performed (ANZDATA, 2018). A successful transplant can significantly improve a patient's quality of life, and means they are no longer required to undergo dialysis. However, transplantation is not a cure for kidney failure, and immunosuppressants must be taken each day to prevent rejection (KHNZ, n.d. -b). Complications, such as rejection, can mean a return to dialysis.

Lastly, people with kidney failure have the option of conservative treatment. The purpose of conservative treatment is to manage the symptoms of ESRF without life-prolonging treatments. It involves medication which protects kidneys for as long as possible, medication to address the symptoms of kidney disease such as nausea, dietary advice, community support, information on where to get financial support, counselling and bereavement support for family/whānau, and referral to a palliative care service (KHNZ, n.d. -a). The life expectancy of a patient who opts for conservative treatment varies, and is contingent upon co-morbidities, degree of kidney function, and physical and emotional strength (KHNZ, n.d. -a). Although 
many patients who opt for conservative treatment are elderly, there are a number of reasons patients may pursue this option. For instance, they may not want to commence dialysis because they consider it will negatively impact their lifestyle, they may wish to discontinue dialysis because their quality of life has become poor, or they may have an underlying co-morbidity which will shorten their life and/or would significantly decrease the benefits of dialysis and transplantation (KHNZ, n.d. -a).

\subsection{Organisation of Thesis}

In Chapter 2: The Commodified Body, I start by outlining the patterns and dynamics of the global trade in organs, offering clarification of various transplant-related practices. Drawing on relevant literature, I comment on the outcomes of those who sell organs under a market arrangement, and of those who purchase and undergo commercial transplantation. I then examine the way in which the organ trade is portrayed by major international bodies, medical organisations, transplant societies and academics. Finally, I discuss the prominent critiques of commodifying bodily tissue, specifically organs.

Chapter 3: Theoretical Framework presents the medical and cultural contexts through which I consider and examine the positionality of medical professionals and the involvement of patients in transplant tourism. I elaborate on how shifts in modern healthcare has impacted the doctor-patient relationship. Further, I describe how technological advancements have shaped contemporary expectations and norms regarding illness and the pursuit of health. In this chapter, I draw on relevant concepts in the literature for analysing the role of medical professionals and experiences of illness, such as gatekeeping and illness narratives.

In Chapter 4: Methodology, I discuss the aims of the research and narrative methodology. I then outline the recruitment and data collection process, commenting on the limitations and ethical considerations of speaking with participants about this topic. Finally, I describe how I used thematic narrative analysis to organise meaningful passages from my interview transcripts, before discussing the presentation of the findings.

My findings chapters, Chapters 5, 6, and 7, are structured around the final themes I selected to focus on in this project: The Desire for Health, Transplant Tourism: An Uncommon Phenomenon, and The Healthcare Response. I present and analyse the data in these three chapters, before moving onto Chapter 8: Discussion of Findings where I critically comment on some of the most significant concepts that were introduced in each findings chapter. In Chapter 5: The Desire for Health, I consider how a patients' natural desire to be healthy can 
help explain their considerations of transplant tourism, especially when their path to transplantation is obstructed by aspects of the New Zealand healthcare system. In Chapter 6: Transplant Tourism: An Uncommon Phenomenon, I examine and present cases of transplant tourism involving New Zealand residents to uncover the dominant factors that encourage the pursuit of transplant tourism. In Chapter 7: The Healthcare Response, I describe the attitudes and professional responses to transplant tourism, commenting on the similarities, differences and limitations of the medical professionals' approaches to deterrence. Here I also consider the legal, ethical and personal difficulties professionals encounter in these scenarios before detailing their reflections on how best to prevent transplant tourism.

In Chapter 8: Discussion of Findings, the personal and institutional factors that encourage transplant tourism revealed in this study are considered in the broader context of existing research. It is proposed that hope, as a state of mind, can play a critical role in how patients cope with and experience illness. For some it can encourage the continuation of dialysis but for others, hope can motivate action in patients to seek transplantation through alternative avenues. Extending on this, I comment on the role of culture in transplant tourism and the possible explanations as to why minority ethnic communities are more likely to pursue transplant tourism. Lastly, I contextualise the conflict of duties reported by the medical professionals in this study and offer clarification of their rights and obligations to patients who (intend to) procure a kidney outside of New Zealand.

In Chapter 9: Conclusion, I summarise the contributions to knowledge in this area, and give some recommendations for initiatives, policy and further qualitative and quantitative research in this area. The suggestions respond to some of the concerns raised by patients, key informants and medical professionals in this study. 


\section{The Commodified Body}

Organ transplantation is a remarkable medical advancement which has allowed doctors to save countless lives and has shifted our understanding of the restoration of health. For patients living with ESRF, kidney transplantation is generally regarded as the most effective therapy because it is more cost-effective and offers a longer life span and an improved quality of life when compared to alternative therapies (Shaw, 2015a). Kidney transplantation emerged in the 1950s, with the first successful transplant performed in 1954 (Starzl, 1994). At the time, this therapy was considered experimental and risky. Due to a series of medical achievements through the 1980s, such as the development of the immunosuppressant drug cyclosporine, kidney transplantation has become a safe and routine procedure conducted internationally (Starzl, 1994). In New Zealand, the first kidney transplant was performed at Auckland hospital in May of 1965 (Ministry of Health, n.d.). Today, this treatment is practiced in 91 countries, with an estimated 89,823 transplants performed internationally in 2016 (Global Observatory on Donation and Transplantation [GODT], 2017).

While the prospect of an organ transplant provides many patients with a great sense of hope that life after organ failure is possible, access to this life-saving therapy through conventional means is restricted. Predictably, where demand outweighs supply, an international market in organs has emerged to meet the demand that is not fulfilled by altruistic donation. Within the market framework, an organ transplant is available to those who are both able and willing to pay and travel for the treatment. Kidneys are the most sought-after and trafficked organ, as it is possible — under optimal healthcare conditions - for a living person to provide a kidney without suffering serious health consequences. Some figures estimate commercial transplants account for 10 percent of all kidney transplants performed annually (Delmonico, 2009).

\subsection{Definitions}

The global trade in organs is an organised crime involving a diverse range of illicit practices. The need for clarification of these practices prompted the World Health Organisation (WHO) to develop a Global Glossary in 2009. The terms organ trafficking, transplant commercialism, transplant tourism, and travel for transplantation are frequent points of reference in this paper, and therefore require explanation. 
As specified by WHO (2009), Organ trafficking is:

the recruitment, transport, transfer, harbouring or receipt of living or deceased persons or their organs by means of the threat or use of force or other forms of coercion, of abduction, of fraud, of deception, of the abuse of power or of a position of vulnerability, or of the giving to, or the receiving by, a third party of payments or benefits to achieve the transfer of control over the potential donor, for the purpose of exploitation by the removal of organs for transplantation. (p. 14)

Transplant commercialism is:

A policy or practice in which an organ is treated as a commodity, including by being bought or sold or used for material gain. (p. 14)

Travel for transplantation is:

The movement of organs, donors, recipients or transplant professionals across jurisdictional borders for transplantation purposes. (p.14)

Transplant tourism is:

Travel for transplantation when it involves organ trafficking and/or transplant commercialism or if the resources (organs, professionals and transplant centres) devoted to providing transplant to patients from outside a country undermine the country's ability to provide transplant services for its own population. (p. 14)

Importantly, the glossary distinguishes between travel for transplantation and transplant tourism which have been used synonymously in some academic texts. The act of travelling outside of one's habitual country in pursuit of medical treatments - a phenomenon also known as medical travel - is not a crime of its own but becomes illegal when it involves illicit practices.

\subsection{Key Players}

Given that the trade in organs is a transnational crime, it requires a network of key players. The individual who purchases and undergoes an illegal transplant is commonly known as a 'recipient', while the individuals from which an organ is harvested are often referred to as 'donors'. The latter terminology can be problematic as it misrepresents the dynamics of an organ exchange and overlooks the motivations of those who sell an organ. From this point forward, I opt to use the term vendor rather donor when referring to those who sell their kidney 
under a black market arrangement. Organ exchanges involve more than just the recipient and vendor, and are also assisted by brokers, transplant teams, and specific public and private sectors - most of whom take a large portion of the recipients' fee.

Primarily, transplant tourism entails cross-border travel of recipients, but in some cases may require the vendor to cross national borders, or both individuals. Shimazono (2007) points out that transplant tourism usually involves (but is not limited to) four modes:

- A recipient travelling to the country where the transplant centre and vendor are located;

- A vendor travelling to the country where the recipient and transplant centre are located;

- A vendor and recipient travelling together to the country where the transplant centre is located;

- A vendor and recipient travelling separately from different countries to another country where the transplant centre is located.

Typically, trafficked organs tend to flow from low-income to high-income countries. Highexporting organ states (i.e. source countries) include China, India, Moldova, Nepal, Brazil, Egypt, Pakistan and the Philippines (Cohen, 2013; Spasovski et al., 2017). High-importing states (i.e. demand countries) include Saudi Arabia, Taiwan, Malaysia, South Korea, Canada, Japan, Australia, and the United States (U.S.). (Budiani-Saberi \& Delmonico, 2008).

\subsubsection{Kidney Vendors}

A number of studies have shown that vendors typically have limited to no formal education and have an extremely low income. Literature in this area frequently report that vendors sell their kidney in the hope that the compensation will resolve their financial situation. However, published research continually reports that kidney vendors suffer a decline in financial, mental, physical, and social well-being as a result of commercial kidney transplantation (BudianiSaberi et al., 2014; Codreanu, Codreanu, \& Delmonico, 2010; Goyal et al., Naqvi et al., 2007; 2002; Tong et al., 2012; Zargooshi, 2001). Some of these difficulties were reported by Tong and colleagues (2012) who conducted a comprehensive thematic synthesis of 17 qualitative studies involving over 676 'commercial donors' from the Philippines, Pakistan, Bangladesh, India, Iran, Brazil and South Africa. The authors proposed that desperation, despair and debasement are common features of kidney sale: 
Three major themes were identified: desperation (the participants' decision to sell their kidney was forced by poverty, debt, or to fulfil a family obligation); despair (destroyed body integrity, shame and secrecy, dehumanized and dispirited, loss of livelihood, heightened sense of vulnerability, disappointment, and regret); and debasement (deception by brokers and recipients, victimized by the hospital, stigmatized by community, and rejected by family). (p. 1138)

The hopes of financial gain held out by many vendors are not realised. A survey of 239 Pakistani kidney vendors revealed the primary motivation for their kidney sale was to pay off debt (93\%), yet $88 \%$ of the participants had no economic benefit of the sale post-transplant (Naqvi et al., 2007). Goyal, Mehta, Schneiderman, and Sehgal (2002) conducted a comprehensive cross-sectional survey of 305 live kidney vendors from India. The findings revealed:

Ninety-six percent of participants sold their kidneys to pay off debts. The average amount received was $\$ 1070 \ldots$ Average family income declined by one third after nephrectomy, and the number of participants living below the poverty line increased. Three fourths of participants were still in debt at the time of the survey. (p. 1589)

Budiani-Saberi and colleagues (2014) interviewed 103 kidney vendors from India who had been victims of HTOR. All were living in abject poverty, and 98\% stated the primary motivation for sale was debt. Of the 103 kidney vendors, one received no payment, the majority (67) received less than US\$900. Despite recipients forking out large payments for a commercial transplant, recent estimates indicate that a kidney vendor's compensation is likely to be less than $10 \%$ of that sum, if any at all (Spasovski et al., 2017). Often the majority is taken by the hospital and brokers, leading vendors to feel deceived and misled (Tong et al., 2012).

Vendors can also face stigma and social isolation as a result of their kidney sale. Tong and colleagues categorised these difficulties in their second theme (despair), reporting that the participants felt shame and lived in fear of judgement and rejection by their family and community. The vendors believed commercial transplantation was considered morally and socially heinous, and therefore felt it was necessary to keep their transplant a secret. Similar findings have been reported by Budiani-Saberi and Mostafa (2011), as well as Moniruzzaman (2012).

Lastly, numerous studies have documented the health consequences experienced by kidney vendors as a result of kidney sale. A study involving 104 Pakistani kidney vendors' concluded 
the general health status of participants was poor, marked by compromised renal function, a high prevalence of Hepatitis $\mathrm{C}$ and of hypertension (Naqvi et al., 2008). Of the 305 vendors included in Goyal and colleagues' study, one third reported long-term back pain, half complained of pain at the nephrectomy site, and the majority (86\%) reported a general decline in health status. Across a range of studies, vendors have reported feeling victimised and misinformed by medical professionals who offered false reassurances about their health (Tong et al., 2012).

\subsubsection{Recipients}

Comparatively, less research has focused on the recipients of a commercial transplant. The scarcity of information and statistics about the scale and nature of transplant tourism is attributable to the inherent difficulty in researching this phenomenon. Not only does the transnational and multimodal nature of transplant tourism make detection increasingly difficult, but recipients are likely to conceal their involvement due to fears of criminal prosecution or social disapproval. Further impeding research on transplant tourism is the increased likelihood that recipients may die as a result of post-operative complications, or receive post-operative care in the destination country, and therefore remain unidentified by their doctors in their habitual country. Yet, when medical professionals do become aware of a patient's intent or involvement in transplant tourism, they are often unwilling to expose their patient because of the professional responsibilities inherent in the doctor-patient relationship. Despite these barriers to research, a number of quantitative studies, and fewer qualitative studies, have explored patients' involvement and outcomes in transplant tourism. Numerous quantitative studies have indicated substantial transplant wait time or inadequate transplant activity in a patients' habitual country to be the primary factors that influence their decisions to pursue kidney transplantation overseas. However, qualitative interviews with recipients have discerned additional motivational factors such as dialysis-related complaints, quality of life, financial strain, feeling discriminated by domestic healthcare systems, connections with common destination countries, renal peers' experiences, and family responsibility.

Some recipients will have family or friends in destination countries who can assist with transplant arrangements. Otherwise, the international brokering of organs can occur through interactive websites. A quick search of the Internet will reveal various individuals and brokers who are willing to sell organs. For example, indiaorgantransplant.com offers potential recipients a liver $(\$ 10,000)$, kidney $(\$ 12000)$, bone marrow $(\$ 20000)$, heart $(\$ 30000)$ or eye 
transplant (\$2000). The site targets patients from high-income countries, presenting transplant costs that are "far less when compared with developed nations", followed by a section outlining their services for international patients. These services include Visa assistance, airport pick up and drop off facilities, boarding and lodging, a complete 'healthcare package', and local travel and food arrangements. The site is littered with large images of white patients and doctors, all smiling, and features large texts that read "No more Kidney Dialysis, get Kidney Transplant in India!", or "Liver Transplant Centres India with 'NO WAITING LINE'. Register Today!" Furthermore, the information is available in English, Arabic, French and Russian, and continually makes claims to have world-class facilities and top surgeons. Susanne Lundin (2016) notes that such interactive websites are short-lived and will disappear after only a few months and resurface under another name. As a result, it is near impossible to regulate these interest-based brokerages.

Medically, there is a considerable amount of risk for recipients who opt for a commercial transplant overseas. Hospitals in low-income countries often lack hygiene, the purchased organ may not be an appropriate match or functioning completely, and the odds of contracting infections (i.e., HIV, hepatitis B virus, cytomegalovirus, fungal infections) increases. Kennedy et al. (2005) reported the experience of 16 Australian patients, of which 13 had been commercially transplanted overseas. Numerous patients presented with infections. The overall 1-year patient survival was $85 \%$, as three patients died within five years of the transplant two had experienced transplant failure and the other died as a result of an HBV infection. The overall 1-year transplant survival rate was reported as $66 \%$, significantly lower than the Australian rate $(90 \%)$. Four transplants had failed within one year, and acute rejection or delayed graft function occurred in four cases. Kapoor and colleagues (2011) reported the outcomes of 10 Canadian patients who received commercial kidney transplants in China (4), Pakistan (3), India (1), Mexico (1) and the Philippines (1). When compared to all transplants performed within Canada, these patients had lower graft and survival rates. One patient in the cohort experienced no significant complications although the remaining presented with various infectious complications, and many with surgical complications also. In addition, three patients had delayed graft function, two patients had acute rejection, and two patients had failed transplants. In a larger study of 115 Turkish patients who received their kidneys in India (106), Iraq (7) and Iran (2), Sever and colleagues (2001) found there was a high incidence of surgical complications and frequent medical complications, with unconventional infections observed in 15 recipients. These included malaria, pneumonia, and invasive fungal infections. 


\subsection{Global Condemnation of Organ Trafficking and Unethical Transplantation}

The success of organ transplantation, and subsequent rise of a black market organ sales, has warranted discussion around ethical procurement, allocation, and implantation of human organs. Today there are several international initiatives which encourage ethical medical practice and combat the growing problem of organ trafficking, transplant commercialism, and transplant tourism. The following initiatives are not legally binding but are widely accepted and have influenced almost all countries to implement prohibition into domestic legislation.

\subsubsection{The World Health Organisation}

The World Health Organisation (WHO) is responsible for international health matters for member states of the United Nations, including New Zealand. For more than thirty years, the WHO has urged member states to prohibit the sale and purchase of human tissue for transplantation from both deceased and living donors. The WHO first expressed concern for a trade in organs when they drafted Development of Guiding Principles for Human Organ Transplantation (Resolution WHA40.13). This document was adopted at the fortieth World Health Assembly (WHA) - the decision-making body for WHO - in May 1987. The Resolution WHA40.13 condemns the organ trade and transplant commercialism, affirming that these are "inconsistent with the most basic human values and contravenes the Universal Declaration of Human Rights and the spirit of the WHO Constitution" (p. 1). This document also called for the development of a set of principles to govern ethical standards of organ acquirement and transplantation.

In 1991, a set of guiding principles for human organ transplantation (Resolution WHA44.25) were established and endorsed by member states. However, the following years saw a growth in the severity of the organ trade prompting further research to be carried out to tackle the issue. In response, the WHO's Guiding Principles on Human Cells, Tissues, and Organ Transplantation (Resolution WHA63.22) was endorsed in May 2010. These guiding principles are intended as a tool recommended to member states and, although not a legal document, they provide an ethical and universally acceptable framework for the regulation, procurement and transplantation of organs. Guiding principle 5 prohibits transplant commercialism whilst reaffirming a preference for altruistic organ donation:

Cells, tissues and organs should only be donated freely, without any monetary payment or other reward of monetary value. Purchasing, or offering to purchase, cells, tissues or organs 
for transplantation, or their sale by living persons or by the next of kin for deceased persons, should be banned. (p. 5)

\subsubsection{The United Nations}

The United Nations Protocol to Prevent, Suppress and Punish Trafficking in Persons, Especially Women and Children, which supplements the United Nations Convention against Transnational Organized Crime (UNTOC), regards organ trafficking as a form of organised crime, defining it within the context of human trafficking. In this Protocol (often referred to as the Palermo Protocol), trafficking in humans for the purpose of organ removal is prohibited. While WHO's guiding principles primarily prohibits financial profit from the sale of organs, the Palermo Protocol recognises and prohibits the practice due to the nature of trafficking, which involves exploitation, coercion and force. As a member state of the United Nations, New Zealand is party to this provision and signed it in December 2000.

\subsubsection{The Declaration of Istanbul}

In 2008, a summit on transplant tourism and organ trafficking, convened by the Transplantation Society (TTS) and the International Society of Nephrology (ISN), was held in Istanbul in response to the WHO's (2004) request for member states to "take measures to protect the poorest and vulnerable groups from transplant tourism and the sale of tissues and organs, including attention to the wider problem of international trafficking in human tissues and organs" (p. 57). The meeting was attended by over 150 international representatives of various countries and professional backgrounds and together they drafted the Declaration of Istanbul (DOI). The DOI is, to date, the most well-known and influential document in condemning black market transplant practices. This document established clear and comprehensive definitions of practices such as organ trafficking, transplant commercialism and transplant tourism. In addition, it provides ethical guidance to international policy makers and health professionals working in the field of transplantation. Most medical professionals are aware of the DOI, it is endorsed by the Transplantation Society of Australia and New Zealand (TSANZ) as well as 37 other countries.

\subsubsection{Council of Europe}

The Council of Europe is the continent's leading human rights organisation, representing 47 European member states. To strengthen global efforts against the organ trade, the Council of Europe Convention against Trafficking in Human Organs (CETS No.216) was adopted by 
the Committee of Ministers of the Council of Europe in 2014. In the preamble, the convention acknowledges trafficking in human organs as a violation of human dignity and the right to life, constituting a serious threat to public health (p. 1). The purpose of the convention is to end illicit transplant activity through the introduction of criminal sanctions and to facilitate global cooperation between both member and non-member states in combatting this global issue. The convention recommends the removal of organs from living or deceased donors should be criminally sanctioned where:

(a)...the removal is performed without the free, informed and specific consent of the living or deceased donor, or, in the case of the deceased donor, without the removal being authorised under its domestic law;

(b)... in exchange for the removal of organs, the living donor, or a third party, has been offered or has received a financial gain or comparable advantage;

(c)...in exchange for the removal of organs from a deceased donor, a third party has been offered or has received a financial gain or comparable advantage (pp. 2-3)

A unique feature of this convention, absent from previous international initiatives, is the recommendation of extraterritorial jurisdiction. In an effort to close loopholes in domestic legislation, it encourages member states to consider taking legislative changes to establish as a criminal offence the removal or implantation of human organs from living or deceased donors when "performed outside of the framework of its domestic transplantation system" (pp. 2-3). Moreover, it encourages member states to take necessary legislative measures to establish jurisdiction over offences which are committed by or against one of its nationals or a person who has their habitual residence in its territory (p. 4). Extraterritorial jurisdiction would provide demand countries with the authority to prosecute residents engaged in transplant tourism.

\subsubsection{The World Medical Association}

The World Medical Association (WMA) is an international body, in official relations with the WHO, which represents physicians and works to ensure the highest standard of medical ethics and healthcare globally. In a policy adopted by the WMA Assembly in 2012, and revised in 2017, the WMA recognises the unique position of physicians and medical associations in their ability to prevent commercial transplantation and transplant tourism.

The preamble requests that national medical associations support attempts to increase the number of living and deceased donor organs available in their country, while adhering to the 
highest ethical standards of procurement, allocation and transplantation of organs. Organ trafficking, transplant commercialism and transplant tourism are outside the framework of what is universally considered ethical medical practice as these activities violate core principles of medical ethics such as autonomy, beneficence, non-maleficence and justice. Therefore the sale and purchase of human organs is condemned, and medical professionals are urged to ensure their conduct aligns with the provisions of the policy:

Organs or tissue suspected to have been obtained through unlawful means must not be accepted for transplantation. Organs and tissues must not be sold for profit. In calculating the cost of transplantation, charges related to the organ or tissue itself should be restricted to those costs directly associated with its retrieval, storage, allocation and transplantation. Transplant surgeons should seek to ensure that the organs and tissues they transplant have been obtained in accordance with the provisions of this policy and should refrain from transplanting organs and tissues that they know, or suspect, have not been procured in a legal and ethical manner. (para. 34-36)

Although medical professionals are internationally called upon to assist in preventing or reporting transplant-related crimes, domestic guidance regarding how to handle (potential) situations of transplant tourism is absent in many countries and they are often left to rely on their considered judgement. Academic literature in this area has indicated that medical professionals in demand countries frequently 'turn a blind eye' to transplant-related crimes, and feel they are unable to prevent transplant-related crimes due to a conflict of duties (Ambagtsheer et al., 2015).

\subsubsection{Academic Researchers}

Globally, prominent doctors and scholars have presented arguments for an allencompassing prohibition on organ sales. Francis Delmonico (2009), a member of the WHO Expert Advisory Panel and founding member of the DOI, has taken an active role in condemning organ sales due to concerns regarding the unethical outcomes of such underground practices:

Organ trafficking, transplant tourism and transplant commercialism threaten to undermine the nobility and legacy of transplantation worldwide because of the reality associated with these practices - the vulnerable in resource-poor countries (such as the illiterate and impoverished, undocumented immigrants, prisoners, and political or economic refugees) 
are exploited for their organs as a major source of organs for the rich patient-tourists who are prepared to travel and can afford to purchase organs. (p. 116)

Nancy Scheper-Hughes, Medical Anthropologist and Director of Organ Watch, has continuously advocated for the prohibition of organ sales. She writes: "The division of the world into organ buyers and sellers is a medical, social, and moral tragedy of immense and not yet fully recognized proportions" (Bakdash \& Scheper-Hughes, 2006, p. 1701). ScheperHughes (2001) has written extensively on international trafficking in bodies and parts for medical use and describes the consumption of bodies in this context as "late modern cannibalism" (p. 1). That is to say, in bio-markets, the body has become a 'highly fetishized object' that is commonly viewed as a source of divisible parts that can be purchased as a resource to extend one's own life (Scheper-Hughes, 2001). The writings of these and many other academic authors support the dominant view that organ donation should occur altruistically, demonstrating respect for autonomy, informed consent, and human dignity.

\subsection{Ethical Critiques of Organ Commodification}

Across high-income countries, it is becoming increasingly apparent that the current altruistic approach to donation has not been successful in addressing the shortfall in organs. This, in terms of public policy, leaves transplantation and medical ethics at a crossroads and has given rise to significant debate about new approaches to address this issue. These range from compensation or incentives, through to the legal commodification of organ donation within a regulated market. Such propositions have been of ethical concern to many philosophers, social scientists, and members of the transplant community. The arguments against commodification are now well-rehearsed in academic literature, and the majority tend to focus on five categories: Slippery Slope Concerns, Improper Inducement, Excessive Harms, Eroding Altruism, and Threat to Human Dignity.

\subsubsection{Slippery Slope Concerns}

A set of concerns regarding the shift from pure altruism to commodification is the potential for a 'slippery slope' effect, where - over time - commodification to any degree may dissolve into a less or non-regulated system of commercial transplantation. Compensation or incentives for donors can be described as restricted commodification, representing a minor shift towards a more commodified approach to organ donation that did not otherwise exist. It has been argued that policies such as these will be leveraged by those in favour of establishing a regulated market in organs for the reason that the rationale behind shifting from pure altruism 
(or non-incentivised donation) to restricted commodification (or incentivised donation) can be used to support a further shift to freer restrictions (Koplin, 2017).

Similarly, regulated markets have been claimed to "contain seeds of their own undoing" (Capron, Danovitch, \& Delmonico, 2014, p. 23). Theoretically, for these markets to be ethically permissible, there would need to be appropriate restrictions and safeguards in place. For example, it would be unethical to allow recipients to buy an organ from a seller, therefore purchase should be restricted to the entity allocating the organs, and there should be a fixed price. However, it is argued to be unrealistic to expect that the state can simultaneously commodify an organ but restrict private purchase. Using the only current legal market in human organs as an example, the Iranian donation system has not kept to such limitations and turns a blind eye to private sales between recipient and vendor. In Iran, potential recipients and donors register at the Iranian Patients' Kidney Foundation. After giving consent and receiving evaluations, each matched pair are introduced to one another and negotiate an amount for the kidney (Aramesh, 2014). Moreover, a fixed price is unachievable in a market system as there is no rational market justification for a fixed price; by nature, markets deal in best or cheap prices. Once the exchange of organs is regarded as a transaction, and organs viewed as a commodified good in an open market, what is the expectation that people will not shop? This has adverse consequences for not only a domestic market, but wider ramifications on the already thriving international black market.

The commodification of organs may lead to gender injustices which negatively impact women in both low-income and high-income countries. The existing gender imbalances in live donation is well-documented in current literature. In the U.S., the majority of live kidney donors are women at a rate of 30 pmp compared with just 19 pmp for men (Gill et al., 2018). Similarly, in New Zealand 52\% of genetically related living donors were women, and of all genetically unrelated living donors, $72 \%$ were women also (ANZDATA, 2018). In Shaw's (2014) interview study of living kidney donors in New Zealand, 13 of the 19 directed donors were women and six were men. Of the non-directed donors included in the study, five were women and one was a man. The findings from this study suggest there may be a gender bias in live kidney donation in New Zealand, as more women than men donated kidneys and more directed donors gave kidneys to men than to women.

Donna Dickenson (2002) draws much needed attention to other feminist concerns, namely the potential exploitation of women for female tissue. It is not feasible to expect that the sale 
and purchase of human parts can be limited to organs. A market in organs is likely to devolve into a market of all parts of the body. So, while Dickenson's concerns include human organs, they primarily centre on the implications for embryonic and foetal tissue:

If all is up for sale, it might be that women's labour in egg extraction and 'surrogate' motherhood will be seen as [...] labour which produces something of value. But this does not necessarily mean that women will benefit from the commodification of practically everything, in either North or South. In the newly developing biotechnologies [...] the reverse is more likely. (p. 62)

\subsubsection{Improper Inducement}

Another common critique of commodifying organs is that of improper inducement. Incentivised, compensated, or paid organ donation is argued to be unethical due to concerns that these methods will a) undermine autonomous decisions and b) coerce poor and/or vulnerable populations to donate. Undue inducement refers to the risk of subjecting potential donors to coercion or pressure, thus undermining their autonomy and informed consent. Should payment for organs be permitted, there may be instances where the offer is 'too good to refuse' which would financially motivate people to accept risks that are against their better judgement or that they would have previously deemed unacceptable (Allen \& Reese, 2013). Unjust inducement refers to the ethical concern of coercing poor, disadvantaged or vulnerable groups to donate an organ. Impoverished groups are subjected to more financial and social pressures than those who are financially well-off, rendering them more susceptible to undue inducements. Within existing contexts where the distribution of wealth is vastly disproportionate, there is evidence to suggest that commodification will lead to a social bias in donor selectivity and recruitment.

\subsubsection{Excessive Harms}

An important concern that warrants consideration is the risk of subjecting sellers to excessive and unacceptable harms. Available literature highlights an alarming association between the sale of kidneys and a decline in the physical, psychological, social, and financial wellbeing of the seller (Codreanu, Codreanu, \& Delmonico, 2010; Goyal, Mehta, Schneiderman, \& Sehgal, 2002; Naqvi et al., 2008; Zargooshi, 2001). The range of harms faced by sellers in current organ markets, which are discussed at length earlier in this chapter (pages 13-15), have caused some to voice concern that similar harms may be reproduced in a regulated market. A study carried out by Zargooshi (2001) examined the quality of life of 300 Iranian 
live kidney vendors post-transplant. Despite being located in a legal organ market, the vendors faced a number of harms similar to those found in illegal markets. Sixty percent of participants complained selling their kidney had negative effects on their physical abilities, and $65 \%$ stated their decision had adverse effects on their employment. Overall, selling a kidney caused somewhat (20\%) to very (66\%) negative financial consequences. Seventy percent of the sample experienced social-isolation, $60 \%$ suffered anxiety, and $71 \%$ developed severe de novo postoperative depression, as a consequence of the sale. Overall, there were somewhat (22\%) to very $(58 \%)$ negative effects on the general health of vendors. Eighty-five percent of the Iranian vendors stated they would definitely not sell their kidney again if given another chance, and $76 \%$ would discourage others from vending. The extent of their regret was immense, with half of the sample indicating that they would be prepared to lose more than 10-years of their life and the majority $(76 \%-100 \%)$ of their properties to regain their kidneys.

\subsubsection{Eroding Altruism}

Motivation-Crowding theory suggests external intervention, such as financial incentives, has the potential to crowd out or undermine intrinsic motivation to do a particular behaviour (Frey \& Jegen, 2001). There is very good evidence, grounded in behavioural economics, to suggest that the sale of organs would not increase the number of transplantable organs but would have a corrosive effect on attitudes to donation that would diminish the current supply.

Philosophers and social scientists have commonly applied the work of Richard Titmuss (1971) to illustrate the likelihood that introducing extrinsic incentives (such as financial reward) will bring about a collapse in altruistic donation. In his book, The Gift Relationship, Titmuss compared the blood donation services operating in the U.S. and the U.K. - the former system permitted the sale of blood while the latter prohibited it, instead favouring altruistic donation. Titmuss discovered that the rate of blood donation in the U.K. was significantly higher than the rate of blood donation in the U.S. and concluded "the commercialization of blood and donor relationships represses the expression of altruism (and) erodes the sense of community" (p. 245). This same rationale is used to argue against the commercialization of organs and highlights the potential danger a market poses to the current donation rate.

Another study, conducted by Gneezy and Rustichini (2000), observed that where intrinsic motivation to perform a behaviour is replaced with financial motivation, it decreased the rate at which the behaviour was performed. In fact, the financial motivation triggered a dramatic and irreversible shift in how that behaviour was perceived which weakened the moral 
commitment to engage in it. When applied to organ markets, the above finding suggests a shift from the current altruistic model to commodification will decrease the rate of organ donation because the act of giving an organ will no longer be perceived as a moral obligation or civic duty. This shift in perception will result in a crowding out of altruistic motivation and a decrease in the overall donation rate.

\subsubsection{Threat to Human Dignity}

Putting aside the debate of whether commodification would prove successful in increasing the supply of transplantable organs, the question of whether it is intrinsically wrong to sell, or purchase, parts of the human body still remains. One of the leading objections to the commodification of organs is that to do so would violate human dignity. Human dignity can be understood as an innate metaphysical property possessed by all people, pertaining to one's unconditional and incalculable worth or value (Alpinar-Şencan, Baumann \& Biller-Andorno, 2017; Koplin, 2017; Nordenfelt 2004; Sulmasy 2007).

It has been proposed that if organs were transformed into a market good, it will diminish the seller's dignity. This Kantian-style critique rests on the assumption that a person's self is not completely distinguishable from their body. That being said, there is concern that objectifying an organ will, in turn, objectify the person in which that organ resides. Walsh (2015) comments that market institutions (e.g. a price) prompt people to assess goods as mere commodities lacking intrinsic value. If we begin to view organs as mere commodities, we are likely to view the sellers in a similar vein. For that reason, it does not seem unreasonable to assert that commodification of this type will encourage the idea that the sellers, and not merely their organs, are purchasable therefore lacking human dignity. Kerstein (2013) points out that this has wider ethical implications when located within existing social contexts:

...where the interests of the poor are already widely seen as less important than the interests of the well off, it is "all too easy to envisage a slide from the thought that ... Poor persons' intimate body parts are for sale to the idea that they themselves are fungible" (as cited in Koplin, 2017, p. 584)

The state-sanctioned organ harvesting practices in China are illustrative of the notion that commodification has the potential to corrode humanity dignity. These practices began in the early 1980s, where organs were harvested from death-row prisoners charged with capital crimes on an ad hoc basis (Gutmann, 2012). From the 1990s onwards, these practices became widespread and involved executing prisoners on demand, usually by a gunshot to the head, 
then harvesting their organs to support both the domestic and illegal organ trade (Sharif et al., 2014). By 2005, it was reported that $95 \%$ of transplanted organs in China came from prisoners, and evidence suggests that a large number of Falun Gong prisoners of conscience were executed to facilitate these transplants (Sharif et al., 2014). 


\section{Theoretical Framework}

This chapter outlines the medical and cultural contexts in which patients are making decisions about transplant tourism and introduces relevant theoretical concepts through which I consider and examine the role of medical professionals and involvement of patients in the global kidney trade.

\subsection{The Medical Context: From Paternalism to Autonomy}

In western contexts, paternalism has historically been a central feature of medical care. It is grounded in the principles of beneficence (i.e., to promote good) and non-maleficence (i.e., do no harm). Philosophers Tom Beauchamp and James Childress (2013) define paternalism as:

the intentional overriding of one person's preferences or actions by another person, where the person who overrides justifies his action by appeal to the goal of benefitting or of preventing or of mitigating harm to the person whose preferences or actions are overridden. (p. 215)

It is perhaps best demonstrated in the Hippocratic Oath, within the vow to use treatments "which will benefit my patients according to my greatest ability and judgement, and I will do no harm or injustice to them" (Pozgar, 2019, p. 283). Examples of paternalism in healthcare include interventions to stop suicide, withholding medical information, denying an innovative therapy a patient wishes to try, or the resuscitation of a patient against their wishes (Beauchamp and Childress, 2013). Paternalistic interventions are not carried out maliciously but are intended to benefit and protect the welfare of the patient.

Beauchamp and Childress (2013) distinguish between two forms of paternalism. Hard paternalism involves overriding a patient's autonomy despite the fact that the patient's risky decisions are voluntary, informed, and autonomous. By contrast, soft paternalism involves intervention where patients are unable to make a competent decision; that is, their decisions and actions are non-voluntary, poorly informed or are made under circumstances that prevents free choice. Choices can be influenced by a range of factors and motivated by different states which can make it difficult for medical professionals to determine whether patients' preferences are autonomous and what the appropriate means of action are. Nevertheless, advocates maintain that soft paternalism is compatible with autonomous choice within modern medical practice as it does not greatly conflict with respect for autonomy and beneficence. Sustein and Thaler (2003) proposed the idea of 'libertarian paternalism' and argue that: 
The idea of libertarian paternalism might seem to be an oxymoron, but it is both possible and legitimate for private and public institutions to affect behaviour while also respecting freedom of choice. Often people's preferences are ill-formed, and their choices will inevitably be influenced by default rules, framing effects, and starting points. In these circumstances, a form of paternalism cannot be avoided. Equipped with an understanding of behavioural findings of bounded rationality and bounded self-control, libertarian paternalists should attempt to steer people's choices in welfare-promoting directions without eliminating freedom of choice. (p. 1)

A broad range of research has marked the more recent 'triumph of autonomy' (Beauchamp, 2006; Moreno, 2007; Wolpe, 1988). It has been recognised that in today's medical context it is critical for patients to feel they can play a full part in their own care and are fully involved in the decision making. Trisha Greenhalgh and Brian Hurwitz (1999) comment that doctors have come to regard their role as one that involves facilitating and emphasising illness from the patient's point of view. Within a clinical encounter, accentuating the patient's voice has the potential to encourage empathy and increase understanding between patients and doctors (Greenhalgh \& Hurwitz, 1999). Now in an age labelled 'the century of the patient', modern healthcare practice is hallmarked by an emphasis on respect for autonomy, whereby doctors and patients communicate in partnership and share decision making (Paterson, 2012). According to Beauchamp and Childress (2013), respect for autonomy includes not only acknowledging a patients right to make choices upon their personal views and beliefs but supporting patients to act autonomously whilst reducing conditions which disrupt autonomous action. There are three conditions by which a choice is deemed to be autonomous: intentionality, understanding and non-control. Beauchamp and Childress (2013) argue that while intentionality is dualistic (intentional or nonintentional), the remaining conditions exist on a continuum, and can satisfy understanding or non-control to a greater or lesser extent. From this view, autonomy can be seen as a matter of degree. Although some commentators hold that respect for autonomy should take precedence above all else, Beauchamp and Childress maintain that a patient's autonomy may be overridden by competing moral considerations. Medical professionals can justifiably restrict autonomy under circumstances where "our autonomous choices endanger the public health, potentially harm innocent others, or require a scarce resource for which no funds are available" (pp. 107-108). Understanding the medical context in which patients are making decisions about transplant tourism frames the discussion of the positionality of medical professionals within the doctor-patient relationship. 


\subsection{Gatekeeping}

Medical professionals are advocates for their patients and have an ethical responsibility to act in their patients' best interests and offer beneficial medical treatments. Despite this, they have an overriding obligation to act as 'gatekeepers' to limited resources (Weinstein, 2001). If medical professionals were to collectively offer all beneficial medical services to all patients who desire them, they would risk exhausting healthcare resources and compromising access to care and quality of care. Eddy (1986, p. 114) comments that when confronted with limited resources, rather than make a simple qualitative judgement that a procedure may be beneficial, medical professionals must make a quantitative estimate about the magnitude of the benefit. By establishing and adhering to a set of agreements to govern and limit the use of such resources, medical professionals are seen to be achieving important health policy goals such as quality, efficiency and responsiveness of healthcare delivery (Reay, 1999).

Since the late 1960s, there has been a desire to treat organ failure with transplantation (Watson \& Dark, 2012). Yet kidney transplantation has arguably become the practice of rationing, with transplant centres functioning as gatekeepers rather than providers (Stratta et al., 2004). The gatekeeping of this procedure is an ethical issue because transplantation is the treatment of choice among most patients with severe organ failure. Evidence suggests that many patients would fare better with a transplant when compared to dialysis. However, given that the supply of donor kidneys does not satisfy every need, transplant physicians are required to take a paternalistic approach to kidney allocation. Deciding who is eligible for kidney transplantation is a complex scenario in which medical professionals must make a network of judgements. In New Zealand, determining who is suitable for transplantation occurs in three phases: Decision to Assess, Clinical Assessment, and Deceased Donor List Maintenance.

The first step in this process, and a key gateway to transplantation, is being identified as a potential transplant candidate. This judgement is carried out at a referring centre where treating nephrologists serve as gatekeepers to transplant assessment. Nephrologists are regarded as experts in the benefits and risks of treatment and the assessment process which enables them to make an individualised and considered decision about each patient's suitability for assessment (NRTS, 2018). Decisions to assess or not assess are usually made in consultation with the patient and are communicated to transplant coordinators when made. Although many patients wish to be considered for transplantation, the gatekeeping of transplant assessment is essential for two main reasons: (1) avoiding assessment for unsuitable patients is important to 
avoid false hope and (2) assessing unsuitable patients is a waste of healthcare resources (NRTS, 2018).

If identified as a potential transplant candidate, patients undergo standardised screening tests designed around clinical requirements for transplantation. The purpose of assessment is largely about defining risk of a poor outcome and avoiding transplantation where that risk is too high (NRTS, 2018). Each patient considered for transplant listing is scored using a projected survival calculator developed in the U.S. Patients are scored at the date which they are first considered, and the current listing criteria is to accept patients with an estimated fiveyear survival of $70 \%$ (Dowen et al., 2017). Although TSANZ recommends an $80 \%$ estimated five-year survival, a threshold of $70 \%$ is used to account for a confidence interval, lack of complexity of predictive factors, and potential differences in New Zealand and U.S. demographics (Dowen et al., 2017). Adequate scores only form part of the assessment and does not guarantee listing. Further, in exceptional circumstances, those with inadequate scores can have their case reviewed by the National Renal Transplant Team. Each patient with a predicted probability of survival higher than $70 \%$ is subject to a clinical review at a multidisciplinary team meeting who will determine suitability for listing (Dowen et al., 2017). Only those who are accepted are transferred to the deceased donor waiting list.

While being listed for a transplant is a key gateway to transplantation, there are still many barriers that impact a patient's likelihood of receiving a transplant. Firstly, the waiting list is under constant management. Listed patients are rescored on an annual basis, or at any point when they have developed new co-morbidities and are subsequently removed from the waiting list if their predicted probability of survival score falls below $70 \%$ (Cross, Dittmer \& Matheson, 2012). Secondly, transplant opportunities are heavily dependent on the availability of deceased donor kidneys. Lastly, when a deceased donor kidney becomes available, it can only be allocated to one of the many patients on the list. The New Zealand Kidney Allocation Scheme (NZKAS) is an algorithm established to ensure that the allocation of all deceased donor kidneys and non-directed live donor kidneys is carried out in an equitable, accountable and transparent manner (NRTS, 2019). Gatekeeping is a necessary part of any healthcare infrastructure and achieves important health policy goals. Nevertheless, the gatekeeping of transplantation can encourage some patients to feel as though they are alone in a healthcare system that presents them with few alternative treatments, despite the fact that patients are offered long-term dialysis. Today, patients have an unprecedented degree of choice in 
healthcare decisions and treatments are increasingly sought through alternative avenues, often via the Internet.

\subsection{The Cultural Context: Health and Illness in the Technological Age}

Historically, patients occupied a fairly passive role in the medical arena and were expected to comply with 'doctor's orders'. Increasingly, in recent years, patients have adopted an active role in the management of their health. This transformation is reflective of contemporary expectations and norms which have been shaped by the advent of increasing choice, consumerism, and an abundance of accessible information (Petersen, 2015).

Arthur Frank (1995), a medical sociologist, notes that contemporary culture regards health as the normal condition that people should have restored. In this context, not only do sick people seek recovery, but they have to contend with societal expectations of hearing stories of restitution. When people speak of their illnesses, Frank proposes they weave between three 'narrative types', the dominating narrative being that of restitution. He summarised this narrative type as: "Yesterday I was healthy, today I am sick, tomorrow I will be healthy again" (p. 77). This is the preferred narrative, reflecting our 'natural desire' to restore and maintain health, and the modern expectation that there is a treatment for every ailment (Frank, 1995, p. 80). Within the field of sociology, the restitution narrative is demonstrated in Talcott Parsons' (1951) conceptualisation of the 'sick role' as behaviour in accordance with institutionalised expectations of being sick. In short, the sick person is relieved of their "normal social role responsibilities, which of course is relative to the nature and severity of the illness" (Parsons, 1951, p. 436). Moreover, they are not blamed for the incapacity, but are expected to view their state as undesirable and are obligated to seek competent care and comply with treatment. Parsons' formulation of the sick role casts physicians as social control agents who possess "unusual expertise" and are "the main or ultimate legitimator of the sick role who charts the patient's recovery" (Levine \& Kozloff, 1978, p. 318). This concept is less concerned with the experience of being ill but, as Frank (1995, p. 83) explains, it "is a powerful narrative of what medicine expects from the ill person and what other social institutions expect from medicine".

The scientific and biomedical innovations witnessed in the 20th and 21st century profoundly transformed some approaches to illness and patient treatment and, in turn, shifted our understanding of the restoration of health (Fennell, 2008). For example, the successful invention of organ transplantation revolutionised the management of organ failure and prolonged the lives of those who would have otherwise faced an inevitable and premature 
death. The success of such biomedical interventions has contributed to the contemporary belief in the ability of science and medical technology to free people from the sufferings and constraints of illness and return them to an idealised state of health (Petersen, 2015). Once the so called 'normalising' potential of technologies was recognised, a belief in the power of technology to enhance current states of health ensued.

Alan Petersen (2015) points out that, over the past thirty years or more, the rise of the 'healthy self' has corresponded with the expansion of neoliberal philosophy and policy in a number of countries. The contemporary preoccupation with health is demonstrated by a marked cultural shift from the production to the consumption of health technologies (Bury, 1997). In recent years, the availability and use of health technologies has been intensified by the advancement of informational tools like the Internet - highlighting the triumph of technological consumerism (Petersen, 2015). Medical anthropologists, Margaret Lock and Vinh-Kim Nguyen (2018, p. 71), describe the healthism phenomenon as "an occupation taken very seriously by many people all over the world today" which reflects expectations that individuals ought to take an active role in restoring, managing and optimising their own health. This is reiterated by Petersen (2015), who argues that 'quantifying the self' has become normalised as a means of maintaining health:

Self-quantification involves citizens active engagements in practices of self-monitoring and self-discipline through integrating self-sensing technologies into different aspects of their biophysical lives, including those that measure bodily input (e.g. quality of food, air, exercise levels) and biophysical states and functioning (e.g. calories burnt, blood oxygen levels, heart rates, mood, arousal, weight, movement during sleep). (p. 79)

In addition to adopting proactive approaches to bodily care, people are actively acquiring knowledge and information about health and medical treatments. The explosion of information technology has had significant implications for clinical treatment. The Internet has massively contributed to the growth of an 'information rich' society, where people are afforded an extraordinary degree of choice in healthcare decisions (Shilling, 2002). By way of the Internet, individuals have the ability to "traverse boundaries between different knowledges, professions and practices" (Shilling, 2002, p. 629). Users are granted access to an abundance of information, allowing them to acquire expert knowledge about medical conditions, search for medical advice, and search for second opinions on diagnoses. Needless to say, the emergence 
of 'expert patients' has had a significant impact on the doctor-patient relationship (Taylor \& Bury, 2007).

In postmodern society, the previously asymmetrical doctor-patient relationship has been reformed, and healthcare providers are now expected to work in a closer partnership with patients. The growing use of the Internet has relegated practitioners to advisors or secondary sources of medical advice. Additionally, informed, knowledgeable patients have increased their capacity to challenge the opinion of their healthcare providers, and demand access to new and emerging treatments. The so called 'demanding patient' of the contemporary era is said to have great expectations about what medical staff can deliver, and some have unrealistic expectations about the miracle of modern medicine (Paterson, 2012). As patients are accustomed to an unprecedented degree of choice, they are more likely to become unhappy when their wishes are not complied with (Paterson, 2012). Paterson (2012, p. 68) observes that in the decade from 2000, patient complaints have risen by $40 \%$ in New Zealand - a similar trend has been replicated in the U.K. also. Given the rise of 'information rich consumers of health' and contemporary expectations of self-governance, patients who feel constrained by paternalism in healthcare may choose to shop around for healthcare instead (Shilling, 2002).

The Internet has provided a space for a diverse range of healthcare services and markets to proliferate, ranging from treatments that are health-restoring to those that are healthenhancing (Petersen, 2015). This includes markets that are both legally organised, such as invitro fertilisation (IVF) treatments, and markets that involve completely illegal practices of trafficking in bodies, tissue and organs (Lundin et al., 2016). Websites such as indiaorgantransplant.com have capitalised on the direct-to-consumer advertising of the Internet and offer treatments and services directly to users without the assistance or advice of intermediaries (Petersen, 2015).

\subsection{Illness Narratives}

Illness narratives are culturally embedded and can take many forms; they can be told by patients, the family of patients, and medical professionals. In the modern era, the medical narrative surpassed all others (Frank, 1995). The story of illness told by medical professionals was that against which patient narratives of illness were legitimated or deemed to be false, as illustrated by Parsons' (1951) sick role theory. Expert practitioners, using "specialised language that is unfamiliar and overwhelming", would interpret and document the pains of others as symptoms, forming the "official story of the illness" (Frank, 1995, p. 5). While 
medical professionals depended on the patient voice to inform them about the patients' physiological conditions, the patient narrative was not recognised to be significant in its own right. It was not until distinctions were made between illness and disease that the illness narratives of patients gained importance in biomedicine and the social sciences (Hydén, 1997). In his book, The Illness Narratives, Arthur Kleinman (1988) clarifies these terms:

Illness refers to how the sick person and the members of the family or wider social network perceive, live with, and respond to symptoms and disability. Illness is the lived experience of monitoring bodily processes such as respiratory wheezes, abdominal cramps, stuffed sinuses, or painful joints. Illness involves the appraisal of those processes as expectable, serious or requiring treatment... Disease, however, is what the practitioner creates in the recasting of illness in terms of theories of disorder. Disease is what practitioners have been trained to see through the theoretical lenses of their particular form of practice. The healer $[\ldots]$ interprets the health problem within a particular nomenclature and taxonomy $[\ldots]$ that creates a new diagnostic entity, an "it" - the disease. (pp. 3-5)

Conceptualising illness as fundamentally distinct from disease recognises that, although professionals can observe the effects of illness, illness can only be experienced and shared by patients. Frank (1995, p. 6) describes the sharing of illness narratives as a postmodern phenomenon characterised by patients' awareness that more is involved in their experience of illness than the medical story can tell.

According to Kleinman (1988, p. 4), narrative is the medium through which patients articulate and present, in accessible and common-sense ways, the sufferings of illness. He labels these sufferings 'illness problems', or the principle difficulties illness and symptoms create in our lives. As Toombs (1988, p. 202) explains, the experience of illness should be understood not simply as a breakdown in the functioning of the body, but as the disintegration and disorder of our 'world'. This is especially the case for chronic illness which significantly disrupts all aspects of our lives and in doing do, disrupts our sense of self and identity (Berglund \& Lundin, 2012; Bury, 1982; Shaw, 2015a), Docherty and McColl (2003) describe this succinctly:

Diagnosis of a chronic illness or the onset of a disability is indeed a stressful event. The transition from well to ill, able-bodied to disabled, represents a challenge to the beliefs many of us operate under at some level, namely, that we are invulnerable, that our lives 
are predictable, that life has meaning, and that we are worthwhile. The onset, sudden or otherwise, of a chronic illness or a disability calls all of those beliefs into question. (p. 20)

The onset of chronic illness forces us to alter our ideas about what is changeable and how we relate to our bodies, selves, and society under these new conditions (Hydén, 1997). Many researchers recognise that, through narrative, patients often reconstruct or reorient their identities and personal life histories around their experiences of illness. Kleinman (1988, p. 8) comments that "the trajectory of chronic illness assimilates to a life course, contributing so intimately to the development of a particular life that illness becomes inseparable from life history". With respect to this, Lars-Christer Hydén (1997, p. 51) points out that narrativising chronic illness within the framework of one's life history makes it possible to give meaning to events. Thus, it is through narratives that we can attempt to understand how the patients in this study cope with and make sense of their illness experiences as it influences their considerations of transplant tourism.

It is important to recognise that illness narratives are unique because unlike other types of narratives, they do not have a foreseeable ending or a 'temporal horizon' to orient their construction (Good, 1994). Thus, illness narratives are built upon the possibility of new endings and are continually in search of meaning (Good, 1994; Hydén, 1997). Interestingly, Hydén (1997, p. 61) comments that it is possible for patients to create a temporal time horizon "by establishing a link between the course of the illness and concomitant medical intervention" which will in turn establish "hope for a possible cure and...the continuation of life". From this view, patients who invest hope in an organ transplant are too seeking a time horizon and setting expectations for their return of health. When people take their 'illness complaints' to a medical professional, they can be seen as searching for an ending to their illness narrative. But in the practitioners recasting of illness as disease, Kleinman (1988) suggests that something essential to the experience of chronic illness is lost, and therefore does not receive intervention. He identifies this a potential source of conflict within the doctor-patient relationship: "Treatment assessed solely through the rhetoric of improvement in disease may confound the patient's assessments of care in the rhetoric of illness problems... those who cannot be cured must continue to live with illness" (p. 6). Extending on this, in the context of kidney allocation, medical professionals are required to assess treatment not only on the basis of improvement of disease, but also on the extent of improvement. This can certainly confound patients' assessments of care, especially given that many would fare better with a transplant when 
compared with dialysis. For this reason, those who are unwilling to continue to live with ESRF may consider transplant tourism as their only pathway to treatment and restored health. 


\section{Methodology}

In this chapter, I explain my research aims and choice of research methodology. I then outline the recruitment and data collection process, commenting on the limitations and ethical considerations of speaking with participants about this topic. Finally, I describe how I used thematic narrative analysis to organise meaningful passages from my interview transcripts, before discussing the presentation of the findings.

\subsection{Outline}

Internationally, the prevailing moral guideline of organ procurement stipulates kidneys should be donated as an act of altruism, rather than as the object of a financial transaction. Yet, despite being a crime in most countries, the number of patients embarking on transplant tourism continues to rise. The present research considers the involvement of New Zealand residents in these practices and examines the responses of healthcare professionals who suspect or discover a patient intends to procure an organ outside of New Zealand. The purpose of this research is to better understand what motivates those who consider or pursue transplant tourism and the difficulties this poses for medical professionals working in the field of organ donation and transplantation.

My honours research (Anderson, 2017) utilised secondary qualitative data to conduct an in-depth analysis of patients' decisions to engage in transplant tourism, guided by Sykes and Matza's (1957) neutralisation theory and Matza's (1964) theory of drift. This theoretical framework allowed me to discern multiple factors that encouraged those patients to participate in transplant tourism. Sykes and Matza developed five techniques of neutralisation to help explain why people commit crime. According to them, when contemplating a criminal act, one or more of the neutralisation techniques are employed by individuals to rationalise the action, and neutralise the guilt associated with violating societal norms. Developed in Matza's later work was drift theory which he defines as an "episodic release from moral constraint" (p. 69). Enabled only by techniques of neutralisation, drift periodically lifts moral and legal binds, allowing an individual to commit crime should they choose to do so. The secondary data employed for this research had a focus on patients within European healthcare systems as no qualitative research with recipients from New Zealand was available for analysis. This inspired and prepared me to facilitate empirical research into occurrences of transplant tourism in New Zealand and the responses of medical professionals. 
For the present study, I received ethics approval from the Human Ethics Committee at Victoria University of Wellington (Appendix 1). My research project was approved in the first instance, with some minor amendments to include an additional sentence to the participant information sheets and recruitment advertisement. As stated in the Introduction of the thesis, the research questions are:

\section{Do New Zealand kidney failure patients consider paid transplantation abroad?}

2. Do New Zealand residents engage in transplant tourism?

\section{How do medical professionals handle occurrences of transplant tourism?}

\subsection{Methodological Approach}

The answers to these questions were investigated through exploratory qualitative research. I used a semi-structured interview approach, which was useful in the context of this research as it offered respondents the chance to explore issues that are significant to them. The social prevalence of interviewing means this method of data collection is familiar to both researcher and respondents, and it is one of the most common methods of qualitative research within the health and social sciences (Braun \& Clarke, 2013). One-on-one interviewing, as opposed to qualitative surveys, are better suited to exploring the perceptions and constructions of topics that respondents have a personal stake in and will likely generate detailed, rich, and often unexpected data.

As described earlier in the thesis, medical professionals are uniquely positioned to many of the aspects that are of significant relevance in this thesis; they are at the frontline of providing services and advice to patients with ESRF and are privy to information about the involvement of New Zealand residents in transplant tourism. For this reason, it was decided that medical professionals would constitute the majority of participants in this study. In order to attain a diverse range of responses and experiences, the medical professionals in the study varied significantly in professional role and geographical location. So as to build a comprehensive picture of New Zealand's involvement in transplant tourism, I also sought to include the voices of those outside of the medical arena. Therefore, I spoke with key informants who are in professional positions which allow them to have specialist knowledge relevant to the aims of this research.

Although the above participant groups have professional insight relating to New Zealand's involvement in transplant tourism, the experience of illness and pursuit of transplant tourism 
can only be shared by the patient. I initially sought to speak with recipients of commercially transplanted kidneys, but I encountered many difficulties in accessing and recruiting such participants. I had hoped that medical professionals would pass on information about my research to known recipients under their care, but most were reluctant to do so. One medical professional was willing to distribute information about this study, but explained that many of the relevant patients spoke English as a second language if at all. In view of the challenges this would create with translation, interviewing, and transcribing, I was required to broaden the direction of my project and was able to meet the aims of this research without that participant group. Instead, I interviewed patients who have considered transplant tourism whilst waiting for a deceased donor transplant. Despite not having embarked on transplant tourism, these patients were able to discuss the factors that motivated their considerations of transplant tourism. Moreover, this participant group was able to provide insight regarding their reservations and the personal factors that are preventing them from embarking on that path to treatment.

\subsection{Doing Narrative Research}

From the late 1960s there has been a surge of narrative theorising, highlighting a "narrative turn' in human inquiry (Riessman \& Quinney, 2005). Since then, personal story telling has come to be seen as a "valid means of knowledge production" (Fraser, 2004, p. 180) and narrative approaches to research have been increasingly legitimised within almost every discipline (Riessman, 2001). Plummer (1995) refers to this as the 'narrative moment':

Stories have recently moved centre stage in social thought. In anthropology, they are seen as the pathways to understanding culture. In psychology, they are the bases of identity. In history, they provide the tropes for making sense of the past. In psychoanalysis, they provide 'narrative truths' for analysis. In philosophy they are the bases for new forms of 'world-making' and they key to creating communities. Even economics has recognised its

'storied character'. Everywhere, it seems, there is an interest in stories, and social scientists have now finally grasped this point. (p. 19)

As discussed in Chapter 3, the concept of narrative can be considered in the context of theory. In addition, narrative is often employed methodologically. Narrative research involves collecting and analysing the stories people tell to describe their experiences and then offer interpretation (Overcash, 2003). Narrative approaches take the story as the object of study, focusing on how people impose order on an otherwise chaotic scenario in their life and organise 
their experiences into temporally meaningful episodes (Bamberg, 2007; Richardson, 1990). Narrative accounts are typically elicited and listened to by way of narrative interviewing. As a qualitative approach, this allows researchers to "delve beneath statistically driven generalisations" and empower the voices of ordinary people (Fraser, 2004, p. 184). With regard to illness narratives, Kleinman (1988) draws attention to the value of empowering, listening to, and interpreting the voices of patients:

...there is evidence to indicate that through examining the particular significances of a person's illness it is possible to break the vicious cycles that amplify distress. The interpretation of illness meanings can also contribute to the provision of more effective care... Not the least of the reasons for studying illness meanings is that such an investigation can help the patient, the family, and also the practitioner. (pp. 9-10)

Narrative interviewing is characterised as relational and 'participant-centred', in that researchers "have made efforts to give up power" and allow participants to control the content, direction and pace of the interview (Anderson \& Kirkpatrick, 2016; Riessman, 2002, p. 2). Therefore, it is best fitting for researchers to employ a semi-structured interview technique, as opposed to fixed and specific lines of questioning (Anderson \& Kirkpatrick, 2015). While centralising the participant, this approach privileges the dialogical interaction between the researcher and participant when accessing in-depth experiential accounts, recognising that meaning is created collaboratively (Anderson and Kirkpatrick, 2015; Riessman, 2005). According to Hydén (1997, p. 60) "to listen to the narrative is to take an active part in its construction in order to be able to understand what it is all about and how it can be expected to develop". Thus, narrative methodology does not assume objectivity, rather, this approach privileges subjectivity and positionality (Riessman, 2002, p. 2).

\subsection{Recruitment Process}

A total of eight medical professionals, two key informants, and two patients were recruited for this study. Of the medical professionals I spoke with, four were female and the other four male. The participants varied in professional positions, which included three nephrologists, a nurse practitioner, a renal physician, a transplant physician, a transplant nurse, and a live kidney donor co-ordinator. As Woods (2005) has commented, the voices and perspectives of nurses on ethical issues that affect healthcare are often unheard. I therefore sought to include nurses' narratives and ethical interpretations of transplant tourism in addition to those of other medical professionals. The two key informants were both male and are described in this study as an 
academic and a stakeholder. The former has specialist legal knowledge regarding organ donation, transplant tourism and transplant-related crimes, while the latter holds knowledge about kidney donation and transplantation in New Zealand. Both patients in this study identified as male and are New Zealand born citizens. The first patient, John (a pseudonym), had previously undergone a LDKT in New Zealand. Since then, he is again receiving dialysis and remains on the waiting list for a deceased donor kidney. John was considering transplant tourism at the time of the interview and had not yet made a decision about whether or not to embark upon commercial transplantation abroad. The second patient, Simon (a pseudonym), received a deceased donor kidney from the waiting list 10-years ago. Today he is in good health and reflected on his illness experience and past considerations of transplant tourism.

The medical professionals and key informants were recruited by convenience and snowball sampling, and the two patients were recruited with the assistance of Kidney Health New Zealand; which posted an advertisement on their Facebook group and national website (Appendix $2 \& 3$ ). All participants were self-selected and geographically distributed, working or residing in various regions across the country. To ensure participants were interviewed in a location that was comfortable and convenient to them, a small research grant was obtained to facilitate travel. All medical professionals and key informants were interviewed at their place of work, one patient was interviewed in their home and the other at a location convenient to them. All but three interviews were conducted individually and face-to-face. As per participant request, two medical professionals from one hospital were interviewed together, one interview with a medical professional was conducted over the phone, and one other was attended by a medical student.

I sent interview participants information sheets (Appendix $4 \& 5$ ) before meeting with them and written informed consent was obtained for all interviews, including authorisation for future use of data in connected studies on organ donation and transplantation. The consent form (Appendix 6) also offered the participants an assurance of confidentiality. To ensure participants in this study remained unidentifiable, the data has been aggregated and pseudonyms have been used where necessary. The interviews typically took between 1 to $1 \frac{1}{2}$ hours, except for two interviews with nephrologists which were approximately 30 minutes duration. The research participants were interviewed and asked open-ended questions structured around guiding themes relevant to each participant group. The interviews with patients began with a discussion of the onset of illness, their symptoms and their illness problems before sharing their perspectives and considerations of commercial transplantation 
overseas. The interviews with medical professionals and stakeholders began with explanations of the medical context and paths to treatment in New Zealand, before sharing their professional knowledge or experience with patients who have considered or pursued transplant tourism. All the interviews were transcribed verbatim, and then sent to participants for review upon request.

\subsection{Limitations and Ethical Considerations}

Although qualitative research is useful for deep and detailed exploration of phenomena, like all methods of research, there are limitations that researchers must be aware of. While considered an inevitable part of qualitative research, the influence of the researcher during each phase of the process can be a potential issue (Anderson, 2010; McKechnie, 2008). The large volume of data generated by qualitative approaches can be difficult to manage and can make the analysis and interpretation of data a time consuming process (Anderson, 2010). In addition, the presentation of qualitative findings must be carefully considered. Given that each observation is highly contextualised, some methodologists suggest that researchers should avoid drawing bold conclusions or sweeping generalisations from a small sample (Norman, 2017).

In addition to being unable to recruit transplant tourists, there were difficulties in getting access to patients in general. I chose to contact two organisations to inquire into the possibility of advertising the research on their website or other media platforms. Given the prominence of social media, I believed these platforms would be frequently visited by patients from all regions of New Zealand and would allow for a greater geographical distribution of participants. Only one of the organisations (KHNZ) was willing to assist in participant recruitment, and the other politely declined as they felt it may be inappropriate to advertise research of this nature on their website. The use of a public platform had advantages and disadvantages. The advertisement posted to Facebook was able to be shared by users to their personal Facebook pages or other relevant groups, which significantly expanded the reach of the advertisement. However, it is also possible that the public nature of the advertisements may have deterred patients who had considered transplant tourism from reaching out.

Thought was given to the ethical considerations of speaking with participants about illness and transplant-related crimes. For patients, it was possible that they experienced a level of discomfort in discussing their considerations of something potentially illegal, or emotional distress in recalling their experience of illness. Further, the medical professionals I interviewed may have felt restricted in what questions they could answer due to their ethical obligation of 
confidentiality to their patients, particularly questions that inquire about their knowledge of New Zealand patients who have travelled overseas for transplantation. Seemingly, all participants were happy to speak about their experiences and views on these subjects, and were encouraged to share only what they felt comfortable discussing.

My positionality as female, Māori, able-bodied and as a student may have impacted on my capacity to fully build non-hierarchical relationships with some participants. Some researchers argue that the 'matching' of a researcher and participant is important for an effective interview, recognising that some participants are more comfortable disclosing information to others who are broadly similar to them (Braun \& Clarke, 2013). Given that matching was not practical for this project, it may have meant that I unintentionally overlooked potential power-dynamics in the interviews. The relationship between researcher and participant is typically conceived as hierarchical as the researcher is in control of the interview (Braun \& Clarke, 2013), especially when interviewing patients who are considered to be members of a vulnerable population (Martin, 1995). Conversely, interviewing people who hold higher societal positions, such as medical professionals, can add a dimension of power between the researcher and participant which can impact the data. How to manage interview power dynamics and the matter of rapport were discussed with my MA supervisor prior to conducting interviews.

Lastly, my positionality may have impacted the interpretation of data (Braun \& Clarke, 2013). A point that should be stated about the practice of narrative research is that this approach is interpretative at every stage:

...from framing the conceptual question through choosing the participants, deciding what to ask them, with what phrasing, transcribing from spoken language to text, understanding the verbal locutions, making sense of the meanings thus encoded, to deciding what to attend to and to highlight. (Josselson, 2007, pp. 7-8)

Cultural-political contexts and social structures shape how people envisage the world and articulate their experiences. Although I strove to use thematic analysis reflexively, 'interviewing across difference' inevitably poses challenges. On a practical level, different communication styles can complicate the interpretation of data as words can hold different connotations for different people (Rubin \& Rubin, 2012). It is also important that, during the process of analysis, the richness of each participants' narrative accounts are not lost (Anderson \& Kirkpatrick, 2016). While highlighting many of the commonalities in the experiences of 
each participant group, I also endeavoured to accurately represent the diversity of the participants' views and experiences.

\subsection{Data Analysis}

The recording of data included audio recordings of the interviews, as well as note-taking of discussions and comments. The interviews were all fully transcribed from the audio recordings, including interruptions, overlapping speech and indication of inaudible utterances. Becoming intimately familiar with the content of the data set required reading and re-reading hardcopies of each transcript. At times, I found it useful to listen to the audio recording in addition to examining the transcript material. Through this process of 'immersion' I was able to begin noticing data of relevance to the research questions (Braun \& Clarke, 2013). I highlighted words or passages of interest, and where appropriate, recorded 'noticings' in the margins to refer back to (Braun \& Clarke, 2013). Noticings can be understood here as any ideas or passages of interest that did not explicitly relate to the research questions but may have warranted further consideration.

Each transcript was then coded systematically and thoroughly by participant group. This process was completed electronically and involved several stages of cutting and pasting excerpts and passages of relevance into a table form. This format was useful at keeping codes distinct and concise. Using an inductive approach across all transcripts, I generated codes that were reflective of the content closely related to the data. The patient transcripts were then recoded using a researcher-derived method, allowing theoretical understanding to contribute to the coding process and production of meaningful passages from the data set. The codes from each transcript were gathered by participant group and were arranged into separate files for what became key themes.

\subsection{Presentation of Findings}

My interpretations do not exhaustively cover the entire scope of this topic. Rather, my discussion is shaped by the research and literature focus discussed earlier. In the three following chapters, I present the perspectives and experiences of participants using some of the frameworks introduced in Chapter 3: Theoretical Framework. Each theme is significant for both academic knowledge in this area and for highlighting the healthcare infrastructures and illness problems that negatively affect patients and their whānau. Each theme addresses a research question, and are presented, analysed, and discussed in the following order. 
In Chapter 5: The Desire for Health, I comment on the factors that motivate patients to consider alternative paths to treatment, specifically transplant tourism. The personal motivations are shared only by the patients in this study, while the institutional motivations are discussed by both patients and medical professionals. Chapter 6: Transplant Tourism: An Uncommon Phenomenon provides an overview of some known cases of transplant tourism from New Zealand. These are derived from the experiences shared by medical professionals and shed light on the dominant factors that encourage the pursuit of transplant tourism. Finally, in Chapter 7: The Healthcare Response, I consider the various approaches to deterrence described by the medical professionals, commenting on their commonalities, dissimilarities, and limitations. I also consider that ethical, legal, and professional difficulties that arise for medical professionals who suspect or know that a patient has consider or pursued commercial transplantation overseas.

As previously stated, the patient participants in this study are referred to by pseudonyms: John and Simon. I have identified medical professional participants as M1 to M8, numbered according to the date of interview. Lastly, I have identified the key informants using the following formula. K1: Key Informant Academic and K2: Key Informant Stakeholder. Where a participant is quoted, I included these details at the end of each sentence in brackets. 


\section{The Desire for Health}

This chapter illustrates how patients will often consider all their options, including transplant tourism, especially when their path to transplantation in New Zealand is obstructed by healthcare infrastructures. A patients' desire to be healthy was recognised by all medical professionals and key informants, who each presented this idea as underpinning patients' motivations to consider commercial transplantation. This same desire manifested in the illness narratives presented by the patients, John and Simon, who both — to varying extents considered embarking on transplant tourism.

\subsection{Patients Consider all Options}

Unanimously, all medical professionals said transplant tourism is absolutely something that people consider. As stated by M2, in circumstances where supply outweighs demand, "there will always be [...] pressure for some people to consider all options including buying a kidney". Many of the medical professionals emphasised that most patients "know that we don't approve of it and therefore they wouldn't bring it up with us if they were thinking about it" (M1). As they described it, it was the patients with limited information about transplant tourism who discussed the option with medical staff. The medical professionals stated these patients had usually just 'heard of it as an option' and were simply making an innocent inquiry. "Most patients don't know that it's unethical necessarily, you know, they've just heard this happens. They don't necessarily know that it's a bad thing. So that... my job is to teach them about that I think in that situation" (M4). The medical professionals did not deem these patients to be seriously considering transplant tourism, and believed they simply wanted to learn whether it is a viable or acceptable option. As M2 explained, upon learning more, these people tend to decide against transplant tourism: "Most of those people actually decide they don't want to do that. I think that's, in general terms.... those are only people who talk to me".

\subsection{Misconceptions of Transplantation}

Transplantation is commonly regarded as the preferred therapy for ESRF when compared to dialysis and is likely to offer a higher quality of life and longer life span (Shaw, 2015a). All medical professionals talked about the value of transplantation in treating ESRF, often describing it as the 'ideal treatment' (M5). One renal physician stated this impression is commonly shared among members of the public: 
...our experience has been, generally speaking, if someone says they've got kidney failure, and you say that to most people in the community, the response will be, "aw, I wonder if they can get a kidney transplant or something. There is an awareness of the benefits of organ transplantation". (M2)

This observation fits with Frank's (1995, p. 77) assertion that, because contemporary culture treats health as the normal condition, there are societal expectations of restored health and restitution stories.

The awareness of the benefits of transplantation can be demonstrated in the way patients approach treatment options. For most patients with ESRF, kidney transplantation is the treatment of choice. Two medical professionals commented on how patients, when steadily approaching the need for RRT, tend to take on a proactive approach towards their treatment and seek out transplantation. "Sometimes the patients come to us and they're all geared up and they're saying, oh, they want a transplant, they don't want dialysis" (M6). "People ring up themselves and say, 'I want to be assessed for transplant' and we would assess them. There's no point antagonising people and saying, 'No, you can't'" (M3). But all of the medical professionals stressed that regarding transplantation as a universal treatment is misguided because "it's not appropriate for everyone based on [their] clinical scenario" (M4). "Not everyone is suitable for transplantation... I've got lots of patients that I know I would kill with the transplant drugs and I don't refer them for transplant... the vast majority of my dialysis patients aren't suitable for transplantation" (M1). As the medical professionals pointed out, this idea can be lost on patients who they characterise as often unwilling to acknowledge the limits of this treatment. M1 baldly stated: "I think that patients are notoriously unrealistic about transplantation and have a great white hope - which is understandable - that transplantations going to cure all their problems and make everything easier for them".

\subsection{Denied Access}

The medical professionals pointed out that a predominant reason why patients explore the possibility of receiving a transplant overseas is because "we might tell you, 'you can't have a transplant"' (M4). The allocation of deceased donor organs is an ethical challenge for medical professionals working in the field of organ transplantation. Given the shortage of altruistically donated kidneys, kidney transplantation has arguably become the practice of rationing, with medical professionals operating as gatekeepers instead of providers (Stratta et al., 2004). A nephrologist in the study explained there are several criteria a patient must meet in order to be 
considered for a transplant; the first being "you have to be able to benefit from a transplant" and the second being "you have to be able to benefit enough if you want to have a transplant" (M4). As detailed in Chapter 3, whether a patient will benefit enough from a transplant is determined by a calculator which "scores people in New Zealand prospectively, and comes up with a number which is, in sense, predicted 5-year survival as percentage" (M2). The medical professionals acknowledged that the second criteria could be considered controversial:

...because [a patient] might say, 'Well, I've got a 70\% chance of living five years after a transplant, with dialysis I'm miserable, there is a 70\% chance I'm going to be here in five years, why is it fair that I don't get a kidney that belongs to the community?' And we say,

'Well, because we have to draw a line somewhere and we don't think that's fair that you take the kidney and there is a third chance that you'll be dead in five years and someone else would have carried that kidney forward.' (M4)

The gatekeeping of transplantation denies patients' hopes of being healthy again, which can engender a yearning for control and a need to act for oneself. Several of the medical professionals explained that, when this occurs, some patients seek hope through transplant tourism instead. There is an implicit assumption that these patients have a false hope about what transplantation can do for them. One transplant physician shared a story about his patient who, despite being told transplantation will worsen his medical condition, underwent a kidney transplant overseas: "He went overseas to Pakistan and got a transplant who we denied access to the transplant list for pretty good reasons. He got a kidney which failed straight away [...] and he came back in dire straits" (M3). Comments such as this, which were reiterated by other medical professionals in the study, suggest the extent to which a patients' unrealistic expectations of transplantation can cloud their judgement and encourage actions that prove to be physically and financially harmful.

\subsection{Waiting and Uncertainty}

The second reason offered by medical professionals to explain why patients explore the possibility of a transplant overseas is the waiting time for a deceased donor kidney coupled with feelings of uncertainty. "I've had patients who have considered it because they know they're going to be on the waiting list for — on average — quite a while. They might not receive a kidney from a transplant waiting list, and time is going on" (M2). This point was reiterated by a nephrologist, who touched on the impact that dialysis treatments have on the 
quality of life of patients, as well as the other challenges patients endure while on the deceased donor waiting list:

I think one of the key factors is the waiting time. If you haven't got a live donor for whatever reason, and you've got to wait two or three years and you're on dialysis, it's a bloody misery actually... that's the other thing, when you go on the waiting list, you can't be sure you're not going to come off the waiting list again before you get your kidney... I think that uncertainty would play a lot into it. (M4)

The uncertainty of the waiting list can have a significant impact on patients' hope for a transplant. John corroborated this idea, and expressed his growing frustration with the waiting list and the allocation of deceased donor kidneys:

I'm a wee bit cynical about [the waiting list], because of the ambiguity around it and it's all by design. I understand some of that because they want to give people a bit of hope and say, 'yeah, you're on the list' but I would say that a lot of people on that list will never get a transplant. How it works as far as who gets the kidney, like I say, the design around that, it all comes down to two or three people up the top that make the call.

As John suggested, medical professionals have the ability to instill a sense of hope in patients when placing them on the transplant waiting list. However, hope is likely to shift to uncertainty as wait time progresses. Prolonged wait time increases the risk of health deterioration, which jeopardies a patients' placement on the waiting list, and may cast doubt on their hope of receiving a transplant in New Zealand. As the medical professionals illustrated, under these circumstances, it is not uncommon for patients to consider alternative avenues to a transplant.

\subsection{Personal Motivations}

Although the medical professionals have insight relating to issues that affect a patient's access to treatment, the experience of illness can only be shared by the patient. Speaking with John and Simon about their experiences of illness revealed personal factors centred around their quality of life on dialysis which influenced their considerations of transplant tourism. In their illness narratives, normality functioned as a point of reference that they used to illustrate how dialysis dependence had significantly disrupted many aspects of their former lives. These disruptions were interpreted as illness problems, which included the pains of dialysis, a loss of freedom, and financial hardship. For John in particular, the illness problems he described served to justify his considerations of transplant tourism. For this reason, I focus primarily on 
John's illness experience. While Simon considered transplant tourism to a lesser extent, he also explains that the illness problems he experienced encouraged him to consider all paths to transplantation.

\subsubsection{Barriers to Kidney Transplantation}

It is important to note that both Simon and John faced barriers to a LDKT which limited their transplant options in New Zealand to the deceased donor waiting list. The medical professionals stated that there are a number of reasons why a live donation may not play out:

Maybe you come from a family where everyone else is sick and can't donate a kidney, or no one else wants to. Or you don't have anyone in your social network who is able or willing to donate you a kidney. If that's that case, your option - if you're well enough - is to go on the deceased donor waiting list. Then you wait for a kidney until one is available. (M4)

This was certainly the case for Simon, who openly discussed a variety of barriers that he encountered:

One of my [relatives] had also been diagnosed with it. The other [relative] had not been diagnosed, but because of his family situation, he had running costs basically - mortgage costs - that were higher than the sickness benefit that he would have to go on to for the period of the donation, and possibly quite a long time if his donation became problematic for him. It would financially break the family so he couldn't do it. So, I had asked them, I had asked a few friends. A couple got tested. Some said, 'Oh, that'd be lovely, I'll think about it and get back to you'. Sort of hesitant. So yeah, I was pretty dependent on the waitlist which at this stage was over five-hundred. Yeah, no live [donors]. None were available.

John encountered a different barrier to live donation. Because he had previously received a kidney from a living donor, and had undergone a variety of treatments, he had become sensitised to human leukocyte antigens (HLA). Under these circumstances, finding a suitable donor match is considerably difficult. He discovered that those who had previously been a live donor match were no longer suitable:

The other sister was, at the time [of the first transplant], a match. Then when we got retested, we are no longer a match because of these antibodies. So that was a bit of a shock to the system because we were, as a family, we kind of had a plan. 
In John's case, his odds of finding a suitable match from the deceased donor waiting list is just as unlikely. Many of the medical professionals in this study indicated that highly-sensitised patients are a group who accumulate on the New Zealand transplant waiting list. M1 pointed out in her interview, these patients "might wait a lot longer because [they're] waiting for the right kidney". With regard to how long they might wait, M3 suggests "there are people who have been waiting for longer than six years [...] most of those people will be highly-sensitised."

\subsubsection{Pains of Dialysis}

As M4 pointed out earlier, until a deceased donor kidney becomes available, patients on the waiting list are required to undergo dialysis which can have a significant impact on their quality of life. The mental and physical exhaustion associated with dialysis featured prominently in the illness narratives of both participants. Prior to John's transplant, he underwent HD treatment in hospital which he painted as a negative and dehumanising experience:

I was on dialysis [in the hospital] which was pretty horrible. The dialysis unit there is not good. Back then I really, really struggled with it... every time I would get these... the worst... these headaches... indescribable, tension headaches...You're just a number there. Just get you in as quickly as they can and get you out so they can get the next person on. Not just that, they're physically really rough with you. At the time I had tubes in my chest, and they're just like pulling on them to... ugh, it's just frightening.

It appeared that this experience prompted John to undertake home-based HD when he approached the need for RRT again. After just one session in a dialysis ward, Simon too requested home-based treatment: "I spent one day doing dialysis on the ward and said, 'I'm out of here.' I got in touch with the training people and demanded to be trained for home dialysis, and I started the next Monday". Home-based HD, when compared to HD on a ward, has the benefit of self-management, offering patients a semblance of normality. This benefit was reiterated by a transplant physician in this study: "if I was doing dialysis, I wouldn't want nurses doing my dialysis I'd want to do it myself. So that I'd have control over it and could do whatever I wanted to, I'd imagine” (M3). But as John stated, the self-management of treatment comes with its own set of challenges:

When you're at hospital you learn how to do everything but it's the things that you don't learn. Inevitably things go wrong, it's just the nature of dialysis, and they can't teach you for every scenario so sometimes you've kind of got to learn the hard way. I've knocked 
myself out three times I think just because when you're programming the machine you program how much fluid to take out of your blood...But if you get it wrong...it's a bit frightening you know especially if you're home by yourself and you lose consciousness.

\subsubsection{Loss of Freedom}

Moreover, HD is a time-consuming treatment. John outlined his treatment regimen which he explained was designed to maximise his time as much as possible:

Well, it takes me about 40 minutes to get set up and then I have to have the machine running for about five hours and then it takes me about another 40 minutes to come off [...] I usually do it Monday Wednesday Friday. I usually get up and get on about half past 4 or 5 in the morning [...] otherwise you lose your whole day.

Although the patients enjoyed more freedom than if they were to dialyse in hospital, they still felt considerably constrained when compared to their lives before illness. The loss of freedom was a particularly significant illness problem for the participants because of the secondary impact it had on the lives of their family and loved ones. John described feeling like a burden to his family who he said are "stuck" and "can't go anywhere" because of his regimented life. When Simon was asked what factors motivated the pursuit of transplant tourism, he reiterates this point, describing how restricted mobility impacted his own family:

Oh, I'll tell you, you try doing dialysis for eight-hours every second night with the machine tugging away by the bed, and your kids saying, 'Why can't we go on a holiday?' Well we can go on holiday if it's to a place I can get dialysis, but the dialysis units are all full because they've been underfunded by the previous government, so actually, we can't go on a holiday.

On numerous occasions John had attempted to travel and take family holidays but had been unable to access dialysis in other regions of the country:

Well, they tell you that 'yeah, you can go anywhere you want', but I've tried half a dozen times to book in sessions at units and it's impossible. They say, '...aw, well it's really busy we don't take anyone or aw, well, we can pencil you in, but we'll have to tell you a few days beforehand if we can do it or not'. How can you plan a holiday around a maybe you know?

It seems tensions arise when patients are confronted with normal-life expectations, such as travel, in the context of dialysis dependence. For Simon and John, kidney transplantation 
symbolised freedom from the constraints of dialysis and they believed restricted mobility was a key motivation for patients to get off dialysis and pay for a transplant abroad. An academic in the study echoed this point, stating that part of the reason patients pursue transplant tourism is because "dialysis is very restrictive to your lifestyle. A lot of your day is spent on dialysis" $(\mathrm{K} 1)$.

\subsubsection{Financial Hardship}

The financial strain brought about by illness and home-based HD was a leading illness problem shared by John. Referring to the period after his initial transplant, John stated: "I just sort of started to rebuild. I had lost everything, financially I had lost everything. You get no assistance from anyone, from any outfit at all". When his transplant began to fail six years later, he and his family were forced to make financial decisions around his declining health circumstances. He explained one major decision they made in preparation was relocating:

When we bought this house, we bought a house that was worth a lot less than we probably could of because we knew that at some point we would be in a situation where we were down to one income. If we had bought something that relied on both our incomes, we could have got right in the shit.

John's decision took into consideration the steep costs associated with home-based HD, which he highlighted as one of the "hardest parts" of his illness experience: "This dialysis machine fuckin' eats the power. Our power bill is about $\$ 400$ a month." John repeatedly expressed frustrations regarding the lack of financial assistance available to people in his circumstances, especially when you consider "the amount of money that it saves the hospital having someone like [him] at home":

If you bloody cut your leg off with a chainsaw, you'll be sweet as, you'll be looked after... I just don't - trying to see that bloody separation between, you do something fucking stupid and you get looked after, but if you get sick, you're just left to yourself to sort it out $[\ldots]$ your capacity to work is just significantly decreased and your health is not great and you're taking all this pressure off the actual hospital, I didn't think it was a whole lot to ask for. I lost everything. I've had no assistance the whole way through.

HD is an expensive treatment and until John receives a transplant from the waiting list, he must endure the pains of dialysis and the associated costs indefinitely. 
Although one can expect to live reasonably well on dialysis, the patients characterised their illness experiences as highly life-threatening. To illustrate, Simon stated: "I felt the dialysis was killing me... I felt like I was on a downhill slope". Similarly, John equated his experience on dialysis to living on "death row" and regarded transplantation as his only "lifeline". For the patients, kidney transplantation symbolised freedom from their illness problems. Fortunately, Simon received a transplant from the deceased donor waiting list, which he said, "changed his life completely" and meant he was no longer "tied to the machine". But for John, transplant tourism was presented as his only path to treatment and represented his last "shot at being healthy again".

\subsection{Summary}

This chapter has demonstrated that kidney transplantation is the treatment of choice among many patients with ESRF because it holds out the promise of restored health and normality that cannot be achieved with dialysis. For this reason, it is common for patients to consider every path to kidney transplantation, including commercial transplantation. It is apparent that considerations of transplant tourism can, to some extent, be prompted by a combination of institutional factors (denied access, extended wait times and uncertainty) and personal factors centred around the quality of life on dialysis. While these factors can help explain why patients consider transplant tourism, they cannot explain the pursuit of transplant tourism because they impact the majority of patients, most of who abstain from transplant travel. This indicates that there may be additional causal factors that encourage the pursuit of commercial transplantation. 


\section{Transplant Tourism: An Uncommon Phenomenon}

The rate of transplant tourism was discussed by medical professionals, who each suggest this phenomenon - while commonly considered - is rarely pursued. Their reports of patients who have embarked on transplant tourism provided valuable insight on the factors that facilitate transplant tourism, namely 'ties' to destination countries, highlighting the significance of opportunity.

\subsection{The Rate of Transplant Tourism}

Five of the eight medical professionals in this study had first-hand experience with at least one patient who succeeded in travelling abroad for a presumed commercial transplant. The three professionals who had not were from the same hospital, which cared for a smaller population of patients when compared to the others. All five medical professionals with experience were quick to emphasise that this phenomenon is uncommon and referred to the number of patients going overseas for a kidney transplant as rare. "I can only think of single figures, maybe two or possibly three... so, it's fairly small numbers of overseas transplants... I mean, if you look over the last ten years or, so it's about one a year" (M2). "I'm not immediately aware of this happening very much at all... Yeah, well it's small numbers" (M4). The numbers offered in interviews, which corroborate the figures presented by ANZDATA, indicate transplant tourism occurs once or twice per year in New Zealand. While medical professionals were rather unanimous about the rate of transplant tourism, one stakeholder appeared sceptical: "I'd be surprised if it's that few. But, possibly" (K2). Although an academic in this study hypothesised occurrences were probably rare, he was not certain: "Very difficult to say. I don't think the numbers from New Zealand, from what we've seen, are very big. But again, we don't know" (K1).

From the discussions with medical professionals and key informants it was made clear that identifying cases of transplant tourism is inherently difficult and there is always the potential for a hidden rate. Firstly, medical professionals can only identify the patients who return to New Zealand for post-operative care. There may be some patients who remain hidden due to a lack of complications, because medical care is sought elsewhere, or because they do not return to New Zealand. One transplant physician said:

If you suddenly become not on dialysis in New Zealand, you're either dead, or we've transplanted you, or you've gone overseas to get a transplant. And we'll get you when you come back again because you've got to get one of us to fill out the special authorities to 
get you immunosuppressant medicines. So, we know of everybody, because it's only transplant specialists who can apply for the medicine. So, we know everybody who is here on immunosuppressants. Unless they go back to where they got the transplant from to get the immunosuppressants. Which they might do. (M3)

A renal physician elaborated on this point saying:

there may be people who we never even hear about at all... it may be that they have the resources that they can not only buy a kidney transplant from overseas, but they can get their own medications and so on. (M2)

Secondly, this study may underreport the rate of transplant tourism because the medical professionals relied on their memory when answering questions about their knowledge of transplant tourism. Especially for the professionals with many years of experience, recalling information from memory may have impacted the accuracy and level of detail they were able to provide.

Professional duties and obligations, such as a doctor's confidentiality oath and privilege of non-disclosure, are a third reason for a potential hidden rate of transplant tourism. Due to their professional confidentiality oath, medical professionals are under no obligation to report cases of transplant tourism as a crime to the appropriate authorities. The confidentiality oath also impacted the findings of this study. In an effort to protect their patients' right to privacy, the medical professionals were often unwilling to provide detailed accounts. Instead of sharing specific details about the cases they had knowledge of or were involved with, they spoke in general and broad terms. One stakeholder predicted this occurrence, stating:

Because of patient privacy I doubt whether renal physicians... they'd talk amongst themselves, but I doubt they'd share an actual number. I can hear [a medical professional] saying, 'I'm not going to put a figure on it, but it does happen'. (K2)

Lastly, medical professionals may not be able to provide detailed information about transplant tourism. Several medical professionals spoke about the challenge of distinguishing between transplant tourism and proper travel for transplantation, the distinction being that the former involves commercialism while the latter does not. Because patients bring back limited to no information about their transplant, it is near impossible for medical professionals to determine the potential illegality of the act: 
Oh, there was a bloke I was aware that was going to have a transplant in the Middle East, and I'm not sure whether that's commercial or not to be honest. It's hard to judge. If they say, 'I'm going to get it from my cousin', how do I know it's really his cousin? (M4).

We also had a girl go to Japan and get a kidney off of her brother as well, so, that was... it's hard to know if that was paid for. (M8)

\subsection{Reports of New Zealand Transplant Tourists}

In total, a minimum of fifteen cases of transplant tourism were discussed by the interviewees (presented in Table 2). Owing to the inherent ambiguity of transplant tourism, and the inclination of medical professionals to protect the privacy of their patients, several of the cases of transplant tourism that were shared were incomplete. Some details which were variably omitted or unknown by professionals were the patients' gender, country of origin, year of transplantation, donor source, and transplant-related complications and/or mortality. Now and again professionals would make general statements instead of disclosing exact figures, demonstrated by renal physician M2: "We've had some people who have gone to China and have come back with kidneys that are not working, or working just..." and "I know of people who have been to India. One older person - a New Zealander of Indian heritage — he went to India, consulted one of the transplant teams over there". Because there is no way of knowing how many people are being referred to in these statements, they have been reported as one person.

As mentioned, several medical professionals talked about the challenge of distinguishing transplant tourism from travel for transplantation. At times, professionals indicated that there were cases of overseas transplantation that they considered to be appropriate transplants:

...he was Sri Lankan. He was within the Sri Lankan health system, and he - as far as I could tell - received that through a usually, hospital based system if I could put it that way rather than a sort of trafficked type situation or underground situation. (M5)

Conversely, the circumstances of other overseas transplants clearly aroused suspicions among medical professionals. This is demonstrated by a renal physician who, like some of the cases discussed previously, struggled to determine whether the patient's relationship with the donor was familial or financial: 
Table 2

Demographics and Relevant Information of Transplant Tourism from New Zealand

\begin{tabular}{|c|c|c|c|c|c|c|}
\hline Gender & Country of origin & Destination country & Transplanted & Donor Source & Complications & Mortality \\
\hline Male* & India & India & No & N/A & Not reported & Not reported \\
\hline Not reported* & Not reported & China & Yes & Not reported & Yes & Not reported \\
\hline Not reported* & Sri Lanka & Sri Lanka & Yes & $\begin{array}{l}\text { Not previously } \\
\text { recognised relations }\end{array}$ & Not reported & Not reported \\
\hline Not reported & China & China & Yes & Not reported & Not reported & Not reported \\
\hline Male & China & China & Yes & Not reported & Not reported & Not reported \\
\hline Male & Pakistan & Pakistan & Yes & Wife & Yes & No \\
\hline Male & Not reported & India & Yes & Not reported & Yes & Yes \\
\hline Male & Middle East & Middle East & No & Distant cousin & Yes & Not reported \\
\hline Male & Not reported & China & Yes & Executed Prisoner & Not reported & Not reported \\
\hline Male & Not reported & India & Yes & Wife & Not reported & Not reported \\
\hline Female & Malaysia & China & Yes & Stranger & Not reported & No \\
\hline Male & China & China & Yes & Executed Prisoner & Not reported & Not reported \\
\hline Male & Not reported & UAE & Yes & Stranger & Not reported & Not reported \\
\hline Female & Not reported & China & Yes (Twice) & Executed Prisoners & Yes & No \\
\hline Female & Japan & Japan & Yes & Brother & Not reported & Not reported \\
\hline
\end{tabular}

Note. *Reported as one case. 
I know some people who have been to Sri Lanka and have been able to get kidney transplants either from rather distant and not previously recognised relations, which does make one wonder if they are in any way related. (M2)

Correspondingly, the cases where medical professionals expressed doubt about the legality of the transplant are included in this report. Equally, where professionals felt confident that their patients had undergone a legal and ethical transplant overseas, these cases are excluded.

Of the fifteen recipients reported, nine were male (60\%), three were female (20\%), and the remaining three were unreported (20\%). All countries and regions mentioned by medical professionals as travel destinations are located within Asia; these include China, India, Middle East, Pakistan, Sri Lanka and the United Arab Emirates. Among the presented cases, most patients sought transplantation in China, followed by India. Given China's reported history of state-sanctioned forced organ harvesting, China has been internationally regarded as a popular destination country for those seeking a paid kidney transplant. "I can think of one guy in our clinic who has had a transplant in China. I believe that's from an executed prisoner, but I don't know" (M4). Although all of the recipients identified by medical professionals received medical follow-up care in New Zealand, travel- and transplant-related outcomes were only discussed in five of the fifteen cases. These patients had severe complications from their pursuit of commercial transplantation.

Notably, one patient who had embarked on transplant tourism suffered adverse health consequences as a result of travel which prevented him from receiving his intended commercial transplant. "He went to have [a transplant], and he got ill when he was there. He had a heart attack, it was a disaster, he got really sick and he didn't have an organ transplant. He came back really crook" (M4). One other patient subsequently died as a result of his commercial transplant. "I remember... a patient who had come back from India having a transplant and they'd been given Hepatitis B, but no one had managed to work that out, and they died later on that day" (M3).

\subsection{The Significance of Opportunity}

A recurring observation, which was communicated by all medical professionals, was that each patient who pursued transplant tourism had a cultural, familial, and/or citizenship connection to their chosen destination country. "We know that last year, there were two people who went overseas and got a transplant. But they were both... they've got dual residency, so they just go back to the other country and get it there. China usually" (M3). Where ethnicity 
was provided, professionals identified these patients as belonging to ethnic minority groups, who often returned to their continent, region, or country of origin in the hopes of receiving a kidney transplant (see Table 3). It can be inferred that patients with ties to destination countries are more susceptible to transplant tourism because they are likely to encounter more opportunities than patients without these connections. As a nephrologist pointed out, arranging a transplant abroad is challenging, particularly for unwell patients. But, for patients with cultural ties outside of New Zealand, relatives in the destination country can assist with the practical arrangements of the commercial transplant:

Someone who's struggling with day-to-day life in New Zealand is not likely to be able to organise themselves to get on a plane and fly to Cambodia to have a transplant... Many of those patients would be either really well connected and health literate, or they'd have connections back in that country - family connections - that they'd be able to do it. (M4)

Another important factor to consider is differences in cultural attitudes towards organ donation and transplantation, which one nurse practitioner spoke about explicitly when reflecting on her experience with patients: "Yeah, it's definitely - without wanting to categorise people - [transplant tourism is] definitely considered an option within certain ethnicities and not within others" (M8). Based on experience, she characterised patients of Chinese descent as often maintaining a pragmatic attitude towards commercial transplantation:

It can be quite direct and blunt with patients who are Chinese... I can think of a specific patient, we talked about donor source after he appeared back and I said, 'Oh, do you know anything about what happened with the donor?' And he said, 'yeah, no he was killed', in plain black and white. [...] They're pretty clear the persons no longer living. I think they see it as it's a right of access, do you know what I mean? Spare parts or... quite like, recycling? I'm not quite sure. But they are very pragmatic. (M8)

To illustrate her point, she went on to discuss another patient who had travelled to China for a commercial transplant. This patient received a transplant which immediately failed, so the patient stayed in China and underwent a second transplant just three days later.

A third consideration, which was only briefly touched on in this study, was that these patients may feel discriminated within the healthcare system. A nephrologist described an informal rule she and her colleagues have applied at times in an effort to prevent possible situations of transplant tourism or harm to the donor: 
Table 3

Number of Patients and Patient Ethnicity by Destination Country

\begin{tabular}{|c|c|c|}
\hline \multicolumn{2}{|l|}{ Transplant Country } & $n(\%)$ \\
\hline \multicolumn{2}{|l|}{ China } & $7(46.6)$ \\
\hline \multicolumn{3}{|c|}{ patient ethnicity } \\
\hline & Chinese & 3 \\
\hline & Malaysian & 1 \\
\hline & Unknown & 3 \\
\hline \multirow{4}{*}{ patient } & & $3(20)$ \\
\hline & thnicity & \\
\hline & Indian & 1 \\
\hline & Unknown & 2 \\
\hline \multicolumn{2}{|l|}{ Sri Lanka (Sri Lankan) } & $1(6.66)$ \\
\hline \multicolumn{2}{|l|}{ Pakistan (Pakistani) } & $1(6.66)$ \\
\hline \multicolumn{2}{|c|}{ Middle East (Middle Easterner) } & $1(6.66)$ \\
\hline \multicolumn{2}{|c|}{ United Arab Emirates (unknown) } & $1(6.66)$ \\
\hline Japan (Japanese) & & $1(6.66)$ \\
\hline
\end{tabular}

...we took a fairly blanket rule of: if the donor comes from a country where they don't have good access to healthcare and they're going to have to pay a lot of money or whatever to have long term management, then we are not comfortable accepting that person as a donor... I personally think that that's a perfectly reasonable rule, that I would never accept a donor if I didn't think that they were going to get adequate medical follow up and that they could afford that and that it was available to them. There are plenty of countries where I don't accept donors from because of that. (M1)

The above intervention, while arguably sensible, highlights the way in which medical professionals can act as gatekeepers to desired treatment, particularly for certain ethnic groups. This is just one example of the many diverse ethical challenges healthcare professionals contend with during their career. I pick up

this point again later, in considering the personal, legal, and professional challenges healthcare professionals face when confronted with instances of transplant tourism.

\subsection{Summary}

It is evident that transplant tourism is endeavoured by only a small number of New Zealand patients. Notably, all of the patients identified by medical professionals in this study had ties to common destination countries. This finding suggests that cultural factors play an important role in the pursuit of transplant tourism. In this section, only few of the possible explanations as to why cultural factors are significant were discussed. In Chapter 8 , these and additional explanations are explored in greater detail. 


\section{The Healthcare Response}

This chapter describes the medical professionals' attitudes, experiences, conflicts of duties and responses to transplant tourism. The participants' varying approaches to deterrence are outlined and critically examined, before discussing their reflections and suggestions on how transplant tourism could be tackled.

\subsection{Attitudes and Responsibilities}

The participants' attitudes were in concert with all eight medical professionals stating they are against transplant tourism:

Uh, I disagree with it. I think that it's a sorry indictment on the world that we have such inequity and poverty in certain areas of the world that some people are wealthy enough [to buy], and other people are desperate enough to sell their organs. (M5)

The most common concerns underpinning their objections to transplant tourism were the ethical considerations concerning the organ vendor, wealth disparities, health inequity and exploitation. Several of the medical professionals indicated that the anti-transplant tourism sentiment is deeply ingrained in the collective attitude of the New Zealand medical community. "I think that if you spoke with a physician who didn't have an issue with transplant tourism, then they'd be in a very, very, very, small minority" (M8). Additionally, one participant emphasised that objecting to transplant tourism is in accordance with the role of a nephrologist:

Well, what I obviously think is that it's completely immoral and unethical and I'm a nephrologist. I'm in the business of protecting people's kidneys and I don't see where anybody who comes from a country where we have all this privilege gets off thinking that they can just go and pay a nominal sum of money to somebody who's poor and would do anything for money and think it's okay to take their organs. (M1)

The participants described their attitudes towards transplant tourism as characteristic of their profession and expressed their duty to protect people's kidneys. All major transplant societies have called upon medical professionals in high-income countries to fulfil this duty by preventing patients from pursuing commercial transplantation overseas. However, the medical professionals identified and openly discussed several professional, legal, and ethical difficulties they encounter when patients (intend to) procure a kidney outside of New Zealand that conflict with their duty to prevent potential harms to vendors. 
Existing professional and legal obligations can actually compel healthcare providers to facilitate the arrangement of an unethical transplant, rather than prevent it. A nephrologist talked explicitly about feeling restrained by the legal and professional obligation to provide patients with medical information upon request:

Some patients would know that [transplant tourism is] a bad thing and then they want to do it anyway, so they'd ask me for support or assistance to do that. Now, that is quite difficult. I need to look after my patient so if they say to me, 'Well, I need my... a copy of my letter', the letter from clinical; well, they're allowed to ask for that. If they say, 'I want a copy of my letter so I can take it to my nephrologist in Cambodia - he's going to give me a live donor transplant', then I'd feel pretty conflicted about that. But it is their right to ask for their health information. I can't stop them doing that. (M4)

Equally, when a patient returns to New Zealand after a presumed commercial transplant, medical professionals can feel conflicted about their obligation to provide that patient with post-operative medical care:

I think some physicians want to not do that but - I can think of two in particular that would quite happily tell them that they're not treating them. Fundamentally, I think they want to [deny post-operative care] but they wouldn't... Ultimately [patients are] still entitled to excellent healthcare in New Zealand. They've done an incredibly selfish and strange - to me - act that I don't understand, but they're still entitled to healthcare. (M8)

In New Zealand healthcare providers have the right to refuse care provided there is an alternative source of care available to that patient. But, as M3 explained, this is practically challenging as nephrologists and transplant physicians "obviously can't do that here because there isn't another transplant centre". Several of the participants discussed this part of their job as an ethical dilemma. One renal physician argued that, on the one hand, medical professionals in New Zealand "are colluding with some ghastly practices going on overseas", while on the other hand, "we don't feel that we can reduce the harm by not looking after a person who has a health problem here" (M2).

The medical professionals recognised the strain transplant tourism could place on their relationship with patients. "I have trouble sometimes relating to patients who have done that because their ethical stance is so far from my own that I don't understand how you could disconnect yourself with the moral consequences of your choices" (M1). In order to fulfil their 
duties of care and maintain a positive therapeutic relationship, the medical professionals in this study felt it necessary to compartmentalise their feelings:

I'm pretty confident I've never let a patient be aware of my disgust. And that is quite strong language, and I'm aware of that... I'm pretty confident that I've never let my personal opinion come into the way I treat a patient. It's almost as if I have to put the act of what they've done separate. (M8)

Similarly, when they return, I can't not look after them because they've had this thing happen. So, I've had to isolate that part of my practice. So, if I try my best, they go anyway, they return, I still look after them...There's no point necessarily dwelling on it once it's happened, and my job is to look after him going forward. (M3)

In some cases, it was suggested that medical professional have found it difficult to separate their feelings from their role:

There have been some physicians who have out and out changed their therapeutic consultation with them because there was a good degree of moral judgement around that, and that definitely affected the care that was delivered in terms of, what I would say would be a kind if respectful interaction. (M8)

Or in situations where the patient is absent, doctors may ease internal feelings of tension through private conversations with colleagues:

I have heard other physicians saying things like, 'yeah, well, oh dear they've got rejection, well that'll teach them' kind of thing. Or 'well what'd they expect?' Or 'they've got an infection, well that serves them quite right'. Or 'they've got Hepatitis C, well...' (M8)

\subsection{Deterrence Conversations}

In New Zealand, the medical professionals' involvement in preventing transplant tourism only occurs pre-travel. All eight of the participants have had experience with deterring patients from overseas transplantation, and all accounts of how deterrence was approached followed a similar format. According to the participants, the opportunity to deter patients from pursing transplant tourism occurs in a one-on-one clinical setting when patients inquire about the option: 
I've had [...] one more serious inquiry in four years from a patient who was approaching the need for either transplant or dialysis. They approached me. Well, they made an inquiry during the consultation and said, you know, 'Could I go overseas to get a kidney? I've got money'. (M5)

I can only think of two people in all the time that I've been here. We have had the conversations... We never bring it up. No, it's not part of our conversations but unless they bring it up and we can discuss it really. (M6)

Most of the medical professionals felt it was inappropriate to enter the subject of transplant tourism into conversation themselves, except for one transplant physician. He spoke about a proactive approach he and his colleagues opt for in some cases, in which they "usually discuss it with people who [they] think might be at risk" (M3). Acknowledging the cultural component to known instances of transplant tourism, an example of a risk factor he provided was "being Chinese".

During deterrence conversations, each medical professional advised against transplant tourism but their individual judgements about how best to deter patients were inconsistent. Two of the eight medical professionals felt deterrence was best achieved by practicing nondisclosure of information about transplant tourism. Their underlying concern was that if they were to engage in a discussion about the option, it would be considered involvement in a crime, or misconstrued by the patient as support. Therefore, they were not prepared to discuss the matter at length:

To which my response, for example, would be, 'other countries though that you might go where there are excess organs to recipients, or you could potentially pay for an organ, are not the sort of countries that I would recommend you go to for pre-op, operative, and postoperative care' [...] No, I think that's where I left the level of detail. I think it would probably be unwise of me to comment any further in terms of being able to provide detailed information to the patient. (M5)

We just... we've got probably a pretty good method of just telling them all the same thing consistently. We tell them about the Declaration of Istanbul, we talk about why we're not actually prepared to engage in discussions around about it. It can be quite cold sometimes I suppose because we're just basically saying to patients straight off, 'I'm not discussing this with you, it's illegal and it's immoral and we're not going to provide you with any information or support to achieve that'. (M8) 
Contrastingly, the deterrence conversations had by the remaining six participants involved a substantial amount of information and detail about transplant tourism:

We'll discuss why it is that you might be able to get a kidney tomorrow, where has it come from, what's the background to that, what sort of assessment is there, what are the risks to you as a recipient going over to a place like that. (M2)

These medical professionals relied on their own knowledge of transplant tourism during deterrence conversations, but two of the six also mentioned employing the use of a pamphlet prepared and distributed by the Declaration of Istanbul Committee:

I've handed that out to people, it's available in various languages, and I've said, 'Well look, you can have a look at this. I have not personally been to Shanghai, but you know, at least have a read about this and go into things with your eyes open'. (M2)

So, if I find out about that, we've got a pamphlet to hand out to them which might describe why that is risky for their health. There are particular health risks about transmissible infections. We're not clear about the quality of their care. (M4)

Notably, not all of the medical professionals in this study were aware of the existence of this pamphlet prior to the interview.

According to the six professionals, the information they provided patients primarily focussed on the patients' medical risks, and only briefly touched on the vendor's circumstances if at all. Despite the medical professionals spotlighting concerns for the vendor in their personal objections to transplant tourism, they believed the patients' risks had a stronger deterrent effect than the ethical concerns for the vendor:

But to people who are actually thinking about that, I don't think the ethical side of things always touches them as much as the medical side of things if they're actively going to do it. (M1)

I don't think that they care because I don't think... even if someone told them, 'oh, this man has come from this village and he's going to get paid ten thousand rupees, that's nothing' and... the ones I spoke to didn't care. (M6)

All the recipient sees is themselves... not the big picture. Just step outside your little square and look at the big picture... they don't. (M7) 


\subsection{Potential Limitations of Deterrence Conversations}

The lack of consistency in deterrence approaches described by medical professionals reflects an absence of formal training and guidance available to them on what to do if a patient is considering, pursing or has been involved in a transplant-related crime. A transplant physician in the study (personal communication, September 11,2019) reiterated that there is no formal training or guidance available to medical professionals in New Zealand. However, they also added that professionals "can access the Declaration of Istanbul website and print off the brochure regarding travelling for transplants" (M3). Occasionally, participants talked about group decisions, approaches, or unwritten rules made between themselves and their colleagues about how to handle different situations. But primarily, medical professionals rely on their individual ethical judgement to navigate conversations and interactions with patients. While two medical professionals were unwilling to engage in deterrence conversations with patients, those who did based their information and advice largely on their own personal knowledge of transplant tourism. Among the participants, there were clear differences in their level of knowledge about transplant tourism. For example, while several of the medical professionals demonstrated a sound understanding of this phenomenon, two admitted they "only know what you see on TV" (M6 \& M7). The degree of knowledge a medical professional possesses will inevitably impact their ability to discuss and offer advice about transplant tourism.

Second, as almost all of the medical professionals do not enter transplant tourism into their clinical conversations, the opportunity for them to deter patients from pursuing this option is largely dictated by the patient. This is particularly problematic because, according to the medical professionals, they are largely unaware of those who are actively pursuing transplant tourism because these patients typically do not inform them beforehand. Rather, healthcare providers only become aware of their patient's decision to pursue transplant tourism if they return to New Zealand for follow up medical care:

In the past when it's happened, they just go and then you don't know and then they come back and they either come back with a kidney or they don't... I've never... no one's ever told me that they're going to do it and then gone and done it. Ever. I've just been involved with people who have come back... Or not come back, as the case may be. (M1)

There are a variety of factors that may influence a patient's decision to talk about transplant tourism with their healthcare provider, such as the strength of their therapeutic relationship, how they perceived their healthcare providers' perspectives of transplant tourism, the patients' 
level of knowledge about transplant tourism, their ethnicity, and how seriously they are considering the option.

Only two professionals described having a conversation with a patient who had already decided they will engage in transplant tourism. These patients were seeking support or needed information to facilitate their transplants. Although physicians are provided the opportunity to deter these patients, they felt their attempts were ineffective as the patients had already made the decision to leave and had most likely begun making the necessary arrangements:

I think about my [patient] that got [illegally transplanted] five years ago. That's his second kidney and his first one was failing and he pretty much planned that he was going. That's what he was doing, that was in his plan and he would do dialysis until his bloods were stable enough, then he would have his last dialysis on that date, thank you very much, and off he'd go. It doesn't matter that we spoke to him about how we don't want him to get a kidney from that source. (M8)

An additional factor mentioned by M8 which impacted her ability to deter her patients was a language barrier: "Usually English is a second language when patients are considering it or it's by an interpreter which can become even more problematic".

Ultimately, medical professionals felt limited in their ability to prevent transplant tourism and all expressed their lack of control in these scenarios:

I don't think we have any control and I can't imagine legislatively that there's any control that you can put in. You can't stop someone leaving the country because you think they're going to do a bad thing. What you have to do is sit down with them and be really clear with them about what they're risking and also making sure that we try to appeal to somebody's ethics. (M1)

I would appeal to their better judgement but in the end, I can't stop them from getting on a plane. If they would do that, then they would often return with their kidney later. (M3)

M7 concluded, "If they're going to do it, they're going to do it".

\subsection{Reflections on How to Prevent Transplant Tourism}

The medical professionals in this study all maintained that the extent of their role in preventing patients from commercial transplantation should only occur pre-travel. Compelling medical professionals to report patients who have received a suspicious or illegal transplant is 
a potential strategy that has been proposed in Australia. I discussed this option with three of the eight participants, and all three strongly disagreed with this approach. A nephrologist believed mandatory disclosure would negatively impact the doctor-patient relationship and compromise the provision of care:

I'm not in favour of mandatory regulations and mandatory reporting in so far as is possible within the confidential patient-doctor relationship. Because anything that starts getting in the way of what patients are willing to disclose to you - in other words, 'well I'm worried, I'm not going to talk to my doctor about $\mathrm{X}, \mathrm{Y}$ or Z because of these mandatory disclosures of X, Y and Z' - I think we have to think very carefully about what doctors should be mandated to disclose. (M5)

But a second medical professional, while against this strategy, found his position particularly difficult to rationalise:

I think that's really flawed because in the end... I don't know how I would rationalise that actually. I have to look after this person. This person's my key concern. If they return from overseas having had done this terrible thing, then... and I... what do I do? Report them to the authorities and then they get arrested and put in jail? And then they don't... can't, you know... should I do that? That feels like that's a bit beyond... sort of, two steps away. But some people argue that's the same as child sex in South East Asia, if you're aware of that, if that happens, you get prosecuted in Australia and New Zealand if that happens off-shore. I feel absolutely that should be reported so I don't know why I think that's different necessarily... (M4)

The care of a patient is the primary concern of medical professionals, who therefore felt uncomfortable with the idea of breaching the confidentiality oath and enforcing laws which may adversely affect their patient. "Report them to who though? Make it like a criminal activity? Criminally... make them open to prosecution? Jesus... I mean that's pretty extreme isn't it really. Yeah, I think that's pretty extreme" (M8). If patients return to New Zealand for post-operative medical care after receiving an illegal transplant abroad, the professionals felt the complex nature of their obligations to their patient prevented them from becoming further involved.

Rather, all of the medical professionals asserted that preventing patients from procuring a kidney overseas would be best achieved by increasing the supply of kidneys in New Zealand. Their suggestions on how to improve the kidney supply primarily focussed on deceased 
donation as opposed to live donation. Some of the participants commented that there is little room for improvement in live donation in terms of increasing the supply. "I'm not sure that there's a big untapped pool and I'm not sure that living organ donation is going to be the answer to the problem" (M2). It is important to recognise that, through the donation process, live donors take on significant risks with regard to their own health and attempts at increasing the number of live donor kidneys, such as expanding the donation criteria, may compromise important principles of medical ethics such as non-maleficence. "We shouldn't be pushing the boundaries of people who we are going to accept as donors too much because we shouldn't be increasing the risk for them to develop kidney disease or problems down in the future" (M1). This point was corroborated by M8, who commented that "we've pushed the live donor envelope fairly wide in recent years compared to what it was previously" and "the point of improvement needs to come from deceased donation". Increasing deceased donation also has the potential to reduce the demand for live donors.

All of the medical professionals highlighted the importance of raising community awareness about deceased organ donation. M2 commented that "New Zealanders are relatively comfortable with the idea of doing something for society" which means that they are likely to be receptive to campaigns that promote organ donation as a "desirable, worth-while, community-minded" act. Another medical professional pointed out that campaigns and advertisements are already used to raise awareness and encourage conversations about a number of important issues:

Now, we have a lot more promotion around things like seatbelts, drug driving...lots of things our community focusses on to try and improve our understanding. It does have a slow affect over time, and it would be great to see organ donation treated in the same way. (M4)

Similarly, M1 voiced her support for the use of "ads on TV that tell people to talk to their relatives about it". Raising community awareness is important, not only because it improves individual understanding of what organ donation entails, but because it will encourage conversations about donation with family and whānau. M4 stated that "at the moment, it's still an education issue for the families in ICUs at the point where their loved ones died, which is just an incredibly tense, kind of terrible moment to bring it up for the first time". A renal physician echoed this point, adding: 
...if a family feel that they've been asked to make a decision in a situation where they cannot make a decision because they're absolutely grief-stricken, then the answer tends to be 'No'. It's no because 'No, I can't make a decision'...People need to have that sort of discussion earlier and be comfortable with it. (M2)

The medical professionals theorised that increasing awareness and encouraging conversations about deceased organ donation could shift cultural attitudes and normalise donation over time:

...it would be great eventually to get to the point where we all sort of said it's like wearing a seatbelt, it's just a normal part of getting into a car. A normal part of dying in the hospital is being an organ donor. It's actually not exceptional anymore, it's a regular part of our community care is being organ donors. I think if we can get to that point, then it won't be a big drama. Then someone dies in an ICU, they'd expect they'd be an organ donor, the family says 'yeah, organ donor? That's fine. What's the next thing we have to talk about?' (M4)

Increasing the support in ICUs was a second measure to increase the supply of kidneys that the participants spoke about. M4 stated that "the big jumps" in organ donation to be had are around ICU practices, training, resourcing and staffing. He added "ICUs are stretched" and “there are probably opportunities whereby those people aren't explored as donors. And there are probably opportunities where they are explored, and the family says no". Increasingly, there are circumstances where patients are "admitted to the intensive care unit in order to allow the discussion of organ donation. Not because that person is going to get out of hospital alive, but because a bit more time might allow organ donation to occur" (M2). M4 described this measure as an "incremental improvement" that is likely to create a donor in the odd circumstance. $\mathrm{He}$ also stated that it is practically challenging given ICUs are jammed and under-resourced. In addition, M2 stressed that this approach can also be ethically challenging:

...how appropriate is it to prolong suffering in order to facilitate donation? The answer is you shouldn't prolong it to any degree really. The care of a person should be the care of a person and the facilitation of organ donation should only come after the recognition and diagnosis of death. But, like all things, we need to find where that line can be drawn and what is appropriate in terms of care of a person. Measures have been done to do that. (M2)

A third approach that had been suggested is the establishment of a donor registry. An academic in this study strongly advocated for this approach to organ donation: 
Yeah, I think the way to go would be an official registry... what's happening at the moment, people have it on their driver's licence, but random family members or a wife or husband can say 'Sorry, but we don't want to do it anymore'... the drivers' licence is merely an indication of your wishes. It's not binding, which is silly...I think the idea of the registry, if you're on there, it is an irrefutable indication of your wishes. It cannot be overruled by anybody... There is no reason why we shouldn't do that. I can't see the legal or ethical objections to it. It's just certainty. (K1)

The medical professionals on the other hand had mixed views about this suggestion. M2 described organ donor registries as a good concept but practically challenging. A stakeholder in the study elaborated on this point, describing registries as a "waste of time and money". He pointed out that a big issue would be the maintenance of a registry and "keeping in touch with [registered donors]". M4 agreed, and suggested the cost to set up and maintain a registry would be better spent on ICUs. Practical issues aside, most of the professionals voiced ethical objections to a donor registry, and each stressed: "we should listen to the family" (M4). M5 was concerned about the potential to upset the loved ones of registered donors, "I think the prospect of having arguments with families and whānau over a patient's death over a matter of organ harvesting is not one I think many people would want to see.” This comment was echoed by M6, who suggested most professionals would avoid upsetting the family: "If family say 'no I don't want this... my mother or son or daughter to donate their organs', I don't... I can't see any doctor overruling that" (M6). In fact, M4 argued that the family's decision should take precedence over the donor's wishes:

It is right to look after the family in that circumstance because they're the ones that are left carrying this trauma forever that this person has suddenly died... It really is important what that family thinks and handling that family and really that information of what the donor thought in the past is a relatively tiny piece of information actually. I don't think if someone said, 'I must not be a donor', and it was right for that family and right in those circumstances, then I think maybe they should be a donor. Similarly, if they said 'I must be a donor' and the husband really doesn't understand it and he's going to be potentially traumatised and he says, 'No I just can't face that', then we shouldn't make them a donor and traumatise the husband. (M4)

One way a donor registry may work, according to M7, is if registering requires the family of the donor to be aware of their decision. M6 agreed and said a donor registry is only worth 
considering "as long as it's accompanied with good conversations to your loved ones, and making your wishes known". But, without increasing public awareness and encouraging families to have the conversation ahead of time, a registry will always be ethically challenging. Some of the participants suggested that an opt-out approach (or presumed consent) as opposed to an opt-in approach is worth considering. A nurse practitioner highlighted that this approach would facilitate family conversations because it will force people to think about whether they'd like to donate - especially the "on the fence people" (M8). But again, without public support, presumed consent could be polarising or controversial:

Some attempts to introduce that have actually reduced the rate of organ donation [...] Optout might be useful but primarily it's a discussion and debate, but you're going to get people who have strong feelings one way or the other, and out of that argument can come bad as well as good. (M2)

A renal physician in the study stated that efforts should be made to increase the current supply of transplantable kidneys but argued that there will always be a demand for transplantation:

I think if the idea of organ donation is to increase the rates to the extent where nobody needs to do dialysis or kidney failure is always treated with transplantation, then it's always going to fail because there are already elements in that process that restrict access to transplantation. If you increase the supply, you will... the pressure will be to reduce the barriers to receiving a transplant... I think as long as we don't have a way of preventing kidney failure, or treating it that isn't transplantation, there will always be a supplydemand mismatch. (M2)

There were suggestions made by the medical professionals, outside of increasing the organ supply, which could prevent patients from pursuing a transplant overseas. M1 recommended efforts be put into the prevention of kidney disease by way of increasing primary care resourcing to improve the management of diabetes. She also suggested that improvements to dialysis could increase the transplant opportunities in New Zealand:

...we need a lot more dialysis funding because the key thing that is really critical is that people might start on dialysis and be suitable for transplantation, but dialysis is such a lifethreatening condition year in and year out that increases your risk of heart attacks and strokes and peripheral vascular disease and all these different things... So those people go from where they were previously suitable, to potentially being unsuitable for 
transplantation while they're sitting on dialysis...Anything we can do to improve dialysis is actually improving our transplant. (M1)

M3 pointed out that they would like to start performing de-sensitising procedures in New Zealand when the results are good enough to go ahead with doing that. These procedures would help prevent highly-sensitised patients from accumulating on the waiting list. Lastly, M5 felt that one way to prevent patients from pursuing a transplant overseas would involve setting realistic expectations from the outset by:

...making clear and transparent to patients and their whānau the pathways in New Zealand, the expected time frames, and the reasons why things take the time they do because generally we're wanting to a thorough job... and that is how long it takes. (M5)

\subsection{Summary}

This chapter revealed that the role of medical professionals in preventing transplant tourism occurs pre-travel in the form of a deterrence conversation. However, there are a number of complex professional, legal and ethical dilemmas which were shown to impact the professionals' ability to prevent the patients from pursuing a commercial transplant. Rather, the medical professionals suggested that increasing the kidney supply in New Zealand would prove useful in reducing the desire to seek transplantation elsewhere. In the following chapter, these strategies are discussed further and clarification of the medical professionals' rights and obligations is offered. 


\section{Discussion of Findings}

\subsection{Hope in Kidney Transplantation}

In Chapter 5: The Desire for Health, I presented the personal and institutional factors that encourage considerations of transplant tourism as described by the patients and medical professionals in this study. The factors offered by the medical professionals focused predominately on the barriers to transplantation in New Zealand (waiting list and denied access), while the patients emphasised the decreased quality of life they experienced while living on dialysis. Congruent with relevant literature, the patients' illness problems spotlighted the impositions and limitations of HD - namely the pains of dialysis, loss of freedom, and financial hardship.

The patients complained of the mental and physical exhaustion associated with HD, especially when describing their experiences of dialysis wards. For instance, John portrayed his experience of hospital-based treatment dehumanising and described feeling like 'just a number' to the hospital staff, who 'get you in as quickly as they can and get you out so they can get the next person on'. Comments like this have been voiced by the patients interviewed by Shaw (2015a), who also compared hospital HD to an 'assembly line'. Like John, the dialysis patients interviewed by Hagren and colleagues (2001) expressed a desire to be seen as individuals by medical professionals, which would allow them develop trust with medical staff, and feel comfortable while dialysing on the ward.

Within this study, the patients opted for home-based HD as their preferred method of dialysis. However, the patients spoke about the physical and mental demands that came with learning how to facilitate their own treatment. The challenges and hurdles discussed in this study were reminiscent of those reported in Shaw's (2015a) study of home dialysis users. While John expressed fears of programming the machine incorrectly, the patients included in Polaschek's (2003) study 'negotiated' their therapy into their lives by making alterations to their dialysis or aspects of treatment against the recommendation of medical staff. Although they generally adhered to their therapeutic prescription, some of the participants felt that small adjustments to their dialysis improved their quality to life.

A significant illness problem voiced by Simon and John was a loss of freedom, who both articulated feeling 'stuck', 'tied to the machine', and like they 'can't go anywhere'. This finding is not uncommon and has been identified many times in literature (Bayhakki \& Hatthakit, 2012; Calvey \& Mee, 2011; Clarkson \& Robinson, 2010; Hagren et al., 2001; Hagren et al., 2005; 
Polaschek, 2003). In this study, reliance on HD regimented the patients' lives, was considered to be time consuming and greatly restrictive in terms of mobility. Much like John, the patients described by Polaschek (2003) dialysed in the early hours of the morning in an attempt to reduce disruption in their day-to-day lives. This advantage of HD allows patients to construct a semblance of normality.

One aspect of normality that the patients were unable to maintain was travel for the reason that dialysis functioned as a 'physical shackle' in their lives (Bayhakki and Hatthakit, 2012). The lack of freedom for holidays featured prominently in the narratives of John and Simon, as well as the impact of restricted mobility on their family. Both of the patients expressed frustration and anger towards their inability to access dialysis units in other regions and much like the patients interviewed by Calvey and Mee (2011, p. 204), there was an element of guilt for burdening their family. Simon asserted travel was not possible in New Zealand because the dialysis units are full and underfunded. Similarly, John stated that, despite being told 'you can go anywhere' on HD, his half a dozen attempts at booking dialysis elsewhere has proved travel to be 'impossible'. The patients' comments are starkly different to those of the New Zealand patients in Shaw's (2015a) study who noted their ability to travel as liberating and described positive experiences of dialysing in hospitals around New Zealand and overseas.

Within this study, the financial strain brought about by ESRF and home HD was one of the 'hardest parts' of John's illness experience. Bayhakki and Hatthakit (2012) report that long term dialysis is expensive and, because it compromises ones' ability to work, often results in a reduction or loss of income. Similarly, the male patients interviewed by Hagan and colleagues (2005) expressed financial concerns associated with HD. The authors reported that the participants' feelings of restriction were enhanced by their inability to earn the salary of a 'healthy' person. Unlike these studies, John's financial concerns focused primarily on the steep maintenance costs of home-based HD and the lack of financial support offered to people in his position. In her study, Shaw (2015a) draws attention to the hidden costs of home HD. She points out that the material resources required for home HD means it is not an optimal treatment option available to patients from lower socio-economic backgrounds.

Unlike some studies in which a number of patients regarded dialysis as a 'lifeline' (Calvey \& Mee, 2011; Hagren et al., 2001), dialysis was discussed by participants in this study as highly-life threatening. Reflecting on his time on dialysis, Simon described feeling like the dialysis was killing him. Likewise, John equated his experience on dialysis to living on death 
row and instead, referred to commercial transplantation abroad as his only 'lifeline'. This statement resembles those made by transplant tourists in literature. For example, Berglund and Lundin (2012, p. 335) describe the experiences of three patients who travelled for a paid kidney transplant, of which one stated he would have preferred to 'have died under the knife...than lived on under "the torture of dialysis".

The prospect of a kidney transplant has been reported to symbolise freedom from dialysis, providing patients with hope and helping them cope with dialysis treatment (Al-Arabi, 2006; Bayhakki \& Hatthakit, 2013; Calvey \& Mee, 2011; Hagren et al., 2001; Polaschek, 2003). This is reminiscent of Hydén's (1997) observation that it is possible for patients to create a temporal time horizon "by establishing a link between the course of the illness and concomitant medical intervention" which will in turn establish "hope for a possible cure and...the continuation of life" (p. 61). For instance, Calvey and Mee (2011) pointed out that their participants" "hopes for the future lay mostly in the prospect of one day receiving transplant and getting back to a normal life" (p. 203). In a similar way, the narratives of the dialysis patients interviewed by Polaschek (2003) indicated that dialysis had created abnormality in their lives and coped "through hoping that the treatment regime does not have to be accepted as permanent, because in the future they will be able to escape from dialysis" (p. 48).

It is worth noting that Polaschek comments that the patients' hopes of transplantation are "objectively somewhat unrealistic but perhaps necessary to cope with life on dialysis" (p. 48). This is congruent with the findings of this study, as medical professionals characterised patients as 'notoriously unrealistic' about transplantation outcomes and as possessing a 'great white hope' that transplantation will solve all of their problems. In bioethics literature hope is often discussed in the context of 'false hope' defined as 'hope based upon an improbable outcome' (Petersen, 2015, p. 48). Sharot (2011) explains that that excessive optimism, akin to false hope, can result in the underestimation of harm and promote risky behaviour.

Numerous studies have recognised that what medical professionals do and say can have an impact on patients' hope (Petersen et al., 2014; Sardell \& Trierweiler, 1993; Simpson, 2004; Wong-Wylie \& Jevne, 1997). Healthcare professionals can be dispensers of hope, can be stealers of hope, or can operate as managers of hope in instances where patients' hope is deemed to be higher than warranted by medical evidence (Petersen, 2015, pp. 92, 144). Indeed, the findings of this study demonstrate how medical professionals, in their role as gatekeepers of kidney transplantation, have a significant impact on patients' ability to hope. John 
recognised how healthcare professionals can be dispensers of hope, stating they 'give people a bit of hope by saying "you're on the list"'. Chong and colleagues (2016) too described the waiting list as instilling a sense of hope in patients, which eased the difficulties of dialysis because patients were able to focus on the possibility of transplantation. Although this finding is reiterated by Moran et al. (2011), these authors note that hope shifts to uncertainty as wait time progresses. This is corroborated by Polaschek's (2003) observation that the 'ongoingness' of dialysis can lead to feelings of uncertainty about the future. In a similar way, denying access to transplantation or the practice of removing patients from the waiting list was shown in this study to "remove their hope of getting a transplant". This was illustrated by M3 who shared a story about his patient who, despite being told transplantation will worsen his medical condition, sought the treatment overseas 'which failed straight away [...] and he came back in dire straits'. A study conducted by Petersen, Sear and Munsie (2014) showed that patients perceived doctors who offered prognoses as denying them hope. These patients ultimately sought hope through alternative avenues to transplantation, pursuing treatment overseas despite being clinically unproven. Likewise, Lundin (2002) describes patients who independently sought treatment even with reservations because they wanted a better life, reduced bodily suffering, and to return to normality.

The findings of this study demonstrated the ways in which illness and dialysis dependence disrupted the lives of Simon and John and demonstrated how their hope for restored health and normality manifested in their expectations of transplantation. This was supported by the narratives of medical professionals who pointed out that patients are 'notoriously unrealistic' about transplantation outcomes and possess a 'great white hope' that transplantation will solve all of their problems. It is suggested that exceptionally high hopes about the miracle of transplantation can underpin considerations of transplant tourism, especially among patients whose hopes of obtaining a transplant in New Zealand are thwarted by existing healthcare infrastructures. Although the personal and institutional factors described by the participants in this study can help explain why patients consider transplant tourism, they cannot explain the pursuit of transplant tourism because they impact the majority of patients, most of who abstain from transplant travel. This indicates that there may be additional causal factors that encourage the pursuit of commercial transplantation.

\subsection{The Role of Culture}

In Chapter 6: Transplant Tourism: An Uncommon Phenomenon, it was recognised that all the transplant tourists identified by medical professionals in this study had ties to common 
destination countries, suggesting cultural factors play an important role. Ethnic ties are a recurring observation in almost all studies of transplant tourism (Ambagtsheer, Zaitch and Willem 2013; Berglund \& Lundin, 2012; Gill et al., 2008; Gill et al., 2011; Van Balen et al., 2016). The body of research in this area indicates that the majority of patients who travel for commercial transplantation are from ethnic minority groups and, like the patients described in the present study, are transplanted in their region or country of birth, have family or friends there, or they have previously lived and/or worked there. Gill and colleagues (2008, p. 1822) found that of 33 U.S. 'tourists', almost all patients underwent transplantation in their region of ethnicity, 64\% of whom were of Asian descent. A study performed with 93 Canadian recipients found that the majority were 'ethnic minorities' who travelled to their countries of origin for the procedure (Gill et al., 2011). Canales and colleagues (2006, p. 1659) identified 10 U.S. residents who travelled for commercial transplantation, all of whom were foreign born. The authors note that, while recipients travelled to different countries, within each ethnic group they travelled to the same country; eight were transplanted in Pakistan (all Somali), one transplanted in Iran (Iranian), and one transplanted in China (Chinese).

Explanations as to why minority ethnic communities are more likely to pursue transplant tourism warrants further attention. An important finding in this study was the significance of having friends and family in destination countries. Several medical professionals stressed that some patients who had procured an organ outside of New Zealand had assistance from friends or family overseas. One nephrologist pointed out that, without those connections, arranging a commercial transplant is unlikely. Although John has not yet decided whether he will be transplanted overseas, he said he began to consider the option when some friends of Indian descent suggested it and offered to cover the transplant costs. John has stated that the only two countries he would consider are India and Thailand because he has connections in both countries that can provide assistance should he need it. Ambagtsheer and colleagues (2013) mention that the patient in their study had friends and family who facilitated his transplant by finding him a Chinese doctor and paying a large portion of the procedure costs. Berglund and Lundin (2012) conducted a study with three recipients, two of whom described having assistance with the transplant arrangements. One patient explained his mother helped pay for the transplant, and the other patient's transplant was arranged with the assistance of his brother's employee.

Aside from the likelihood that these groups are better connected in destination countries, a marked difference in cultural attitudes towards donation and transplantation may help explain 
why these patients are more inclined than others to pursue transplant tourism. In this study, M8's observation of her patient's differing moral perspectives on organ procurement corresponds with the explanation offered by Gill and colleagues (2011) in their study of transplant tourism:

It is conceivable that individuals who originate from regions of the world where poverty is rampant, social hierarchies are entrenched, and human suffering and exploitation are common might have a different perspective of transplant tourism than individuals in the developed world. (p. 1029)

In New Zealand, the idea that organs should be donated as an act of altruism is rooted in cultural norms, however residents who originate from outside of New Zealand may harbour differing or antithetical ideas.

The moral perspectives of patients who have been recipients of trafficked organs have received limited academic attention. One study carried out by Van Balen and colleagues (2016) reported that of the patients who had moral reflections about their transplant, the majority stated they did not agree with certain aspects of transplant tourism but largely felt they were left with no alternatives. Similarly, the patients interviewed by Berglund and Lundin (2012) all had successful commercial transplants but felt the purchase of organs should be prohibited due to the risks to vendors and recipients. Although they disagreed with transplant tourism on the level of principle, they believed in their circumstances they had no choice but to pay for a transplant.

Another explanation discussed in literature on transplant tourism, but only briefly touched on in this study, is perceived discrimination in healthcare (Berglund and Lundin, 2012; Van Balen et al., 2016). Berglund and Lundin (2012) presented discrimination as one of the primary reasons the patients in their study underwent commercial transplantation outside of Sweden. All three (Iranian, Lebanese, and Iraqi) felt that both government officials and medical staff did not treat them equally with Swedish natives. One patient shared a story of his sister who travelled to Sweden to donate her kidney but was prevented from entering the country. Feelings of alienation and discrimination led these patients to lose faith in the waiting list and fear list removal. It is possible that New Zealand residents with different ethnic backgrounds may feel discriminated by the healthcare system.

Racial disparities in access to transplantation is well documented internationally and has been the focus of numerous studies. Myaskovsky and colleagues (2012) found in their study 
that African American patients took significantly longer to get accepted for transplantation than did white patients. These patients, when compared to white patients, also reported experiencing more discrimination in healthcare, higher medical mistrust, and more perceptions of racism in healthcare. Further, a study performed in the Netherlands found that ethnic minority patients (African, Antillean, Indonesian, Moroccan, 'Various', Surinamese, Turkish) are far less likely to receive a transplant (Roodnat et al., 2010). Yeates and colleagues (2009) conducted a multinational evaluation of indigenous access to kidney transplantation, focussing on New Zealand, Australia, Canada and the U.S. The authors found that, when compared with white patients, indigenous patients in each country had a significantly lower likelihood of receiving a transplant and significantly longer overall median wait times. Of all the patients who received a transplant in New Zealand during 2017, the majority were identified as New Zealand European (45.5\%), while patients of Asian descent were the second lowest ethnic group to be transplanted, constituting just $15 \%$ of all transplanted patients (ANZDATA, 2018). Cronin and colleagues (2011) suggest that, taking into consideration that ethnic minorities in the U.K. are least likely to receive a kidney transplant, it is perhaps unsurprising they are more likely to pursue commercial transplantation in their region of origin where they are more familiar with, and trusting of, the country's healthcare system (as cited in Ambagtsheer, Zaitch \& Weimar, 2013).

Language barriers in healthcare have been shown to motivate patients to look for a transplant in their countries of origin. A Chinese transplant recipient interviewed by Ambagtsheer, Zaitch and Weimar (2013) described communication with his physicians in the Netherlands as difficult, complaining that his knowledge of the Dutch language was poor and that they spoke too quickly. The authors explained "he felt relieved when he arrived in a hospital in China because he could finally communicate in his mother tongue with physicians about his illness and understand the nature of his disease" (p. 16). A number of studies have noted a language barrier faced by immigrants in New Zealand healthcare (Lee, Kearns \& Friesen, 2010; Ngai, Latimer \& Cheung, 2001; Walker, Wu, Soothi-O-Soth \& Parr, 1998) which was also recognised by a medical professional in this study. Lee, Kearns and Friesen (2010) interviewed six first-generation Korean immigrants in New Zealand who returned to their homeland for medical treatments. The authors stated that a language barrier was one of the factors that encouraged some patients to return to South Korea for treatment. They noted that some participants voiced a desire to communicate on behalf of themselves and became frustrated with their inability to communicate exactly what they would like to say to their 
healthcare provider in New Zealand. In addition, some patients expressed a lack of trust in translators, believing their knowledge of English was also limited and that there are particular Korean words that cannot be accurately conveyed in English. Similar findings are repeated in other studies of the experiences and views of Asian patients in the New Zealand healthcare system (see Ngai, Latimer \& Cheung, 2001; and Walker Wu, Soothi-O-Soth \& Parr, 1998).

\subsection{Medical Professionals' Rights and Obligations}

In Chapter 7: The Healthcare Response, I described the attitudes, experiences, and conflicts of duties reported by medical professionals. This study revealed that the medical professionals are against transplant tourism, largely because it harms and exploits vulnerable populations. There are a range of international initiatives (see Chapter 2), many that New Zealand are party to, which call upon medical professionals to combat transplant tourism and help prevent harms inflicted on kidney vendors. The medical professionals described their attempts to deter patients who they suspected were considering commercial transplantation which, by their accounts, occur in a one-on-one clinical setting in the form of a deterrence conversation. These attempts attest to the participants understanding that they have a responsibility to prevent unethical transplantation where possible. This responsibility is restated by Muller (2016, p. 37) who argues "doctors need to understand that they are fulfilling a dual role - looking after recipients and treating them, but also protecting young, vulnerable and poor people from being exploited". Yet, the findings of this study revealed that little understanding exists on how medical professionals can pragmatically fulfil both roles. This lack of understanding is illustrated by the medical professionals' reported conflict of duties and differing approaches to deterrence; and is hindered by a marked inconsistency in their knowledge of transplant tourism.

The two major problems reported by the medical professionals in this study were (1) the inability to prevent or report transplant tourism because of the confidentiality obligation, and (2) facilitating transplant tourism by providing medical records pre-transplant or medical aftercare post-transplant. Similar conflicts of duty have been reported by a range of healthcare staff internationally (Ambagtsheer et al., 2015; Ambagtsheer, Zaitch and Weimar, 2013; Wright et al., 2013). Perhaps unsurprisingly, a study conducted with 241 transplant professionals in the Netherlands revealed $80 \%$ reported a need for guidelines and clarification about how doctors should interact with patients who are (potentially) involved in transplant tourism. For instance, the Canadian Society of Transplantation and Canadian Society of Nephrology developed a policy statement on Organ Trafficking and Transplant Tourism (Gill 
et al., 2010, p. 817) to "help establish a unified and consistent approach to deter transplant tourism by Canadian healthcare provider, and in so doing, will ensure the optimal care of Canadian patients with end organ failure". This policy document offers definitions of organ transplantation and related practices, summarises the fiduciary and legal obligations of Canadian healthcare professionals, and provides recommendations and guidance regarding pretransplant and post-transplant interactions with patients. Although these initiatives are important and needed, they exist only in few countries.

New Zealand medical professionals are expected to follow the standards set out in two documents, The Code of Ethics (2014) and Good Medical Practice (2016). The former, developed by the New Zealand Medical Association (NZMA), outlines the standards of ethical behaviour expected of medical professionals, and offers advice on ethical frameworks, issues, and decision making. While the latter, developed by the Medical Council of New Zealand (MCNZ), clarifies professional and legal standards and provides the basis for physicians to monitor their own professional conduct and that of their colleagues. Although the standards outlined in these two documents are open to interpretation and can still inform ethical, legal, and professional judgements, medical professionals in New Zealand cannot be expected to successfully fulfil two competing duties without some form of specific guidance. The findings of this study raise the following questions: Does the confidentiality oath inhibit medical professionals from combatting transplant tourism? Do medical professionals have a duty to provide patients with medical records if it will facilitate transplant tourism? Do medical professionals have an obligation to treat patients who have undergone an illegal transplant?

\subsubsection{Confidentiality Oath}

Confidentiality is required of medical professionals in numerous countries with the aim to establish and maintain trust between healthcare providers and patients. Indeed, medical professionals in New Zealand have a responsibility to "keep in confidence information derived from a patient" (NZMA, 2014, p. 6). This obligation was shown to be a source of conflict for medical professionals in this study. Similarly, of the 241 transplant professionals surveyed by Ambagtsheer and colleagues (2015), the majority indicated they experienced a conflict of duties due to the confidentiality oath which prevented them from protecting potential vendors and meant that nothing could be done to deter patients. Though, the duty of confidentiality is not absolute and there are unique circumstances in which medical professionals are justified in breaching this obligation. It is outlined in the Health Information Privacy Code (1994, p. 20) 
that disclosure of patient information is allowed when "necessary to prevent or lessen a serious and imminent threat to public health or public safety or the life and health of an individual". Similarly, the Code of Ethics states medical professionals may divulge patient information "with the permission of the patient or in unusual circumstances when it is clearly in the patient's best interests or there is an overriding public good, including the risk of serious harm to another person" (NZMA, p. 6). This document stipulates that when information is divulged without a patient's consent, "this must be done only to the proper authorities" (p. 6). Further, medical professionals in New Zealand are advised to act "without delay to prevent risk to patients" (MCNZ, 2016, p. 6). While it can be suggested that transplant tourism constitutes a 'serious and imminent threat to the life or health' of the potential organ vendor, and poses a significant risk to patient health, there are an array of complex issues professionals must consider before deciding to breach patient confidentiality.

It is important to point out that the Health Information Privacy Code (1994) only permits disclosure of information when it will prevent harm, which means that a breach of confidentiality is only justifiable pre-transplant. As the present study illustrates, medical professionals are largely unaware of those who are actively pursuing transplant tourism because these patients do not inform their doctor beforehand. This finding is demonstrated by M1, who stated: 'I've never... no one's ever told me that they're going to do it and then gone and done it. Ever. I've just been involved with people who have come back'. This point was voiced by the participants in Ambagtsheer, Zaitch and Weimar's (2015, p. 11) research, and is also consistent with the findings presented by McKay and colleagues (2008). In their study, they described four patients who underwent kidney transplantation outside of the U.S., none of whom discussed their interest in this option with their healthcare provider beforehand. Further, a report by Ambagtsheer, Gunnarson, Van Balen and colleagues (2014, p. 77) suggested patients generally do not tell doctors that they will purchase an organ or are selective about what information they share.

Because patients typically do not provide medical professionals with information before or after overseas transplantation, it is almost impossible for medical professionals to determine whether there was a financial component to the procedure. As Ambagtsheer and colleagues (2015) suggest, this task is particularly difficult because:

If a patient travels abroad and pays a hospital for a transplant, this payment does not qualify as a kidney purchase. In order to establish that a kidney purchase will take or has taken 
place, it needs to be proven that the donor and/or broker received or will receive remunerations for the kidney. (p. 1763)

Furthermore, without adequate information about the procedure, medical professionals may not be able to predict or prove that the transplant poses an 'imminent threat' to the safety or life of another person or establish whether a transplant is illegal. The sale of organs is prohibited in many countries, including New Zealand. Yet, like those countries, we do not have extraterritorial jurisdiction and cannot prosecute someone for activity that occurred in another country. By contrast, recipients who purchase an organ from a donor in Iran are not prohibited from doing so, and are not prosecuted (Greenberg, 2013). Muller (2016) points out that medical professionals are not trained to understand the complex laws that exist internationally regarding organ procurement and implantation.

Ultimately, it was revealed in this study that medical professionals felt transplant tourism is covered by the confidentiality obligation. From this view, reporting patients who (intend to) undergo commercial transplantation abroad was presented as unethical, a breach of this obligation, and as beyond the scope of their role.

\subsubsection{Provision of Care}

Providing medical treatment and care that may enable transplant tourism was reported as another significant source of conflict for some of the medical professionals. In regard to pretravel, M4 described feeling conflicted about his duty to provide a clinical letter to his patient who intended to undergo a live donor transplant overseas but explained that 'it is his [patients] right to ask for that'. This dilemma has been reiterated by medical professionals internationally (Ambagtsheer et al., 2015; Ambagtsheer, Zaitch \& Weimar, 2013; Wright et al., 2013). From their interviews with thirteen transplant professionals in the Netherlands, Ambagtsheer, Zaitch and Weimar (2013) found many of their participants:

...emphasised that by providing medical care to patients that potentially aids them with a paid transplant abroad (such as giving them their medical file upon departure) they may breach regulations under criminal law that prohibit doctors to help facilitate commercial transplants. Reversely, if doctors would refuse to provide medical care, such as withholding patients' medical files, they would breach vital healthcare regulations including patients' rights to care. (p. 19) 
A larger study conducted by Ambagtsheer and colleagues (2015) revealed half of the medical professionals felt conflicted about supplying patients with medical records due to fears of participating in illegal activity. This finding was also presented by Wright and colleagues (2013, p. 923) who explain that, for Canadian healthcare providers, "conflict revolves around the duty to care for a patient, and the fact that provision of care enables [transplant tourism], which often involves harms to others".

In New Zealand, patients have a moral and legal right to access their personal medical records. Despite medical professionals having a legal obligation to provide these, they may refuse to disclose this information in certain circumstances. Section 27 (p. 43) of the Privacy Act 1993 stipulates that an agency may refuse access to information if disclosure would "prejudice the maintenance of the law, including the prevention, investigation, and detection of offences, and the right to a fair trial" or "endanger the safety of any individual." Further, Caulfield and colleagues (2016) point out that:

Physicians have no obligation to take any actions that would facilitate an illegal transplant, such as providing a patient with a summary of the medical file or a letter for the surgeon that is going to perform the transplant. Nor are physicians obliged to do additional tests to facilitate transplantation. (p. 2)

All things considered, it would seem that unless medical professionals know that the information will directly contribute in the harm or death of another individual, they are not justified in obstructing a patients' right to access this information.

Second, the medical professionals in this study felt conflicted about 'colluding' in a criminal act as a result of their obligation to provide patients with medical aftercare. This obligation is clearly outlined in Good Medical Practice:

You must not refuse or delay treatment because you believe that a patient's actions have contributed to their condition. Nor should you unfairly discriminate against patients by allowing your personal views to affect your relationship with them. Your personal beliefs, including political, religious and moral beliefs, should not affect your advice or treatment. If you feel your beliefs might affect the advice or treatment you provide, you must explain this to patients and tell them about their right to see another doctor. (p. 12)

This obligation is a significant source of tension for medical professional. In New Zealand, medical professionals do "have the right, except in an emergency, to refuse to care for a 
particular patient... as long as an alternative source of care is available and the appropriate avenue for securing this is known to the patient" (NZMA, 2014, p. 6). Malpas (2018) suggests that transplant professionals practicing in New Zealand are justified in exercising this right, but she, like the medical professionals in this study, points out that this suggestion is not without challenge. In the field of organ transplantation, opportunities to transfer patients are limited by the size of the clinical centre, small professional teams, or no alternative doctor to assume care. Realistically, medical professionals have "little choice but to continue to care for a patient whose actions one deeply opposes" (Malpas, 2018, p. 58). 


\section{Conclusion}

Motivated by the perspective that there needs to be greater understanding of New Zealand's involvement in the global kidney trade, this research sought to address the following questions:

1. Do New Zealand kidney failure patients consider paid transplantation abroad?

2. Do New Zealand residents engage in transplant tourism?

3. How do medical professionals handle occurrences of transplant tourism?

I presented and analysed some of my findings, which I gathered through qualitative interviews with patients, medical professionals and key informants. The data was categorised into three themes, each pertaining to an aim of research. A lack of New Zealand based evidence about transplant tourism has restricted options for assessing and addressing why residents opt for commercial transplantation outside of the healthcare system, and what the appropriate responses are. While the findings of this qualitative research are not generalisable, they serve to address a gap in existing literature, guide future research, and contribute to clinical knowledge about the illness experiences of ESRF patients as it influences their considerations of transplant tourism.

\subsection{Recommendations}

Based on the some of the findings, I provide a number of recommendations to be considered by policy analysts, researchers, government staff and medical organisations. This section does not include suggestions on ways to increase the supply of donated organs in New Zealand. Rather, ongoing support and encouragement is extended to the experts who are already effecting change in this area.

Firstly, a key conclusion of the research is that some patients may experience feelings of hopelessness as a result of dialysis dependence along with current healthcare infrastructures that delay or prevent access to kidney transplantation. Under these circumstances, it is shown that these patients may be more inclined to consider or pursue transplantation outside of New Zealand. In accordance with the suggestions proposed by medical professionals in this study, it is recommended that medical professionals assist patients and whānau in setting realistic expectations of their treatment pathways in New Zealand from the outset. Clarkson and Robinson (2010) recognise that knowledge can be an empowering tool for patients and their family. Their study provided insight into areas of improvement from the perspective of U.S. 
dialysis patients which, if addressed, might have made a difference in their lives and eased the burden of ESRF. Specifically, these patients expressed the need for preparation for their life changes, a desire to learn how to manage medication and treatment side effects and requested to be informed of why they need to follow their treatment regimen and the consequences of not doing so.

Secondly, this study showed that the organ waiting list can be a significant source of frustration and uncertainty for a number of patients; a finding that is corroborated by literature in this area. While prolonged waiting times are inevitable, one patient in this study described feeling cynical about the 'ambiguity' of the waiting list. Given that we live in an era where patients are accustomed to accessing an abundance of information, it is possible that the inability to acquire waiting list information may exacerbate feelings of frustration and uncertainty for some patients. Paterson (2012) acknowledges that New Zealand prides itself on promoting full healthcare information disclosure, having been "one of the first countries in the world to pass a law requiring doctors, nurse and other health practitioners to provide patients with information about their condition and treatment options, including the risks, side effects, benefits and costs of each option" (pp. 41-42). Therefore, the lack of publicly accessible information regarding the New Zealand organ waiting list is an unfortunate oversight which leaves ESRF patients in the dark.

Annually, the ANZDATA have released a thorough report of the incidence, prevalence, and outcomes of dialysis and transplant treatment for patients with ESRF. Despite a comprehensive chapter dedicated to Australian waiting list statistics each year, the New Zealand waiting list data have been unreported since 2012. This information gap is particularly bewildering given that New Zealand data features alongside Australian data in all other chapters of the report. Therefore, it is recommended that the transparency of the deceased donor waiting list in New Zealand is increased. To achieve this, one recommendation is that Blood Service New Zealand work closely with ANZDATA to ensure this data is reported annually alongside the Australian statistics, and to the same level of detail. It is also recommended that Organ Donation New Zealand include an annual summary of this report on their website, so it is easily accessible to the New Zealand public.

Thirdly, this study revealed that medical professionals have varying approaches to deterring patients from transplant tourism. The professionals in this study, along with others described overseas, reported a conflict of duties. While this issue is complex and warrants 
deeper investigation, it is suggested that an important step be the development of a policy statement on organ trafficking and transplant tourism. Much like the statement existing in Canada (see Gill et al., 2010), this statement should clarify the pre-transplant and posttransplant obligations of medical professionals in relation to organ purchase and offer guidance on how they can interact with patients who travel or plan to travel abroad for a transplant. Some of the medical professionals felt that deterrence is best judged on a case-by-case basis; therefore, a policy statement is recommended not as a rule but as general guidance to be used as physicians see fit and in conjunction with their considered ethical judgement. The need for formal guidance on this issue for medical professionals in New Zealand has also been recommended by Malpas (2018).

Lastly, for the purpose of strengthening deterrence conversations, it is suggested that professionals at all levels are offered education about transplant tourism. The DOI pamphlet is the primary resource of reliable information available to medical professional in New Zealand. Yet, it was revealed in this study that very few mentioned employing the use of this material and others were unaware of its existence. Because medical professionals are on the frontline of offering advice to patients who inquire about transplant tourism, they must feel confident in their ability to inform patients of the ethical, medical, legal and psychosocial aspects of commercial transplantation overseas (Malpas, 2018).

\subsection{Suggestions for Further Research}

To explore the involvement of New Zealand residents in transplant tourism, this research largely relied on the accounts of medical professionals working in the field of organ donation and transplantation. This was due in part to the difficulty in accessing recipients of commercially transplanted kidneys. Although the medical professionals had knowledge of recipients residing in New Zealand, most were justifiably unwilling to assist with participant recruitment because of their ethical obligation of confidentiality. Without the assistance of medical professionals, recruiting recipients is certainly challenging as the population of patients is small and they are likely to conceal their involvement in transplant tourism. While this study did not have the capacity to interview recipients of purchased kidneys, it is important that their experiences are documented in future qualitative research. Efforts to interview recipients will more than likely require the help of medical professionals in participant recruitment, and potential language barriers should be considered. 
Some discussion regarding the potential rate of transplant tourism was included in this study but there is currently no systematic registration of New Zealand patients who have travelled abroad for transplantation. As mentioned, medical professionals in New Zealand may report this information to ANZDATA, but reporting is not mandatory. Therefore, it would be useful if dedicated quantitative efforts were made to assess the scale of this phenomenon in future research. One direction this can take is to comprise a national survey for all transplant professionals in New Zealand. Recently, Smith and colleagues (2019) distributed a survey to 540 registered Australian transplant professionals that inquired about their experience with patients who had considered or actually travelled for an organ transplant. When compared to the ANZDATA reports during the same period, a total of 49 instances identified in the survey were not reported in the ANZDATA registry. It is equally important to undertake further research into the outcomes of New Zealand patients who have been commercially transplanted overseas. Similar research has been conducted in Australia (see Kennedy et al., 2005) and would aid the knowledge of medical professionals in New Zealand, allowing them to offer informed advice about the heightened risks to life of patients considering commercial transplantation.

\subsection{Final Word}

This research has provided platforms for further academic and policy-focused consideration. Embarking on this project has allowed me to contribute to knowledge in this area through offering insights about the illness experiences of dialysis patients, the factors the contribute to transplant tourism in New Zealand, and the conflicts of duties that arise for medical professionals engaged with patients who have considered or pursued a commercial kidney transplant abroad. The lack of public acknowledgement of transplant tourism as an option some patients consider downplays rhetoric around an organ shortage in New Zealand and patients' concerns about access to a transplant within the New Zealand healthcare system. This research has shown that transplant tourism is an option that is considered and, to a lesser extent, pursued by desperate patients who feel they have no other choice. It is my hope that this project can be used to inform discussion about organ donation and transplantation that is necessary for improvements in the provision of care, and more crucially, for the overall wellbeing of the patients and their whānau. 


\section{References}

Al-Arabi, S. (2006). Quality of life: subjective descriptions of challenges to patients with end stage renal disease. Nephrology Nursing Journal, 33(3), 285-293.

Allen, M. B., \& Reese, P. P. (2013). Financial incentives for living kidney donation: Ethics and evidence. Clinical Journal of the American Society of Nephrology, 8(12), 20312033. doi:10.2215/CJN.09820913.

Alpinar-Şencan, Z., Baumann, H., \& Biller-Andorno, N. (2017). Does organ selling violate human dignity?. Monash Bioethics Review, 34(3-4), 189-205. doi:10.1007/s40592017-0070-x.

Ambagtsheer, F., Zaitch, D., \& Weimar, W. (2013). The battle for human organs: Organ trafficking and transplant tourism in a global context. Global Crime, 14(1), 1-26. doi:10.1080/17440572.2012.753323.

Ambagtsheer, F., Gunnarson, M., Van Balen, L., Ivanovski, N., Lundin, S., Byström, I., \& Weimar, W. (2014). Organ recipients who paid for kidney transplantations abroad: a report. Retrieved from http://hottproject.com/reports/reports.html

Ambagtsheer, F., Van Balen, L. J., Duijst-Heesters, W. L. J. M., Massey, E. K., \& Weimar, W. (2015). Reporting organ trafficking networks: a survey-based plea to breach the secrecy oath. American Journal of Transplantation, 15(7), 1759-1767. doi:10.1111/ajt.13245.

Anderson, C. (2010). Presenting and evaluating qualitative research. American Journal of Pharmaceutical Education, 74(8), 141.

Anderson, C., \& Kirkpatrick, S. (2016). Narrative interviewing. International Journal of Clinical Pharmacy, 38(3), 631-634. doi:10.1007/s11096-015-0222-0.

Anderson, O. (2017). Paid Kidney Transplantation: The Decision-Making Process Through Neutralization and Drift Theory. Unpublished Honours Dissertation, Victoria University of Wellington, Wellington.

ANZDATA Registry. (2018) 41st Annual Report. Australia and New Zealand Dialysis and Transplant Registry, Adelaide, Australia. 2018. Retrieved from http://www.anzdata.org.au

Aramesh, K. (2014). A closer look at the iranian model of kidney transplantation. The American Journal of Bioethics, 14(10), 35-37. doi:10.1080/15265161.2014.947044.

Bakdash, T., \& Scheper-Hughes, N. (2006). Is it ethical for patients with renal disease to purchase kidneys from the world's poor?. PLoS Medicine, 3(10), e349. doi:10.1371/journal.pmed.0030349

Bamberg, M. (Ed.). (2007). Narrative state of the art (Vol. 6). John Benjamins Publishing Company, Philadelphia, PA.

Bayhakki, \& Hatthakit, U. (2012). Lived experiences of patients on hemodialysis: a metasynthesis. Nephrology Nursing Journal, 39(4), 295-304. 
Beauchamp, T. L. (2006). The right to die as the triumph of autonomy. Journal of Medicine and Philosophy, 31(6), 643-654. doi:10.1080/03605310601096619.

Beauchamp, T. and Childress, J. (2013). Principles of Biomedical Ethics. Oxford University Press.

Berglund, S., \& Lundin, S. (2012). 'I had to leave'. A cultural analysis of motives for commercial transplantations. In M. Gunnarson \& F. Svenaeus (Eds.) The Body as Gift, Resource, and Commodity: Exchanging Organs, Tissues and Cells in the 21st century (pp. 321-342). Huddinge: Södertörns Studies in Practical Knowledge.

Braun, V. and Clarke, V. (2013). Successful qualitative research: A practical guide for beginners. London: SAGE.

Budiani-Saberi, D. A., \& Delmonico, F. L. (2008). Organ trafficking and transplant tourism: a commentary on the global realities. American Journal of Transplantation, 8(5), 925929. doi:10.1111/j.1600-6143.2008.02200.x

Budiani-Saberi, D., \& Mostafa, A. (2011). Care for commercial living donors: the experience of an NGO's outreach in Egypt. Transplant International, 24(4), 317-323. doi:10.1111/j.1432-2277.2010.01189.x

Budiani-Saberi, D. A., Raja, K. R., Findley, K. C., Kerketta, P., \& Anand, V. (2014). Human trafficking for organ removal in India: a victim-centered, evidence-based report. Transplantation, 97(4), 380-384. doi:10.1097/01.TP.0000438624.83472.55

Bury, M. (1982). Chronic illness as biographical disruption. Sociology of health \& illness, 4(2), 167-182.

Bury, M. (1997). Health and Illness in a Changing Society. New York: Routledge.

Calvey, D., \& Mee, L. (2011). The lived experience of the person dependent on haemodialysis. Journal of Renal Care, 37(4), 201-207.

Canales, M. T., Kasiske, B. L., \& Rosenberg, M. E. (2006). Transplant tourism: outcomes of United States residents who undergo kidney transplantation overseas.

Transplantation, 82(12), 1658-1661. doi:10.1097/01.tp.0000250763.52186.df

Capron, A. M., Danovitch, G. M., \& Delmonico, F. L. (2014). Organ markets: Problems beyond harms to vendors. The American Journal of Bioethics, 14(10), 23-25. doi:10.1080/15265161.2014.947048

Caulfield, T., Duijst, W., Bos, M., Chassis, I., Codreanu, I., Danovitch, G., ... \& Shin, M. (2016). Trafficking in human beings for the purpose of organ removal and the ethical and legal obligations of healthcare providers. Transplantation Direct, 2(2). doi:10.1097/TXD.0000000000000566

Chong, H. J., Kim, H. K., Kim, S. R., \& Lee, S. (2016). Waiting for a kidney transplant: the experience of patients with end-stage renal disease in South Korea. Journal of Clinical Nursing, 25(7-8), 930-939. doi:10.1111/jocn.13107

Clarkson, K. A., \& Robinson, K. (2010). Life on dialysis: a lived experience. Nephrology Nursing Journal, 37(1). PMID: 2033901 
Codreanu, I., Codreanu, N., \& Delmonico, F. (2010). The Long-Term Consequences of Kidney Donation In The Victims Of Trafficking In Human Beings (Vthbs) For The Purpose Of Organ Removal. Transplantation, 90, 214.

Cohen, I. G. (2013). Transplant tourism: the ethics and regulation of international markets for organs. The Journal of Law, Medicine \& Ethics, 41(1), 269-285.

Coombs, M., \& Woods, M. (2017). Organ Donation Practices and End-of-life Care: Unusual Bedfellows or Comfortable Companions?. In R. M. Shaw (Ed.), Bioethics Beyond Altruism. Palgrave Macmillan.

Council of Europe Convention against Trafficking in Human Organ. (2015, March 25). CETS No. 216. [Treaty]. Retrieved from https://www.coe.int/en/web/conventions/full-list/-/conventions/treaty/216.

Cross, N., Dittmer, I., \& Matheson, P. (2012). Policy for Use of New Zealand Survival After Kidney Transplant Predictor System in Patients Assessed for Deceased Donor Transplantation in New Zealand (Version 1.0). Retrieved from https://www.health.govt.nz/about-ministry/leadership-ministry/expertgroups/national-renal-transplant-service/nrts-papers-and-reports

Declaration of Istanbul Custodian Group (2014). Thinking of buying a kidney? Stop! What you need to know. [Pamphlet]. Available at http://www.declarationofistanbul.org/resources/patient-brochure-thinking-about-akidney

Delmonico, F. L. (2009). The implications of Istanbul Declaration on organ trafficking and transplant tourism. Current Opinion in Organ Transplantation, 14(2), 116-119. doi:10.1097/MOT.0b013e32832917c9

Dickenson, D. (2002). Commodification of human tissue: implications for feminist and development ethics. Developing World Bioethics, 2(1), 55-63.

Docherty, D., \& McColl, M. A. (2003). Illness stories: Themes emerging through narrative. Social Work in Healthcare, 37(1), 19-39. doi:10.1300/J010v37n01_02

Dowen, F., Cross, N., Clayton, P., \& Pilmore, H. (2017). Deceased donor kidney transplantation in New Zealand: use and audit of a survival prediction tool. New Zealand Medical Journal, 130(1464), 33-39.

Eddy, D. M. (1986). Successes and challenges of medical decision making. Health Affairs, 5(2), 108-115. doi:0.1377/hlthaff.5.2.108

Fennell, M. L. (2008). The new medical technologies and the organizations of medical science and treatment. Health Services Research, 43(1 Pt 1), 1-9. doi:10.1111/j.14756773.2007.00832.x

Frank, A. (1995). The Wounded Storyteller: Body, Illness and Ethics. Chicago and London: University of Chicago Press.

Fraser, H. (2004). Doing narrative research: Analysing personal stories line by line. Qualitative social work, 3(2), 179-201. doi:10.1177/1473325004043383 
Frey, B. S., \& Jegen, R. (2001). Motivation Crowding Theory: A Survey of Empirical Evidence. Journal of Economic Surveys, 15(5), 589-611. doi:10.1111/14676419.00150

Gavin, C., Malpas, P., \& Bartlett, A. (2015). The experiences, motivations, and opinions of New Zealand's live liver donors. New Zealand Medical Journal, 128(1425), 54-60. Retrieved from https://www.nzma.org.nz/journal/read-the-journal/allissues/20102019/2015/vol-128-no-1425-20-november-2015/6725

Gill, J., Madhira, B. R., Gjertson, D., Lipshutz, G., Cecka, J. M., Pham, P. T., ... \& Danovitch, G. M. (2008). Transplant tourism in the United States: a single-center experience. Clinical Journal of the American Society of Nephrology, 3(6), 1820-1828. doi:10.2215/CJN.02180508

Gill, J. S., Goldberg, A., Prasad, G. R., Fortin, M. C., Hansen, T. B., Levin, A., ... \& Cole, E. H. (2010). Policy statement of Canadian Society of Transplantation and Canadian Society of Nephrology on organ trafficking and transplant tourism. Transplantation, 90(8), 817-820. doi:10.1097/TP.0b013e3181efd030

Gill, J., Diec, O., Landsberg, D. N., Rose, C., Johnston, O., Keown, P. A., \& Gill, J. S. (2011). Opportunities to deter transplant tourism exist before referral for transplantation and during the workup and management of transplant candidates. Kidney International, 79(9), 1026-1031. doi:10.1038/ki.2010.540

Gill, J., Joffres, Y., Rose, C., Lesage, J., Landsberg, D., Kadatz, M., \& Gill, J. (2018). The change in living kidney donation in women and men in the United States (20052015): a population-based analysis. Journal of the American Society of Nephrology, 29(4), 1301-1308. doi:10.1681/ASN.2017111160

Gneezy, U., \& Rustichini, A. (2000). A fine is a price. The Journal of Legal Studies, 29(1), 117.

Good, B.J. (1994) Medicine, Rationality, and Experience. An Anthropological Perspective. Cambridge: Cambridge University Press.

Goyal, M., Mehta, R. L., Schneiderman, L. J., \& Sehgal, A. R. (2002). Economic and health consequences of selling a kidney in India. The Journal of the American Medical Association, 288(13), 1589-1593. doi:10.1001/jama.288.13.1589

Greenberg, O. (2013). The global organ trade: A case in point. Cambridge Quarterly of Healthcare Ethics, 22(3), 238-245. doi:10.1017/S0963180113000042

Greenhalgh, T., \& Hurwitz, B. (1999). Why study narrative?. British Medical Journal, 318(7175), 48-50.

Gutmann, E. (2012). Bitter harvest: China's' organ donation nightmare. World Affairs, 175(2), 49-56.

Hagren, B., Pettersen, I. M., Severinsson, E., Lützén, K., \& Clyne, N. (2001). The haemodialysis machine as a lifeline: experiences of suffering from end-stage renal disease. Journal of Advanced Nursing, 34(2), 196-202. doi:10.1046/j.13652648.2001.01745.x 
Hagren, B., Pettersen, I. M., Severinsson, E., Lützén, K., \& Clyne, N. (2005). Maintenance haemodialysis: patients' experiences of their life situation. Journal of clinical nursing, 14(3), 294-300.

Health Information Privacy Code 1994. Retrieved from https://www.privacy.org.nz/theprivacy-act-and-codes/codes-of-practice/health-information-privacy-code-1994/

Hydén, L. C. (1997). Illness and narrative. Sociology of health \& illness, 19(1), 48-69.

Josselson, R. (2007). Narrative research and the challenge of accumulating knowledge. In M. Bamberg (Ed.), Narrative - State of the art (pp. 7-17). Amsterdam, The Netherlands: John Benjamins.

Kapoor, A., Kwan, K. G., \& Whelan, J. P. (2011). Commercial renal transplantation: A risky venture? A single Canadian centre experience. Canadian Urological Association Journal, 5(5), 335. doi:10.5489/cuaj.11018

Kennedy, S. E., Shen, Y., Charlesworth, J. A., Mackie, J. D., Mahony, J. D., Kelly, J. J., \& Pussell, B. A. (2005). Outcome of overseas commercial kidney transplantation: an Australian perspective. Medical Journal of Australia, 182(5), 224-227.

Kidney Health New Zealand. (n.d. -a). Conservative Treatment. [Pamphlet] Retrieved from https://www.kidneys.co.nz/resources/file/conservative treatment.pdf

Kidney Health New Zealand. (n.d. -b). Having a Kidney Transplant. [Pamphlet] Retrieved from https://www.kidneys.co.nz/resources/file/having_a_kidney_transplant.pdf

Kidney Health New Zealand. (n.d. -c). Treatment options for Chronic Kidney Disease (CKD). [Pamphlet]. Retrieved from https://www.kidneys.co.nz/resources/file/ckd_treatment_options.pdf

Kleinman, A. (1988). The illness narratives: Suffering, healing, and the human condition. New York: Basic Books.

Koplin, J. J. (2017). The body as gift, commodity, or something in between: ethical implications of advanced kidney donation. Journal of Medicine and Philosophy, 42(5), 575-596. doi:10.1093/jmp/jhx017

Lee, J. Y., Kearns, R. A., \& Friesen, W. (2010). Seeking affective health care: Korean immigrants' use of homeland medical services. Health \& Place, 16(1), 108-115. doi:10.1016/j.healthplace.2009.09.003

Leung, S. S., \& Shiu, A. T. (2007). Experience of Hong Kong patients awaiting kidney transplantation in mainland China. Journal of Clinical Nursing, 16(11c), 341-349. doi:10.1111/j.1365-2702.2007.02070.x

Levine, S., \& Kozloff, M. A. (1978). The sick role: Assessment and overview. Annual Review of Sociology, 4(1), 317-343.

Lock, M., \& Nguyen, V. (2018). An Anthropology of Biomedicine (2nd ed.). Wiley Blackwell. 
Lundin, S. (2002). Creating Identity With Biotechnology: The Xenotransplanted Body as the Norm. Public Understanding of Science, 11(4), 333-345.

Lundin, S. (2016). Organs for sale: an ethnographic examination of the international organ trade. Springer.

Lundin, S., Kroløkke, C., Petersen, M. N., \& Muller, E. (Eds.). (2016). Global bodies in grey zones: Health, hope, biotechnology (Vol. 9). African Sun Media.

Malpas, P. (2018). New Zealand transplant patients and organ transplantation in China: some ethical considerations. New Zealand Medical Journal, 131(1478), 55-61.

Martin, P. A. (1995). Recruitment of research subjects. Applied Nursing Research, 8(10), 5054.

Martin, P. (2013a). Finding a living kidney donor: experiences of New Zealand renal patients. Australian Health Review, 37(1), 48-53. doi:10.1071/AH12159

Martin, P. (2013b). Increasing the Rate of Living Donor Kidney Transplantation in New Zealand: Developing an Evidence Base. PhD thesis, Victoria University of Wellington. Retrieved from http:// researcharchive.vuw.ac.nz/handle/10063/2932

Martin, P. (2014). Living donor kidney transplantation: preferences and concerns amongst patients waiting for transplantation in New Zealand. Journal of health services research \& policy, 19(3), 138-144. doi:10.1177/1355819613514957

Matas, A. J., \& Delmonico, F. L. (2012). Living donation: the global perspective. Advances in Chronic Kidney Disease, 19(4), 269-275.

Matza, D. (1964). Delinquency and Drift. New York: Wiley.

McKay, D., Potter, S. R., Behrend, T., Stella, F., \& Steinberg, S. (2008). Patients seeking alternatives to the long waiting list: a reality faced by transplant physicians. Progress in Transplantation, 18(3), 203-207.

McKechnie, L. E. F. (2008). Reactivity. The SAGE Encyclopedia of Qualitative Research Methods, 2, 729-730.

Medical Council of New Zealand. (2016). Good medical practice: a guide for doctors. Retrieved from https://www.mcnz.org.nz/about-us/publications/good-medicalpractice/

Ministry of Health. (n.d.). Background information on organ donation and transplantation in New Zealand. Retrieved from https://www.health.govt.nz/our-work/hospitals-andspecialist-care/organ-donation-and-transplantation/deceased-organ-donation-and$\underline{\text { transplantion-national-strategy/review-deceased-organ-donation-and-transplantation }}$

Ministry of Health. (2017). Increasing Deceased Organ Donation and Transplantation: A national strategy.Wellington: Ministry of Health.

Ministry of Health. (2019, March 26). Becoming a Live Donor. Retrieved from https://www.health.govt.nz/your-health/conditions-and-treatments/treatments-and- 
surgery/organ-donations-and-transplants/live-organ-donation/becoming-live-organdonor

Moniruzzaman, M. (2012). "Living cadavers" in Bangladesh: Bioviolence in the human organ bazaar. Medical Anthropology Quarterly, 26(1), 69-91. doi:10.1111/j.15481387.2011.01197.x

Moran, A., Scott, A., \& Darbyshire, P. (2011). Waiting for a kidney transplant: Patients' experiences of hemodialysis therapy. Journal of Advanced Nursing, 67(3), 501-509. doi:10.1111/j.1365-2648.2010.05460.x

Moreno, J. D. (2007). The triumph of autonomy in bioethics and commercialism in American healthcare. Cambridge Quarterly of Healthcare Ethics, 16(4), 415-419. doi:10.1017/S096318010707051X

Muller, E. (2016). Making decisions but living organ providers: The medical professional perspective. In S. Lundin, C. Kroløkke, M. Petersen \& E. Muller (Eds.), Global Bodies in Grey Zones: Health, Hope, Biotechnology (pp. 35 - 46). African Sun Media.

Myaskovsky, L., Doebler, D. A., Posluszny, D. M., Dew, M. A., Unruh, M., Fried, L. F., ... \& Shapiro, R. (2012). Perceived discrimination predicts longer time to be accepted for kidney transplant. Transplantation, 93(4), 423. doi:10.1097/TP.0b013e318241d0cd

Naqvi, S. A. A., Ali, B., Mazhar, F., Zafar, M. N., \& Rizvi, S. A. H. (2007). A socioeconomic survey of kidney vendors in Pakistan. Transplant International, 20(11), 934-939. doi:10.1111/j.1432-2277.2007.00529.x

Naqvi, S. A. A., Rizvi, S. A. H., Zafar, M. N., Ahmed, E., Ali, B., Mehmood, K., ... \& Mazhar, F. (2008). Health status and renal function evaluation of kidney vendors: a report from Pakistan. American Journal of Transplantation, 8(7), 1444-1450. doi:10.1111/j.1600-6143.2008.02265.x

National Renal Transplant Service. (2018) Improving Live Donor And Kidney Recipient Processes [Continuous Improvement Resource]. Retrieved from https://www.health.govt.nz/about-ministry/leadership-ministry/expertgroups/national-renal-transplant-service/nrts-papers-and-reports

National Renal Transplant Service. (February, 2019). National Kidney Allocation Scheme. Retrieved from https://www.health.govt.nz/about-ministry/leadership-ministry/expertgroups/national-renal-transplant-service/nrts-papers-and-reports

Newsletter Transplant (2018, vol.23). International figures on donation and transplantation 2017, EDQM. Retrieved from http://www.transplant-observatory.org/

New Zealand Medical Association. (2014). Code of Ethics: For the New Zealand Medical Professional. Retrieved from https://www.nzma.org.nz/publications/code-of-ethics

Ngai, M. M. Y., Latimer, S., \& Cheung, V. Y. M. (2001). Final report on healthcare needs of Asian people: Surveys of Asian people and health professionals in the North and West Auckland. Retrieved from https://www.ecald.com/resources/publications/ 
Nordenfelt, L. (2004). The varieties of dignity. Healthcare Analysis, 12(2), 69-81.

Norman, G. (2017). Generalization and the qualitative-quantitative debate. Advances in Health Sciences Education, 22(5), 1051-1055. doi:10.1007/s10459-017-9799-5

Organ Donation New Zealand. (2017). Annual Report 2017. Retrieved from https://www.donor.co.nz/media-centre/

Overcash, J. A. (2003). Narrative research: a review of methodology and relevance to clinical practice. Critical Reviews in Oncology/Hematology, 48(2), 179-184. doi:10.1016/j.critrevonc.2003.04.006

Parsons, T. (1951). Illness and the role of the physician: a sociological perspective. American Journal of Orthopsychiatry, 21(3), 452.

Paterson, R. (2012). The good doctor: what patients want. Auckland: Auckland University Press.

Petersen, A., Seear, K., \& Munsie, M. (2014). Therapeutic journeys: the hopeful travails of stem cell tourists. Sociology of Health \& Illness, 36(5), 670-685. doi:10.1111/14679566.12092

Petersen, A. (2015). Hope in health: The socio-politics of optimism. Palgrave Macmillan.

Plummer, K. (1995) Telling Sexual Stories: Power, Change and Social Worlds. London: Routledge.

Polaschek, N. (2003). Living on dialysis: concerns of clients in a renal setting. Journal of Advanced Nursing, 41(1), 44-52.

Pozgar, G. (2019). Legal and Ethical Issues for Health Professionals (5th ed., p. 283). Burlington, Massachusetts: Jones \& Bartlett Learning.

Reay, T. (1999). Allocating scarce resources in a publicly funded health system: Ethical considerations of a Canadian managed care proposal. Nursing ethics, 6(3), 240-249.

Richardson, L. (1990). Narrative and sociology. Journal of Contemporary Ethnography, 19(1), 116-135.

Riessman, C. K. (2001). Personal Troubles as Social Issues: A Narrative of Infertility in Context. In I. Shaw and N. Gould (Eds.), Qualitative Research in Social Work: Method and Context (pp. 73 - 82). Newbury Park, CA: Sage

Riessman, C. (2002) Analysis of personal narratives. In J. Gubrium and J. Holstein (eds), Handbook of Interview Research. Thousand Oaks, CA: SAGE.

Riessman, C. K. (2005). Exporting ethics: A narrative about narrative research in South India. Health:, 9(4), 473-490. doi:10.1177/1363459305056414

Riessman, C. K., \& Quinney, L. (2005). Narrative in social work: A critical review. Qualitative social work, 4(4), 391-412. doi:10.1177/1473325005058643

Roodnat, J. I., van de Wetering, J., Zuidema, W., van Noord, M. A., Kal-van Gestel, J. A., IJzermans, J. N., \& Weimar, W. (2010). Ethnically diverse populations and their 
participation in living kidney donation programs. Transplantation, 89(10), 1263-1269. doi:10.1097/TP.0b013e3181d84ca7

Rubin, H., \& Rubin, I. (2012). Qualitative interviewing: The Art of Hearing Data (3rd ed.). Los Angeles: SAGE Publications Ltd.

Sardell, A. N., \& Trierweiler, S. J. (1993). Disclosing the cancer diagnosis. Procedures that influence patient hopefulness. Cancer, 72(11), 3355-3365.

Scheper-Hughes, N. (2001). Bodies for sale-whole or in parts. Body \& Society, 7(2-3), 1-8.

Sever, M. Ş., Kazancioğlu, R., Yildiz, A., Türkmen, A., Ecder, T., Kayacan, S. M., ... \& Ark, E. (2001). Outcome of living unrelated (commercial) renal transplantation. Kidney International, 60(4), 1477-1483.

Sharif, A., Singh, M. F., Trey, T., \& Lavee, J. (2014). Organ procurement from executed prisoners in China. American Journal of Transplantation, 14(10), 2246-2252. doi:10.1111/ajt.12871

Sharot, T. (2011). The optimism bias. Current biology, 21(23), R941-R945.

Shaw, R.M. (2014). Live kidney donation as body work. Critical Social Policy, 34(4), 495514. doi:10.1177/0261018314538795

Shaw, R. (2015a). Being-in-dialysis: The experience of the machine-body for home dialysis users. Health, 19(3), 229-244. doi:10.1177/1363459314539775

Shaw, R. (2015b). New Zealanders' experiences of organ donation and transplantation. New Zealand Sociology, 30(4), 210-228.

Shaw, R. M., \& Bell, L. J. (2015). 'Because you can't live on love': living kidney donors' perspectives on compensation and payment for organ donation. Health Expectations, 18(6), 3201-3212. doi:10.1111/hex.12310

Shaw, R.M. (2019). Altruism, solidarity and affect in live kidney donation and breastmilk sharing. Sociology of Health \& Illness, 41(3), 553-566. doi:1111/1467-9566.12805.

Shilling, C. (2002). Culture, the 'sick role'and the consumption of health. The British journal of sociology, 53(4), 621-638. doi:10.1080/0007131022000021515

Shimazono, Y. (2007). The state of the international organ trade: a provisional picture based on integration of available information. Bulletin of the World Health Organization, $85,955-962$.

Simpson, C. (2004). When hope makes us vulnerable: a discussion of patient-healthcare provider interactions in the context of hope. Bioethics, 18(5), 428-447.

Smith, G., Gujari, D., Russell, O., Palmer, L., Toews, M., Wong, G., .. Coates., PT. (2019). Internation travel by Australians for overseas transplantation. The Medical Journal of Australia. Advance online publication. doi:10.5694/mja2.50333

Spasovski, G., Busic, M., Matovinovic, M. S., \& Delmonico, F. L. (2017). Kidney Transplantation in Developing Countries. In G. Orlando, G. Remuzzi \& D. Williams 
(Eds.), Kidney Transplantation, Bioengineering and Regeneration (pp. 687 - 698). Academic Press. doi:10.1016/B978-0-12-801734-0.00049-7.

Starzl, T. E. (1994). The early days of transplantation. Journal of the American Medical Association, 272(21), 1705.

Steering Committee of the Istanbul Summit. (2008). Organ trafficking and transplant tourism and commercialism: the Declaration of Istanbul. The Lancet, 372(9632), 5-6. doi:10.1016/S0140-6736(08)60967-8

Stratta, R. J., Rohr, M. S., Sundberg, A. K., Armstrong, G., Hairston, G., Hartmann, E., ... \& Adams, P. L. (2004). Increased kidney transplantation utilizing expanded criteria deceased organ donors with results comparable to standard criteria donor transplant. Annals of surgery, 239(5), 688-697. doi:10.1097/01.sla.0000124296.46712.67

Sulmasy, D. P. (2007). Human dignity and human worth. In J. Maplas \& N. Lickiss (Eds.) Perspectives on Human Dignity: A Conversation (pp. 9 - 18). Springer, Dordrecht.

Sunstein, C. R., \& Thaler, R. H. (2003). Libertarian paternalism is not an oxymoron. The University of Chicago Law Review, 70(4), 1159-1202.

Sykes, G. M., \& Matza, D. (1957). Techniques of neutralization: A theory of delinquency. American Sociological Review, 22(6), 664-670.

Taylor, D., \& Bury, M. (2007). Chronic illness, expert patients and care transition. Sociology of health \& illness, 29(1), 27-45. doi:10.1111/j.1467-9566.2007.00516.x

Titmuss, R. (1971). The gift relationship: From human blood to social policy. London. Pantheon.

Tong, A., Chapman, J. R., Wong, G., Cross, N. B., Batabyal, P., \& Craig, J. C. (2012). The experiences of commercial kidney donors: thematic synthesis of qualitative research. Transplant International, 25(11), 1138-1149. doi:10.1111/j.14322277.2012.01534.x

Toombs, S. K. (1988). Illness and the paradigm of lived body. Theoretical Medicine, 9(2), 201-226.

United Nations. (2000). Protocol to prevent, suppress and punish trafficking in persons, especially women and children, supplementing the United Nations convention against transnational organized crime. General Assembly Resolution 55/25.

Van Balen, L. J., Ambagtsheer, F., Ivanovski, N., \& Weimar, W. (2016). Interviews with patients who traveled from Macedonia/Kosovo, The Netherlands, and Sweden for paid kidney transplantations. Progress in Transplantation, 26(4), 328-334. doi: $10.1177 / 1526924816667951$

Walker, R., Wu, C. W. D., Soothi-O-Soth, M., \& Parr, A. (1998). New Zealand's Asian population: views on health and health services. Auckland: Health Funding Authority.

Walsh, A. (2015). Compensation for blood plasma donation as a distinctive ethical hazard: Reformulating the commodification objection. HEC Forum, 27(4), 201-416. 
Watson, C. J. E., \& Dark, J. H. (2012). Organ transplantation: historical perspective and current practice. British Journal of Anaesthesia, 108(S1), i29-i42.

doi:10.1093/bja/aer384

Watts, C., Southerwood, C., Maxwell, A., O’Riordan, Z., Gray, W., Coombs, M., Poynter, C. (n.d.). Activities of a Clinical Specialty Nurse (CSN) Role in Organ Donation: The First 12 Months in Post. Presented at ANZICS Annual Federal Conference, Auckland 2015. Retrieved from http://www.wellingtonicu.com/PubResPres/Presentations/

Weinstein, M. C. (2001). Should physicians be gatekeepers of medical resources?. Journal of Medical Ethics, 27(4), 268-274.

Wolpe, P. R. (1998). The triumph of autonomy in American medical ethics: A sociological view. In R. De Vries \& J. Subedi (Eds.), Bioethics and Society: Constructing the Ethical Enterprise of Bioethics. Prentice Hall, New York.

Wong-Wylie, G., \& Jevne, R. F. (1997). Patient hope: exploring the interactions between physicians and HIV seropositive individuals. Qualitative Health Research, 7(1), 3256.

Woods, M. (2005). Nursing ethics education: are we really delivering the good(s)?. Nursing Ethics, 12(1), 5-18. doi:10.1191/0969733005ne754oa

World Health Organization. (1987, May). WHA40. 13 Development of guiding principles for human organ transplants. Fortieth World Health Assembly, Geneva. Retrieved from https://www.who.int/transplantation/publications/en/

World Health Organization. (1991, May). WHA44. 25 Human organ transplantation. FortyFourth World Health Assembly, Geneva. Retrieved from http://www.transplantobservatory.org/download/resolution-wha44-25-endorsing-the-1991-guidingprinciples/

World Health Organization. (2004, May). WHA57.18 Human organ and tissue transplantation. Fifty-Seventh World Health Assembly, Geneva. Retrieved from https://www.who.int/transplantation/publications/en/

World Health Organization. (2009). Global Glossary of Terms and Definitions on Donation and Transplantation. Retrieved from https://www.who.int/transplantation/publications/en/

World Health Organization. (2010, May). WHA63. 22 Human organ and tissue transplantation. Sixty-Third World Health Assembly, Geneva. Retrieved from https://www.who.int/transplantation/publications/en/

Wright, L., Zaltzman, J. S., Gill, J., \& Prasad, G. V. R. (2013). Kidney transplant tourism: cases from Canada. Medicine, Healthcare and Philosophy, 16(4), 921-924. doi:10.1007/s11019-012-9450-4

Yeates, K. E., Cass, A., Sequist, T. D., McDonald, S. P., Jardine, M. J., Trpeski, L., \& Ayanian, J. Z. (2009). Indigenous people in Australia, Canada, New Zealand and the United States are less likely to receive renal transplantation. Kidney International, 76(6), 659-664. doi:10.1038/ki.2009.236 
Zargooshi, J. (2001). Quality of life of Iranian kidney “donors". The Journal of Urology, 166(5), 1790-1799. 


\section{Appendix 1: Ethics Approval}

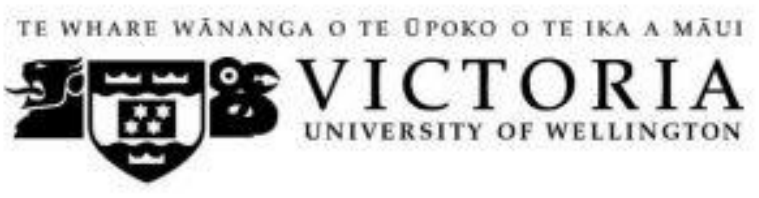

MEMORANDUM

Phone 0-4-463 6028

Email judith.loveridge(vuw.ac.nz

\begin{tabular}{l|l}
\hline TO & Liv Anderson \\
\hline FROM & Dr Judith Loveridge, Convenor, Human Ethics Committee \\
\hline DATE & 30 October 2018 \\
\hline PAGES & 1 \\
\hline & \multicolumn{2}{|l}{$\begin{array}{l}\text { Ethics Approval } \\
\text { Number: } 26785 \\
\text { Title: Transplant Tourism: New Zealand residents who } \\
\text { undergo kidney transplantation overseas }\end{array}$} \\
\hline
\end{tabular}

Thank you for your application for ethical approval, which has now been considered by the Human Ethics Committee.

Your application has been approved from the above date and this approval is valid for three years. If your data collection is not completed by this date you should apply to the Human Ethics Committee for an extension to this approval.

Best wishes with the research.

Kind regards,

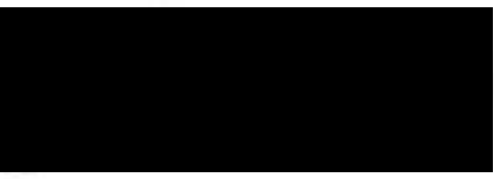

Judith Loveridge

Convenor, Victoria University of Wellington Human Ethics Committee 


\section{Appendix 2: Patient Recruitment Advertisement}

$\mathrm{Hi}$, my name is Olivia Anderson and I am undertaking a Master's degree at Victoria University of Wellington. My thesis is about kidney transplantation and I am interested in talking to people who have considered travelling abroad, or have travelled abroad for a kidney transplant. The aim of my research is to gather information on patients' motivations and experiences. A key outcome of this study is to utilise the findings for preventative strategies in favour of increasing transplant opportunities in New Zealand. Although much more research will need to be done to help increase transplant opportunities in New Zealand, this study is an important step towards that goal. If you wish to participate in the study or have any queries about the research, please contact me on liv.anderson@vuw.ac.nz for more information. All interviews will be confidential and can be scheduled at a time and place that is convenient for you. Thank you. 


\section{Appendix 3: Medical Professional Recruitment Email}

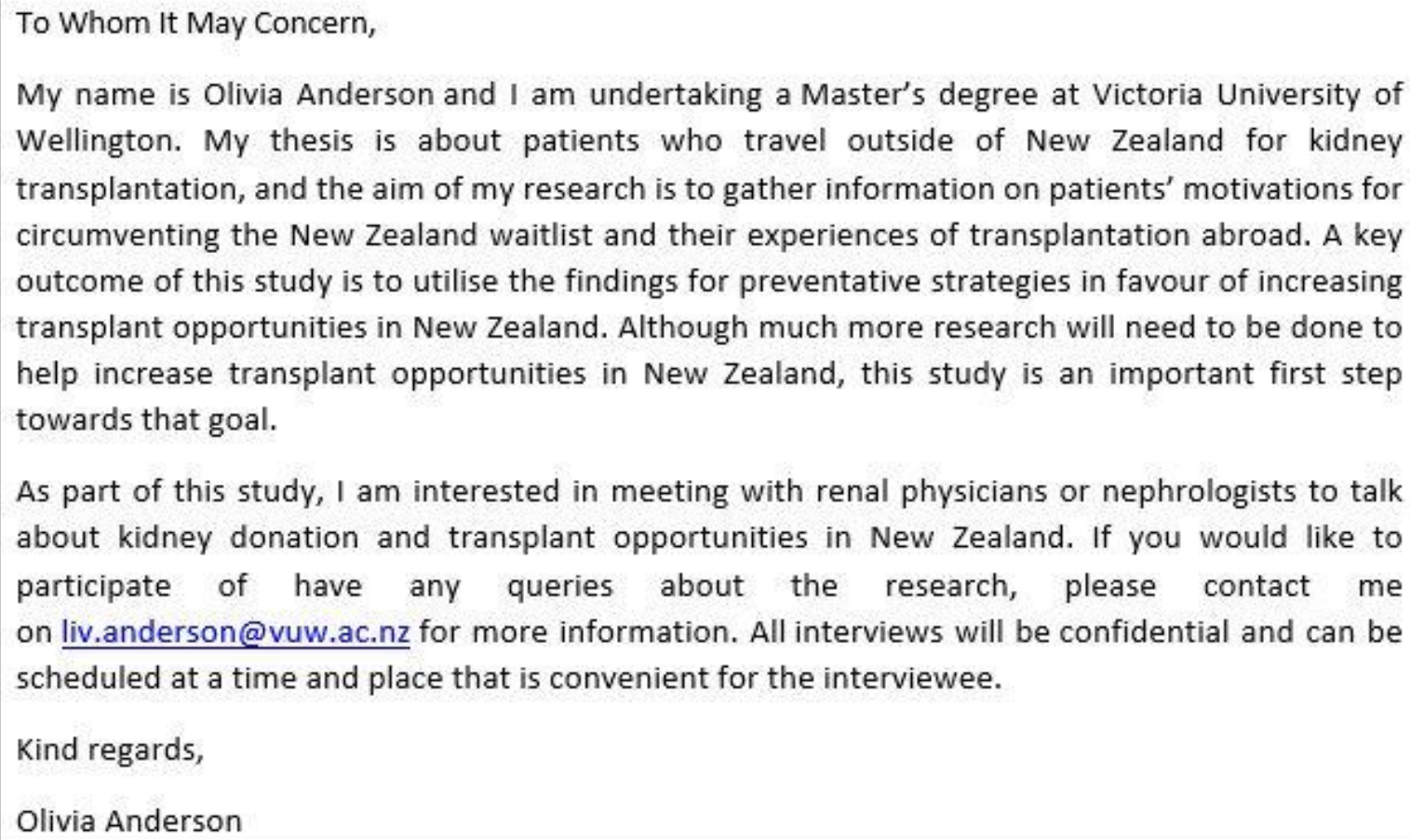

As part of this study, I am interested in meeting with renal physicians or nephrologists to talk about kidney donation and transplant opportunities in New Zealand. If you would like to participate of have any queries about the research, please contact me on liv.anderson@vuw.ac.nz for more information. All interviews will be confidential and can be scheduled at a time and place that is convenient for the interviewee.

Kind regards,

Olivia Anderson 


\title{
Appendix 4: Participant Information Sheet (Patients)
}

\author{
TE WHARF WX̃NAVGA O TE OPOKO O TE TKA A MÃUI

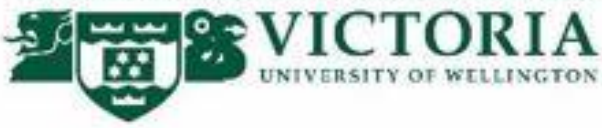 \\ New Zealand residents who undergo kidney transplantation overseas \\ INFORMATION SHEET FOR PARTICIPANTS
}

You are invited to take part in this research. Please read this information before deciding whether or not to take part. If you decide to participate, thank you. If you decide not to participate, thank you for considering this request.

\begin{abstract}
Who am I?
My name is Olivia Anderson and I am a Masters student in Sociology at Victoria University of Wellington. This research project is work towards my thesis.
\end{abstract}

\section{What is the aim of the project?}

This project is about travel for kidney transplantation and I am interested in talking to people who have considered travelling abroad, or have travelled abroad for a kidney transplant. The aim of my research is to gather information on patients' motivations and experiences, and how their transplants were facilitated. A key outcome of this study is to use the findings for preventative strategies in favour of increasing transplant opportunities in New Zealand. This research has been approved by the Victoria University of Wellington Human Ethics Committee [0000026785].

\section{How can you help?}

You have been invited to participate because you have either considered travelling overseas or have travelled overseas for a kidney transplant. If you agree to take part, I will interview you at a time and place convenient for you. I will ask you questions about your motivations for travel and your experience. The interview will take approximately 1 hour, although it may go longer. I will audio record the interview with your permission and write it up later. To thank you for your participation, you will receive a $\$ 20$ gift voucher. You can choose to not answer any question or stop the interview at any time, without giving a reason. You can withdraw from the study by contacting me within 4 weeks after the interview. If you withdraw, the information you provided will be destroyed or returned to you.

\section{What will happen to the information you give?}

This research is confidential. This means that the researcher named below will be aware of your identity, but the research data will be combined, and your identity will not be revealed in any reports, presentations, or public documentation. 
Only my supervisor and I will read the notes or transcript of the interview. The interview transcripts, summaries and any recordings will be kept securely on a password protected hard drive and destroyed on June $30^{\text {th }} 2022$.

I understand the potentially sensitive nature of this topic. Should you like a debrief after the interview, I recommend contacting Kidney Health NZ at www. kidneys.co.nz.

\section{What will the project produce?}

The information from my research will be used in my Masters' thesis. This material may also be used in subsequent research such as a PhD, submitted to journals, published as an academic article, disseminated in the media and/or presented in seminars and at conferences.

\section{If you accept this invitation, what are your rights as a research participant?}

You do not have to accept this invitation if you don't want to. If you do decide to participate, you have the right to:

- choose not to answer any question;

- $\quad$ ask for the recorder to be turned off at any time during the interview;

- withdraw from the study within four weeks after your interview;

- ask any questions about the study at any time;

- receive a copy of your interview transcript;

- receive a 2-3-page report at the end of this research;

- be able to read any reports of this research by emailing the researcher to request a copy.

\section{If you have any questions or problems, who can you contact?}

If you have any questions, either now or in the future, please feel free to contact either:

\section{Student:}

Name: Olivia Anderson

University email address:

liv.anderson@vuw.ac.nz

\section{Supervisor:}

Name: Dr. Rhonda Shaw

Role: Associate Professor

School of Social and Cultural Studies rhonda.shaw@vuw.ac.nz

\section{Human Ethics Committee information}

If you have any concerns about the ethical conduct of the research, you may contact the Victoria University HEC Convenor: Dr Judith Loveridge. Email hec@vuw.ac.nz or telephone +64-4-463 6028. 


\section{Appendix 5: Participant Information Sheet (Professionals)}

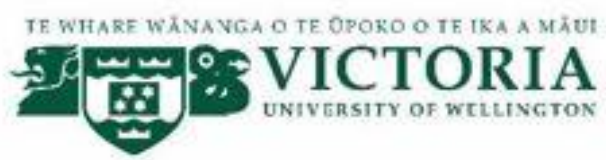

\section{New Zealand residents who undergo kidney transplantation overseas \\ INFORMATION SHEET FOR PARTICIPANTS}

You are invited to take part in this research. Please read this information before deciding whether or not to take part. If you decide to participate, thank you. If you decide not to participate, thank you for considering this request.

\section{Who am I?}

My name is Olivia Anderson and I am a Masters student in Sociology at Victoria University of Wellington. This research project is work towards my thesis.

\section{What is the aim of the project?}

This project is about travel for kidney transplantation and $\mathrm{I}$ am interested in gathering information on New Zealand residents who travel abroad for a kidney transplant, what their motivations are and how their transplants were facilitated. A key outcome of this study is to use the findings for preventative strategies in favour of increasing transplant opportunities in New Zealand. This research has been approved by the Victoria University of Wellington Human Ethics Committee [0000026785].

\section{How can you help?}

You have been invited to participate because you are a medical professional with insight into the transplant opportunities and activity in New Zealand. If you agree to take part, I will interview you at a time and place convenient for you. I will ask you questions about your knowledge of transplant opportunities in New Zealand, and your perspectives on patients who travel outside of New Zealand for kidney transplantation. The interview will take approximately 1 hour. I will audio record the interview with your permission and write it up later. You can choose to not answer any question or stop the interview at any time, without giving a reason. You can withdraw from the study by contacting me within 4 weeks after the interview. If you withdraw, the information you provided will be destroyed or returned to you.

\section{What will happen to the information you give?}

This research is confidential. This means that the researcher named below will be aware of your identity, but the research data will be combined, and your identity will not be revealed in any reports, presentations, or public documentation.

Only my supervisor and I will read the notes or transcript of the interview. The interview transcripts, summaries and any recordings will be kept securely on a password protected hard drive and destroyed on June $30^{\text {th }} 2022$. 


\section{What will the project produce?}

The information from my research will be used in my Masters' thesis. This material may also be used in subsequent research such as a PhD, submitted to journals, published as an academic article, disseminated in the media and/or presented in seminars and at conferences.

\section{If you accept this invitation, what are your rights as a research participant?}

You do not have to accept this invitation if you don't want to. If you do decide to participate, you have the right to:

- choose not to answer any question;

- $\quad$ ask for the recorder to be turned off at any time during the interview;

- withdraw from the study within four weeks after your interview;

- ask any questions about the study at any time;

- receive a copy of your interview transcript;

- receive a 2-3-page report at the end of this research;

- be able to read any reports of this research by emailing the researcher to request a copy.

If you have any questions or problems, who can you contact?

If you have any questions, either now or in the future, please feel free to contact either:

\section{Student:}

Name: Olivia Anderson

University email address:

liv.anderson@vuw.ac.nz

\section{Supervisor:}

Name: Dr. Rhonda Shaw

Role: Associate Professor

School of Social and Cultural Studies

rhonda.shaw@vuw.ac.nz

\section{Human Ethics Committee information}

If you have any concerns about the ethical conduct of the research, you may contact the Victoria University HEC Convenor: Dr Judith Loveridge. Email hec@vuw.ac.nz or telephone +64-4-463 6028. 


\section{Appendix 6: Consent Form}

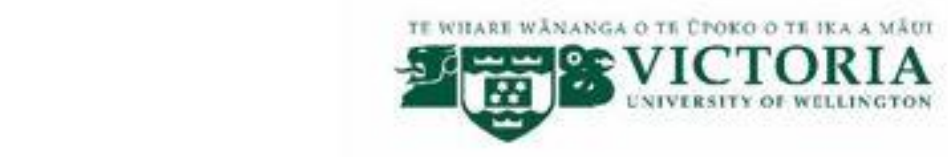

\section{New Zealand residents who undergo kidney transplantation overseas CONSENT TO INTERVIEW}

This consent form will be held for 3 years.

Researcher: Olivia Anderson, Sociology, Victoria University of Wellington.

- I have read the Information Sheet and the project has been explained to me. My questions have been answered to my satisfaction. I understand that I can ask further questions at any time.

- I agree to take part in an audio recorded interview.

I understand that:

- I may withdraw from this study at any point within 4 weeks of being interviewed, and any information that I have provided will be returned to me or destroyed.

- $\quad$ The identifiable information I have provided will be destroyed on June $30^{\text {th }}, 2022$.

- Any information I provide will be kept confidential to the researcher and the supervisor.

- I understand that the results will be used for a Masters' thesis and may be used in subsequent research and/or presented at seminars and conferences.

- My name will not be used in reports, nor will any information that would identify me.

- I would like a copy of the transcript of my interview:

Yes $\square \quad$ No

- I would like a 2-3-page report when the research is complete:

Yes $\square \quad$ No $\square$

- I would like to receive a copy of the final report and have added my email address below.

Yes $\square \quad$ No

Signature of participant:

Name of participant:

Date:

Contact details: 